\title{
CHARACTERIZING GYMNASIUM ACOUSTICS
}

\author{
By
}

Greer C. M. Stanier

BArchSc., Ryerson University, 2017

\begin{abstract}
A Thesis
presented to Ryerson University

in partial fulfillment of the requirements for the degree of Master of Applied Science in the Program of Building Science
\end{abstract}

Toronto, Ontario, Canada, 2020

(C) Greer C. M. Stanier, 2020 


\section{AUTHOR'S DECLARATION FOR ELECTRONIC SUBMISSION OF A THESIS}

I hereby declare that I am the sole author of this thesis. This is a true copy of the thesis, including any required final revisions, as accepted by my examiners. I authorize Ryerson University to lend this thesis to other institutions or individuals for the purpose of scholarly research. I further authorize Ryerson University to reproduce this thesis by photocopying or by other means, in total or in part, at the request of other institutions or individuals for the purpose of scholarly research.

I understand that my thesis may be made electronically available to the public. 


\title{
CHARACTERIZING GYMNASIUM ACOUSTICS
}

\author{
Master of Applied Science 2020, Greer C. M. Stanier \\ Building Science, Faculty of Engineering and Architectural Science, Ryerson University
}

\begin{abstract}
There are currently no Canadian standards that specify the acoustical quality of gymnasia despite the persistent issue of poor speech intelligibility in these spaces. Several studies have found gymnasium acoustics problematic due to the non-diffuse nature of the sound field. The aim of this thesis is to characterize four gyms using reverberation time, sound pressure level, and speech transmission index to analyse the sound field of this typology. The analysis involved collecting results from field testing at two heights and modelling them in ODEON for comparison. It was shown that when measured in the field in accordance with ISO 3382, the presence of perimeter absorption does stratify the sound field to a small degree. There was found to be a large discrepancy in sound pressure level distribution in the measured versus simulated data.
\end{abstract}




\section{Acknowledgements}

I would like to thank my supervisor, Professor Umberto Berardi, who encouraged me to do research in the field of acoustics. I would also like to thank my second reader, Professor Ramani Ramakrishnan for his guidance and assistance in conducting my research. Finally, I would like to thank my family and friends for tolerating me talking about nothing but acoustics for months on end. 


\section{Table of Contents}

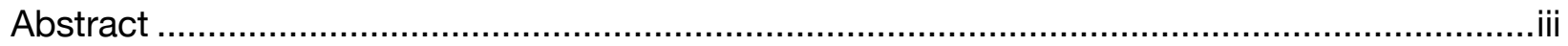

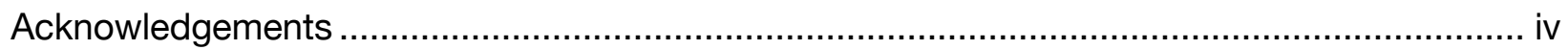

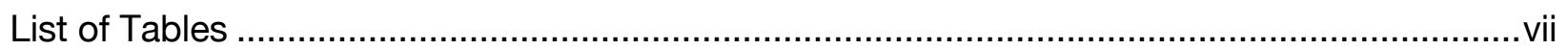

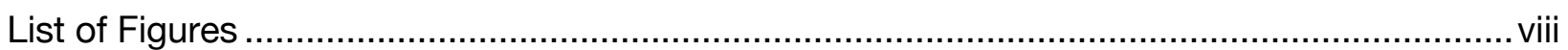

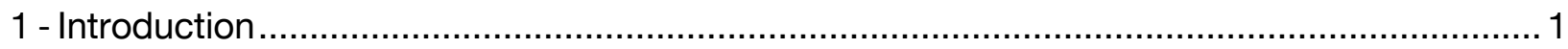

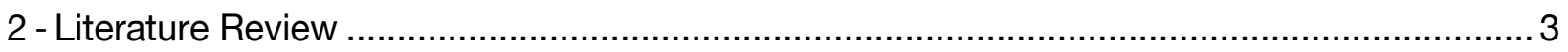

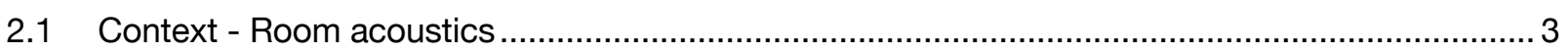

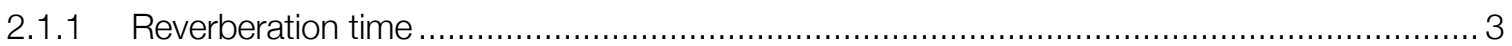

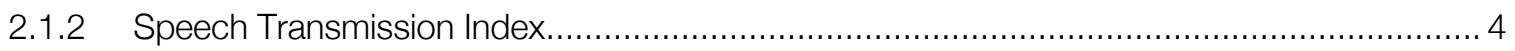

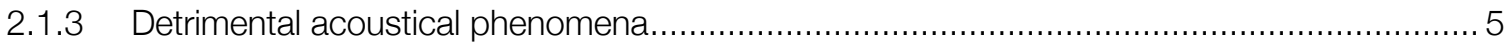

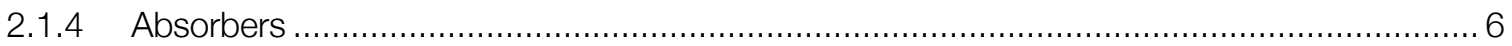

2.1.5 Computer Simulation in Room Acoustics …......................................................... 7

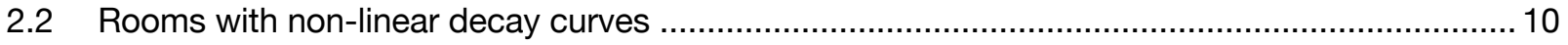

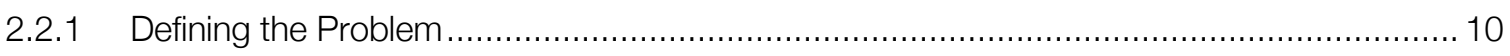

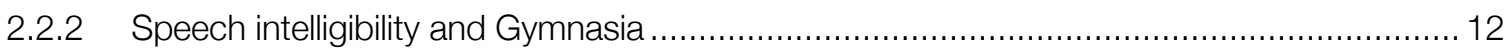

2.3 Aim of Current Investigation and Research Plan .................................................................. 14

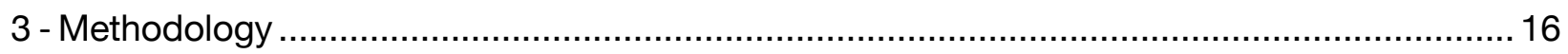

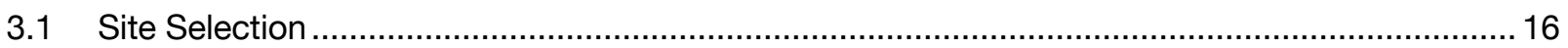

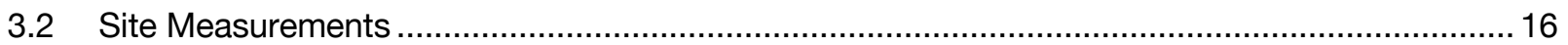

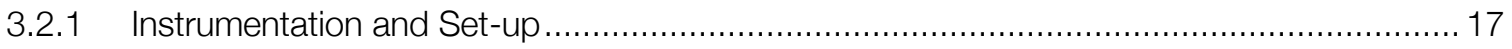

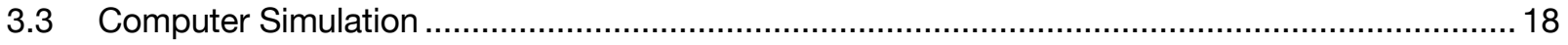

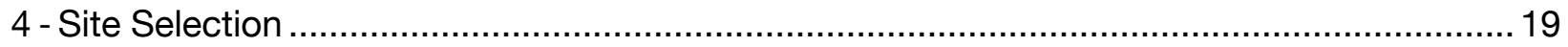

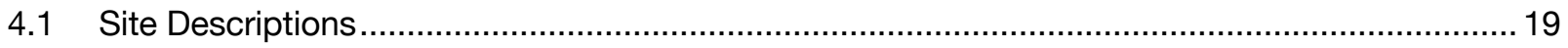

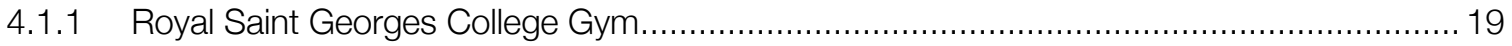

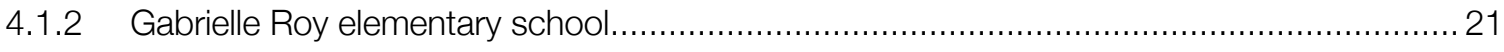

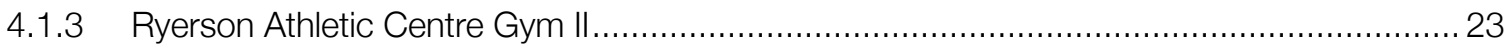

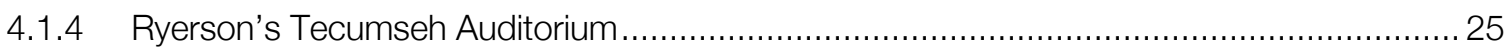

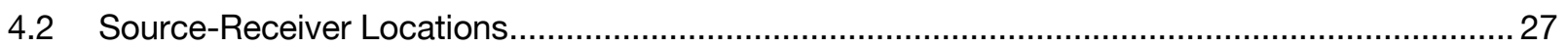

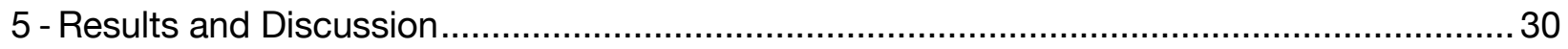

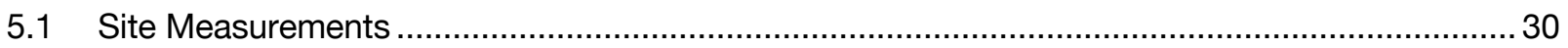

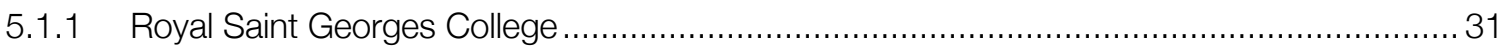

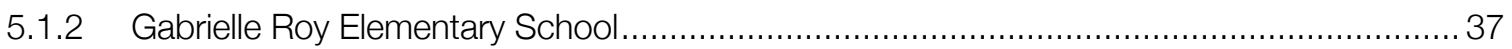




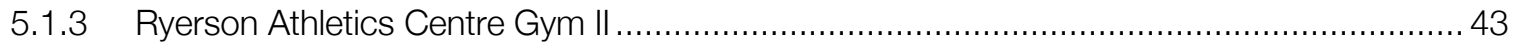

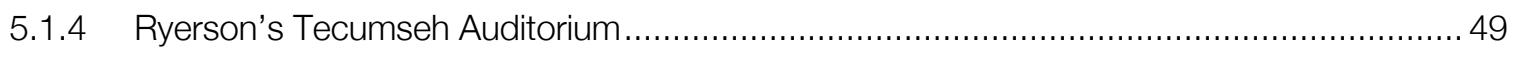

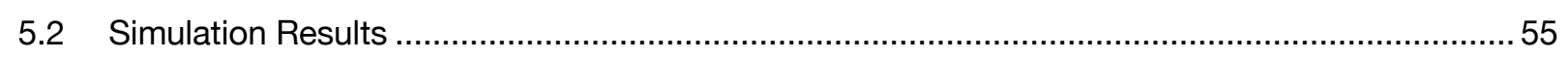

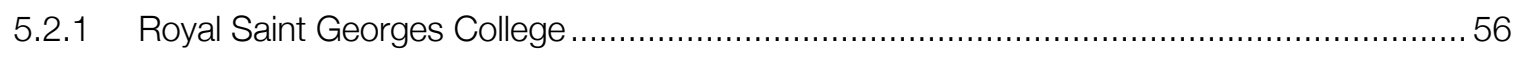

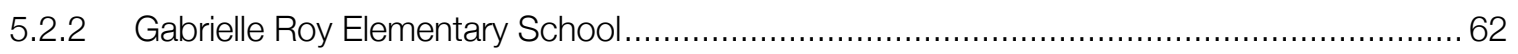

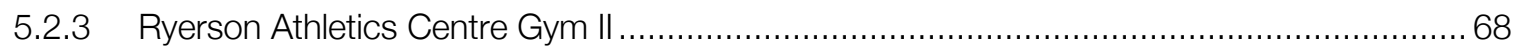

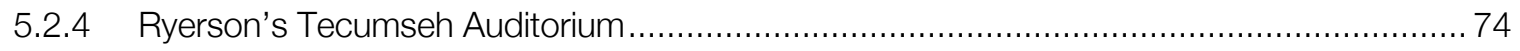

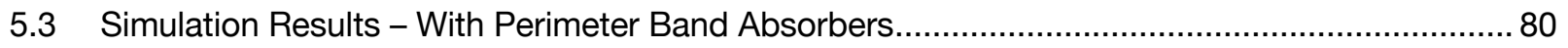

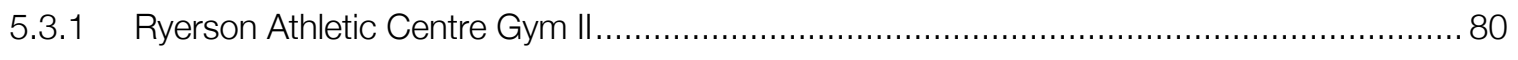

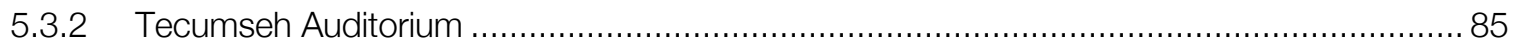

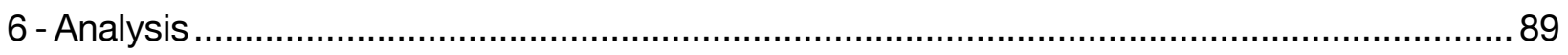

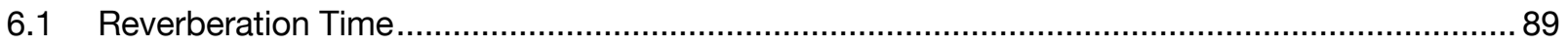

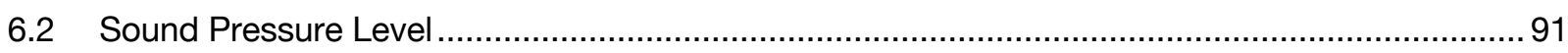

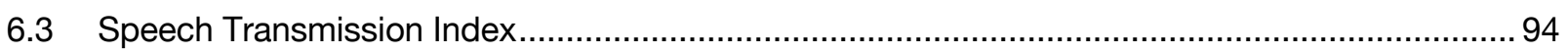

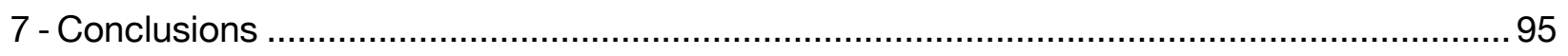

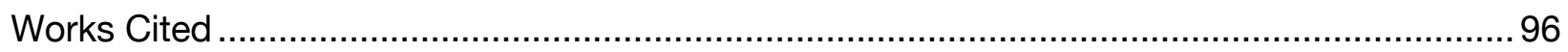




\section{List of Tables}

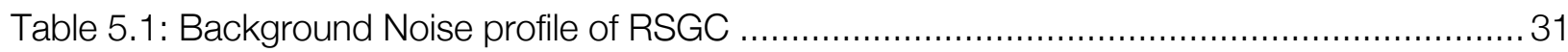

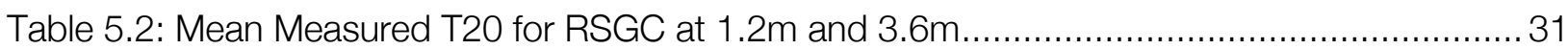

Table 5.3: Standard Deviation of RSGC's T20 measurements at 1.2m and 3.6m...................... 32

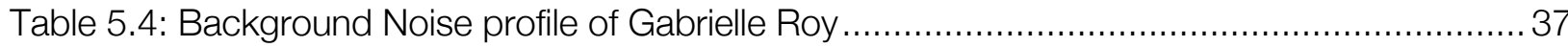

Table 5.5: Mean Measured T20 for Gabrielle Roy at 1.2m and 3.6m .................................. 37

Table 5.6: Standard Deviation of T20 data from Gabrielle Roy at $1.2 \mathrm{~m}$ and $3.6 \mathrm{~m} \ldots \ldots \ldots \ldots \ldots \ldots \ldots . . . . . . . . . . .38$

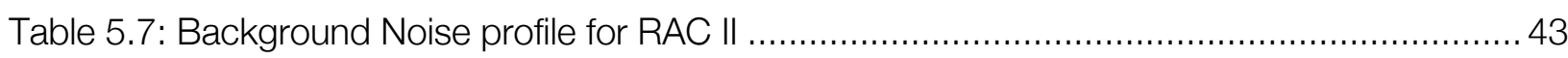

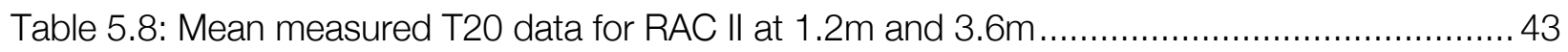

Table 5.9: Standard deviation of T20 data from RAC II at 1.2m and 3.6m ............................. 44

Table 5.10: Background Noise profile of Tecumseh Auditorium .............................................. 49

Table 5.11: Mean measured T20 for Tecumseh Auditorium at 1.2m and 3.6m.........................49

Table 5.12: Standard deviation for T20 data for Tecumseh Auditorium at 1.2m and 3.6m...........50

Table 5.13: Calibrated Material Absorption Coefficients for Royal St Georges College.................. 56

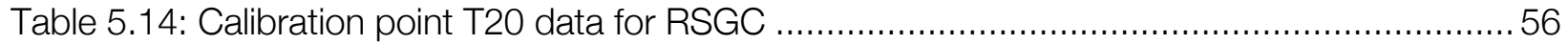

Table 5.15: Comparison of measured and modelled T20 data from RSGC ..............................56

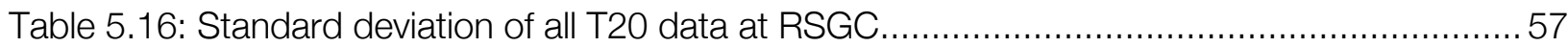

Table 5.17: Calibrated Material Absorption Coefficients for Gabrielle Roy................................. 62

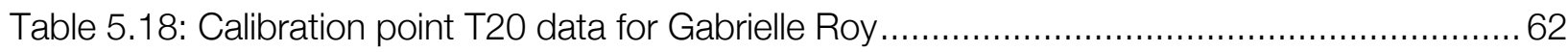

Table 5.19: Comparison of measure and modelled T20 data at Gabrielle Roy ..........................62

Table 5.20: Standard deviation of all T20 data at Gabrielle Roy ............................................ 63

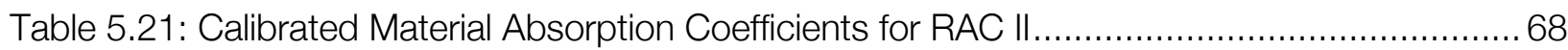

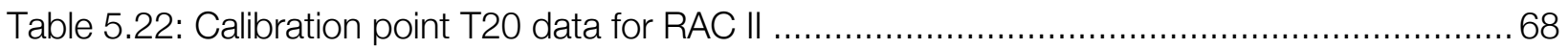

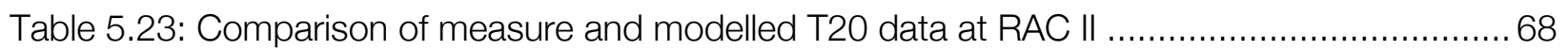

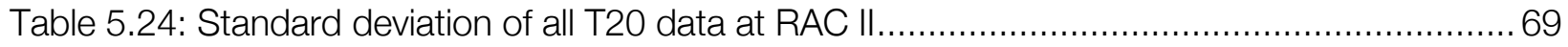

Table 5.25: Calibrated Material Absorption Coefficients for Tecumseh ................................... 74

Table 5.26: Calibration point T20 data for Tecumseh Auditorium ........................................... 74

Table 5.27: Comparison of measure and modelled T20 data Tecumseh Auditiorium................... 74

Table 5.28: Standard deviation of all T20 data at Tecumseh Auditorium .................................. 75

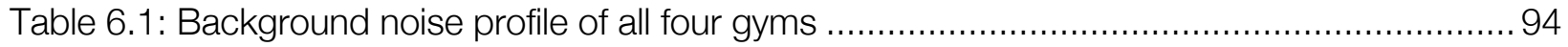




\section{List of Figures}

Figure 2.1: Diagram of image source acoustic calculations [18].......................................... 8

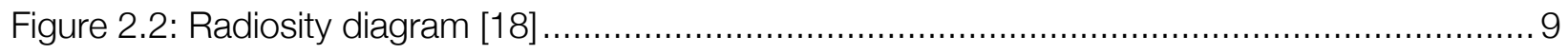

Figure 2.3: Diagram of Sound Attenuation in Large Shoebox Rooms [4] ................................. 11

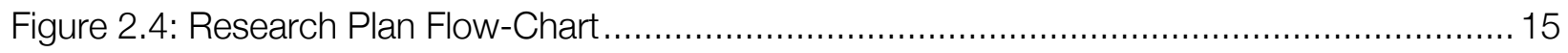

Figure 3.1: Data Collection for the 3.6m set-up in RAC II .................................................. 17

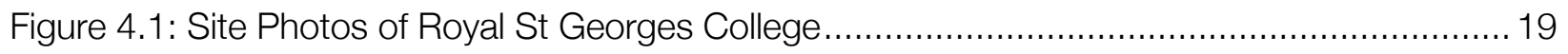

Figure 4.2: Schematic Representation of Royal St Georges Gym's Surfaces.............................. 20

Figure 4.3: Site Photo of Gabrielle Roy Elementary School Gym .......................................... 21

Figure 4.4: Schematic Representation of Gabrielle Roy's Gym Surface ..................................... 22

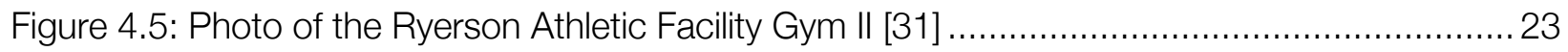

Figure 4.6: Schematic Representation of RAC II's Gym Surfaces ............................................. 24

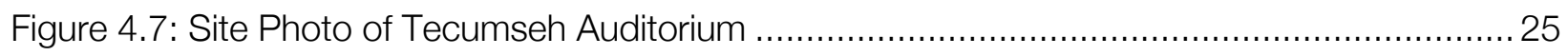

Figure 4.8: Schematic Representation of Tecumseh's Gym Surfaces....................................... 26

Figure 4.9: Royal St. Georges College source-receiver positions .......................................... 28

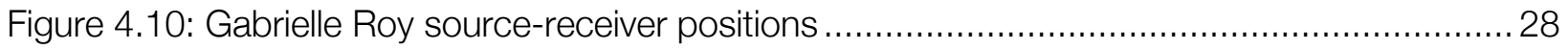

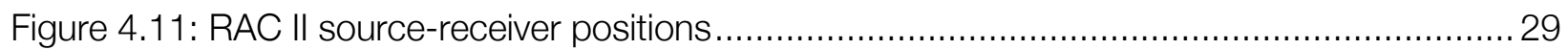

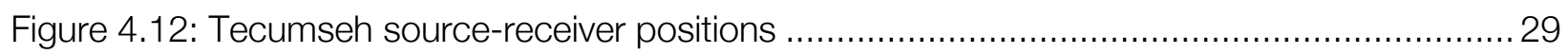

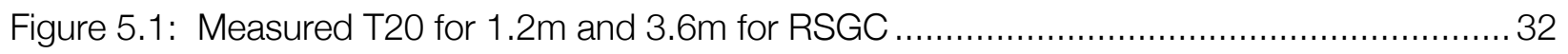

Figure 5.2: T20 data for all 1.2m receiver points for RSGC.................................................. 33

Figure 5.3: T20 data for all 3.6m receiver points for RSGC .................................................. 33

Figure 5.4: RSGC SPL distribution for all S1 receiver points at (left to right) $63 \mathrm{~Hz}, 125 \mathrm{~Hz}, 250 \mathrm{~Hz}$,

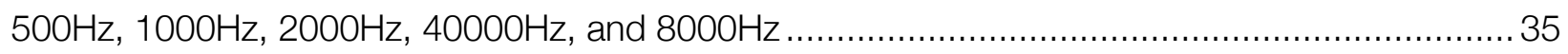

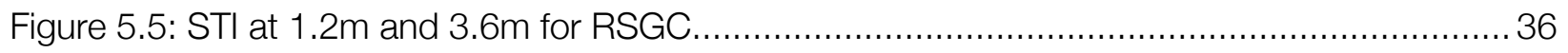

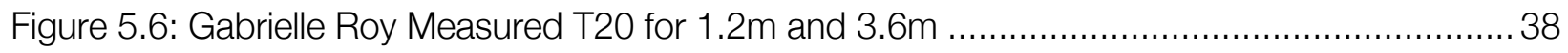

Figure 5.7: T20 data for all 1.2m receiver points for Gabrielle Roy ........................................... 39

Figure 5.8: T20 data for all 3.6m receiver points for Gabrielle Roy .......................................... 39

Figure 5.9: Gabrielle Roy SPL distribution for all S1 receiver points at (left to right) $63 \mathrm{~Hz}, 125 \mathrm{~Hz}$,

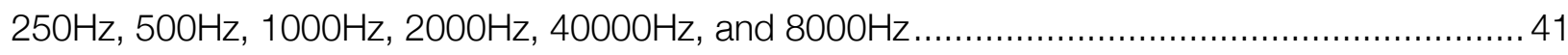

Figure 5.10: STI at 1.2m and 3.6m for Gabrielle Roy ....................................................... 42

Figure 5.11: RAC II Measured T20 at 1.2m and 3.6m ......................................................... 44 


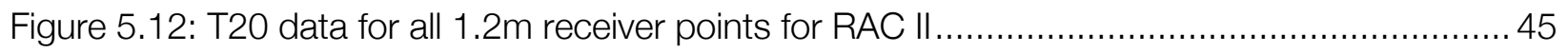

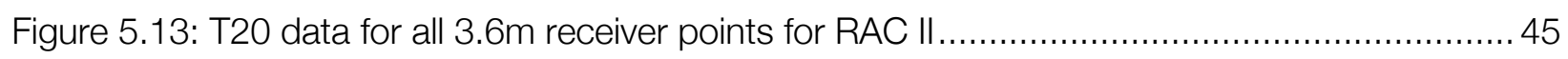

Figure 5.14: RAC II SPL distribution for all S1 receiver points at (left to right) $63 \mathrm{~Hz}, 125 \mathrm{~Hz}, 250 \mathrm{~Hz}$,

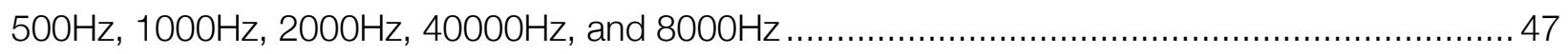

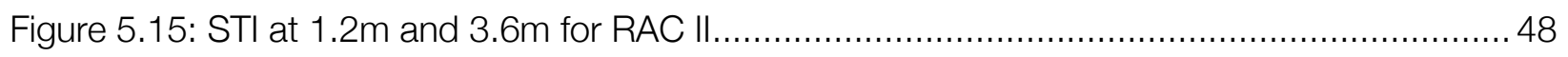

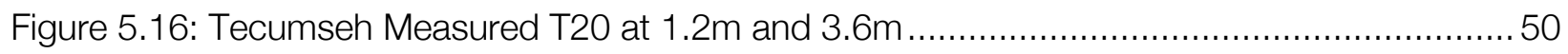

Figure 5.17: All 1.2m receiver points T20 data for Tecumseh Auditorium ............................... 51

Figure 5.18: All 3.6m receiver points T20 data for Tecumseh Auditorium .............................. 51

Figure 5.19: Tecumseh SPL distribution for all S1 receiver points at (left to right) $63 \mathrm{~Hz}, 125 \mathrm{~Hz}$,

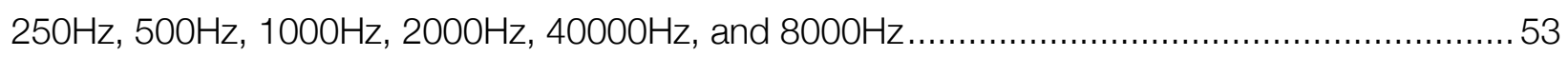

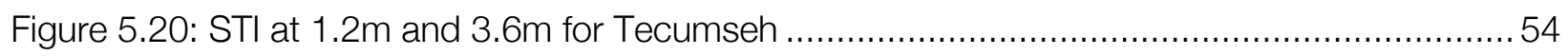

Figure 5.21: RSGC T20 Measured vs Simulated ........................................................... 57

Figure 5.22: All simulated 1.2m receiver points T20 data for RSGC ...................................... 58

Figure 5.23: All simulated 3.6m receiver points T20 data for RSGC....................................58

Figure 5.24: All simulated 6.0m receiver points T20 data for RSGC................................59

Figure 5.25: RSGC simulated SPL distribution for all S1 receiver points at (left to right) $63 \mathrm{~Hz}$,

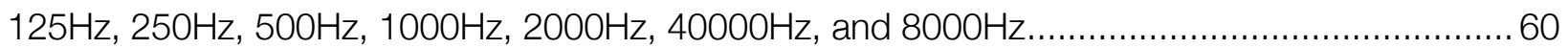

Figure 5.26: Simulated STI at 1.2m, 3.6m, and 6.0m for RSGC ..................................... 61

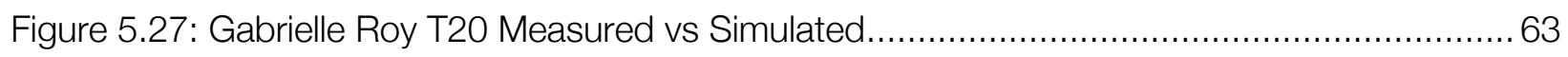

Figure 5.28: All simulated 1.2m receiver points T20 data for Gabrielle Roy ............................. 64

Figure 5.29: All simulated 1.2m receiver points T20 data for Gabrielle Roy................................. 64

Figure 5.30: All simulated 6.0m receiver points T20 data for Gabrielle Roy............................... 65

Figure 5.31: Gabrielle Roy simulated SPL distribution for all S1 receiver points at (left to right) $63 \mathrm{~Hz}$,

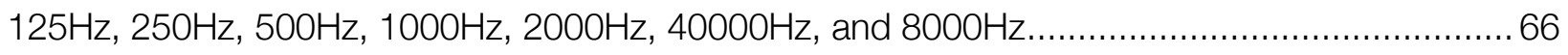

Figure 5.32: Simulated STI at 1.2m, 3.6m, and 6.0m for Gabrielle Roy ................................. 67

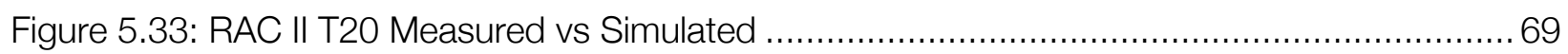

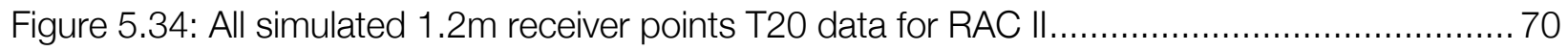

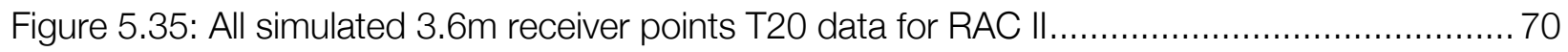

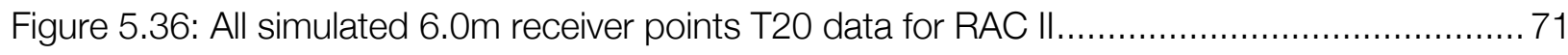

Figure 5.37: RAC II simulated SPL distribution for all S1 receiver points at (left to right) $63 \mathrm{~Hz}$,

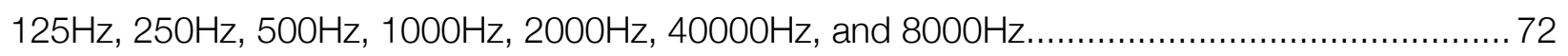

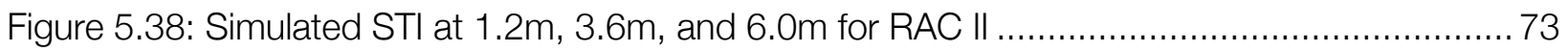




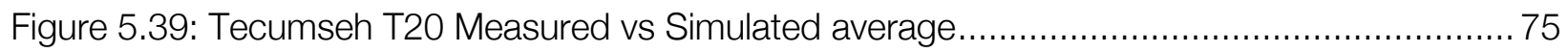

Figure 5.40: All simulated 1.2m receiver points T20 data for Tecumseh .................................... 76

Figure 5.41: All simulated 3.6m receiver points T20 data for Tecumseh ..................................... 76

Figure 5.42: Tecumseh simulated SPL distribution for all S1 receiver points at (left to right) $63 \mathrm{~Hz}$,

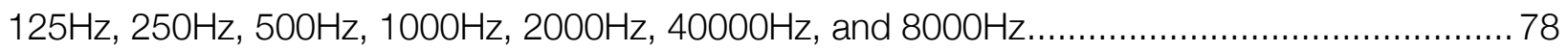

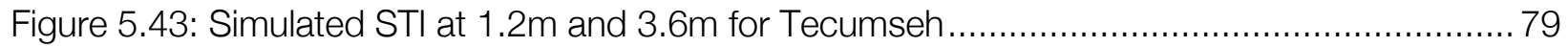

Figure 5.44: RAC II T20 simulated with and without absorption for $1.2 \mathrm{~m}, 3.6 \mathrm{~m}$, and $6.0 \mathrm{~m} \ldots \ldots \ldots . . .80$

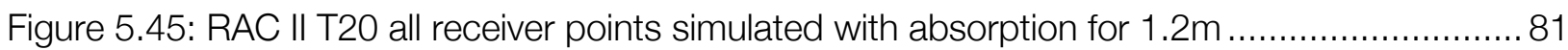

Figure 5.46: RAC II T20 all receiver points simulated with absorption for 3.6m ........................... 82

Figure 5.47: RAC II T20 all receiver points simulated with absorption for $6.0 \mathrm{~m} \ldots \ldots \ldots \ldots \ldots \ldots \ldots \ldots \ldots . . . . . . . . . . . . . .82$

Figure 5.48: RAC II simulated SPL distribution with and without absorption at (left to right) $63 \mathrm{~Hz}$,

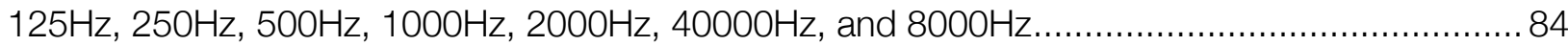

Figure 5.49: Tecumseh T20 simulated with and without absorption for $1.2 \mathrm{~m}$ and $3.6 \mathrm{~m}$.............. 85

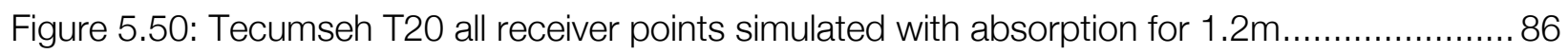

Figure 5.51: Tecumseh T20 all receiver points simulated with absorption for $3.6 \mathrm{~m} . . . \ldots \ldots \ldots \ldots \ldots . . . . . . . . . .86$

Figure 5.52: Tecumseh simulated SPL distribution with and without absorption at (left to right)

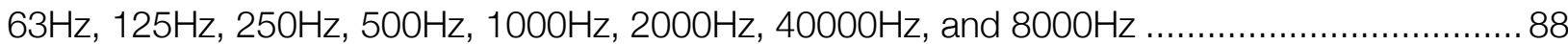

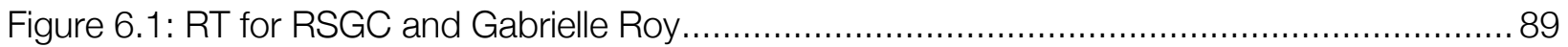

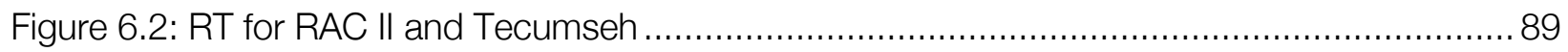

Figure 6.2: SPL distribution for $500 \mathrm{~Hz}$ (right) and $1000 \mathrm{~Hz}$ (left) for (top to bottom) RSGC, Gabrielle

Roy, RAC II and Tecumseh ............................................................................................ 92

Figure 6.3: SPL distribution for $500 \mathrm{~Hz}$ (right) and $1000 \mathrm{~Hz}$ (left) for (top to bottom) RSGC, Gabrielle

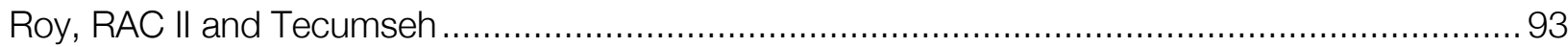




\section{Introduction}

School gymnasia have the unique problem of being used for multiple functions that require clear speech intelligibility in a room geometry that has inherently bad acoustics. Gyms are often reported as being too loud with too much echo, and direction for lively physical activity is unintelligible. Several case studies have looked at these problems in an attempt to find ways of improving the acoustics, all of them using reverberation time (RT) as the main parameter [1] [2] [3]. These studies used the addition of acoustic absorption in various forms and arrangements to reduce the RT of the gyms with varied success. Studies [1] [2] [3] posit that these rooms have a non-diffuse sound field which is not predicted by computer modeling and reduces the effectiveness of absorbing acoustical treatments.

Typically, school gyms are large, rectangular rooms with the floor-to-ceiling height being the shortest dimension. These "shoebox" rooms create a non-optimal sound field for a few reasons. The volume consists of three sets of parallel surfaces that can reflect sound off each other and create echoes [4]. Sound traveling in the vertical plane dissipates faster than in the horizontal plane by virtue of undergoing more reflections for a given elapsed time. Such polarization of the sound field means that absorbers placed in the ceiling or in a perimeter band at the top of the walls are less effective after they absorb the initial incident sound [5]. This arrangement is typical in most gymnasia; soft absorbers are cheaper for school boards and since they are not durable, they are installed on the ceiling and high on the walls. Yet, no studies have measured RT in the upper portions of the gym to investigate whether the sound field changes as a result of these installations. 
The current investigation focuses on characterizing the sound field of a shoebox room using reverberation time $(\mathrm{RT})$, sound pressure level (SPL), and speech transmission index (STI) at different heights. To analyze the sound field of a large shoe box style room, data was collected at four large gymnasia, two with perimeter absorption and two without. Computer models were calibrated using the measured data and used to generate simulations of the rooms in order to compare the accuracy of prediction models. 


\section{Literature Review}

\subsection{Context - Room acoustics}

Room properties such as dimensions, geometry, and surface texture all have a significant bearing on how sound is reflected and perceived by a receiver in a space. Different types of listening experiences are better served by different combinations of room characteristics. In order to quantify "good" acoustics, engineers developed metrics that translate the physical behaviour of sound to values we can measure and compared. When specifying parameters for a room, acousticians regularly use $\mathrm{RT}$, and occasionally SPL and STI to ensure the desired environment.

\subsubsection{Reverberation time}

Reverberation time (RT) remains the most consistently used parameter when specifying acoustic requirements for a space and is the only acoustic descriptor used in Canadian standards that isn't related to sound transmission. The only standards that currently have requirements for RT are ANSI S12.60-2010, which specifies RT maximums for classrooms [6], and Alberta Infrastructure and Transportation Guidelines which specify that the RT of gymnasia should not exceed $2 \mathrm{~s}$ in the $500-2000 \mathrm{~Hz}$ range [7]. RT specifically refers to the amount of time it takes for a sound impulse to reduce by 60 decibels.

The reverberation time of a space can be measured or calculated using equations or computer models. The current standard for measuring RT60 is prescribed in ISO 3382 [8]. In field tests, an omnidirectional sound source plays sound that is recorded by a receiver. The measurement starts once the sound has decayed by $5 \mathrm{~dB}$. Given that there is generally background noise and it is difficult to generate a sound that exceeds $65 \mathrm{~dB}$ above background noise, T60 values are 
generated based on T20 or T30 measurements. According to the ISO 3382, an impulse response is considered inaccurate if the T30 and T20 values are significantly dissimilar; this indicates a non-linear decay curve and invalidates prediction based on early decay. The cut-off point for the admissibility of data is gauged by the non-linear parameter $\xi$; values that exceed $10 \%$ indicate a decay curve that has deviated from perfect linearity to a degree that brings the extrapolated T60 value into question [8].

Predicting the RT of a room mathematically was first explored by Wallace C. Sabine in 1898 . His equation calculates the RT of a room based on its volume, surface area, and absorption coefficients [9]. In equation $1, \alpha$ is the average absorption coefficient of a room weighted by surface area.

$$
T_{S}=0.161 \frac{V}{\alpha S}
$$

\section{Equation 1 [10]}

This equation assumes a purely diffuse sound field and, as a result, is only accurate for small, proportionate rooms that have evenly distributed absorption. While there have been many new equations developed, no one equation has been found to be more accurate over all scenarios and these equations remain the most fundamental [10]. In practice, software is more accurate at predicting the RT60 of a room; this will be explored more in Section 2.5.

\subsubsection{Speech Transmission Index}

Speech Transmission Index, STI, is a metric used to estimate speech intelligibility with a value that ranges from zero to one. In its long form, the metric is measured using a speech-like signal played over a loudspeaker to directly measure the modulation in each octave band, 
referred to as the direct STI method. Though accurate, direct STI method requires a lot of time. STI can also be approximated using the indirect method, which is a measurement derived from an impulse response [11].

A standard that specifies a STI value for gymnasia is the CAM standard which proposes that the gym STI be over 0.5. At 0.5, speech intelligibility is considered "fair; over 0.6 would be considered good [12]

\subsubsection{Detrimental acoustical phenomena}

A lack of diffusion in a room, especially a large shoe-box style room, can lead to a range of unpleasant acoustical phenomena. A non-diffuse sound field in a room with a loud sound source has been found to produce echo, combing, and image shift, all of which can be detrimental to sound intelligibility. All these phenomena are an unpleasant result of specular primary reflections not being considered in design. Some of the most common acoustical phenomena are described below.

\section{Echo}

In a small room, the time elapsed between the initial sound and early reflections is small enough that they are generally perceived as one signal which generally contributes positively to intelligibility. Sometimes these rooms can have flutter echoes, a phenomenon observed in smaller rooms with parallel reflective surfaces. If the distance between the walls is a multiple of the wavelength, the incident and reflective waves will cause interference at mid-to-high frequencies. In a larger room, there is enough of a delay that the reflected sound can be perceived as a distinct replica of the direct sound [10]. The same wavelength-to-dimension relationship that causes flutter echoes at higher frequencies is also observed in rooms with large dimensions at lower frequencies and it referred to as a room node. Higher frequencies 
are less likely to cause echo in larger rooms, as they dissipate from air resistance faster than low frequencies.

\section{Combing}

A combing filter is the effect achieved when two signals from different sources interfere with each other. In a room with mainly specularly reflected sound, the reflected sound acts as a delayed, identical version of the primary signal. At the receiver, there can be constructive and destructive wave interference in the perceived sound [10].

\section{Image shift}

Uncontrolled first order reflections can make it very hard for the listener to locate the sound source. If a source is perceived to be in a different location than its actual position, it is called image shift. This happens when high energy first order reflections reach the receiver from a distinctly different angle than the direct sound [10].

\subsubsection{Absorbers}

Absorbers are a class of surface that are designed to reduce the energy of a sound wave upon reflection. Typically, there are two categories of absorbers; resonators and, porous absorbers. Porous absorbers like rockwool or foam work because the open cells of a porous material increase the surface area of the air's viscous boundary layer, causing attenuation by friction. Resonators rely on two components; a mass that vibrates and a spring. Thin masses are classified as membrane absorbers, which rely on the vibration of a thin surface to transform sound energy into friction at a small frequency range. Another common resonator is a Helmholtz absorber which uses a surface with holes in it to create an air plug (mass) and an air cavity (spring) [10]. 
All absorbers are described by the absorption coefficient which indicates the ratio of energy that is lost when a signal is reflected from a given surface. The value, between 0 and 1 , is frequency dependent but has a corresponding frequency-weighted average for simplified calculations. Whether or not a surface is designated as an absorber, it has an absorption coefficient.

\subsubsection{Computer Simulation in Room Acoustics}

Computer models that predict the behaviour of sound in a space to an acceptable degree of accuracy generally use a combination of image source method, ray tracing, and radiosity. However, none of these techniques account for the wave properties of sound and do not simulate the interference patterns or diffraction at lower frequencies [13]. This is less of a problem at higher frequencies where the wavelength is small, and sound acts more like a ray in any case. To accurately model the wave properties of sound, the finite element method can be used.

The most commonly used software in the papers studied was ODEON, a software that uses ray tracing, image source method, and radiosity to model the acoustics of a space. The software has been proven to be amongst the most accurate mainly for its inclusion of scattering modeling [14] [15] [16]. One problem of the software is the lack of consistency when specifying a transition order. This is the point at which a specified reflection order is reached, and the image source modeling is transitioned to ray tracing for the purpose of modeling diffuse reflections [5]. The most common prediction models used in computer simulations for room acoustics are outlined below. 


\section{Image source modelling}

Image source modelling assumes purely specular reflection of a sound source against a reflection geometry. A sound source is reflected against all surfaces within a model to create an image source, which is again reflected off all surfaces. This is a recursive process that terminates after a reflection order or response time has been reached. The reflection paths that terminate at the receiver position can be totaled as a sum of all the contributing image sources, represented as the impulse response. The image sources degenerate for every reflection relative to the impedance of the surface and of air [17].

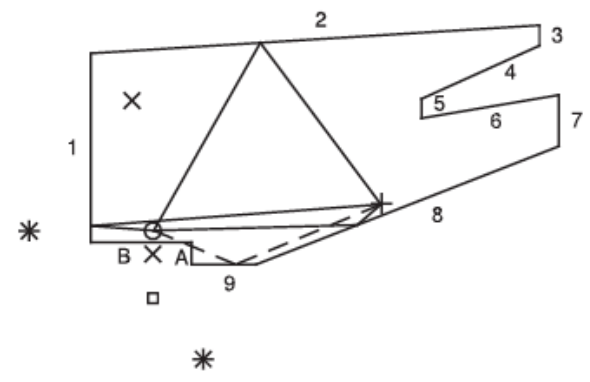

Figure 2.1: Diagram of image source acoustic calculations [17]

Figure 2.2 illustrates a scenario after one reflection, with the source represented by $\mathrm{O}$, receiver by + , valid image sources by *, obstructed paths are shown with a dashed line, and the obstructed source as .

\section{Ray tracing method}

Rays are cast out from a sound source and are reflected off the bounding geometry. Each ray has a corresponding energy value that is reduced based on the properties of the surface it is reflected off. The absorption coefficient of the surface is frequency dependent, and a ray will 
terminate after all frequencies are below a certain value or it has travelled a maximum distance. To model diffuse reflections, a scattering coefficient can be assigned to a surface. When a ray hits the surface, the model generates a number randomly between $0-1$. If the number is below the value of the scattering coefficient, the ray is diffusely reflected. If the number is above the scattering coefficient, the ray is specularly reflected [18]. A more computationally demanding method is to reflect a portion of each reflection as specular and as diffuse, based on the ratio of the scattering coefficient [17].

\section{$\underline{\text { Radiosity }}$}

Radiosity is a surface-based method that assumes purely diffuse reflections. It assumes angleindependent properties of a surface and for each reflection, calculated an energy equilibrium between incoming and outgoing energy multiplied by the absorption of the material [17].

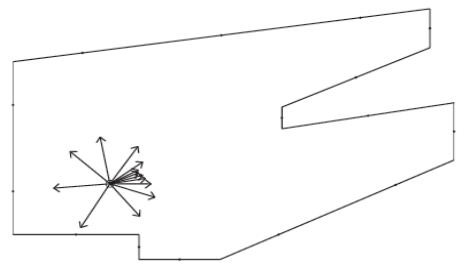

(a)

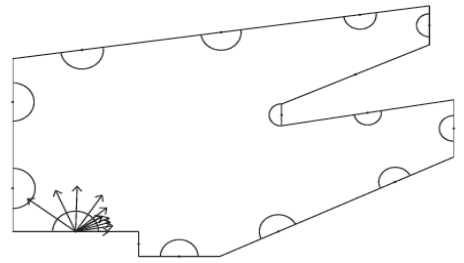

(b)

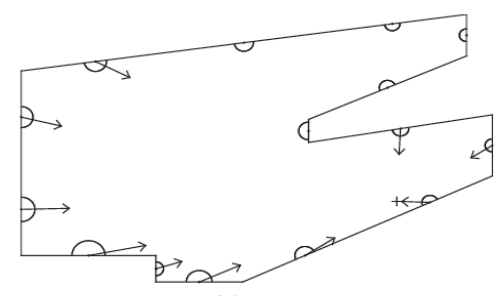

(c)

Figure 2.2: Radiosity diagram [17]

Figure 2.2 shows how a) the energy is emitted from the source position to all surfaces, then in b) reflected off the surfaces and c) the collective response from all the reflections at the receiver point is calculated. 


\section{Finite element method}

The finite element method (FEM) models the wave equation using ordinary differential equations to predict the sound pressure at volume grid points. One model is generally limited to a frequency range that displays consistent behaviour [19]. This method requires a relatively simple, closed space and requires a prohibitive amount of processing time. Deines et al. created a hybrid between a modified ray tracing method called phonon tracing and FEM to more accurately represent the low frequency behaviour and interference patterns of sound pressure [19] [20].

\subsection{Rooms with non-linear decay curves}

A disproportionate room can be characterized as having one dimension that is significantly shorter than the others, such as a rectangular parallelepiped room with the height being shorter than length or width. In large rooms without diffusion or absorption, this "shoe-box" geometry inherently creates a non-linear decay curve, which denotes a non-diffuse sound field. A diffuse sound field is one where all reflected signals are in different phases, from all angles, and of even power levels at any given point [21] A disproportionate rooms' acoustical properties like RT cannot be predicted by equations like Sabine and Erying that rely of diffuse field theory.

\subsubsection{Defining the Problem}

This phenomenon was originally investigated by Murray Hodgson who measured the sound decay in shoe-box rooms and scale models and compared it to Sabine and Eyring predictions as well as computer models. The rooms were modelled using image-source software that doesn't account for scattering. The results of the field test showed that model-of-image software underpredicted reverberation time and over predicted sound power level at distances greater than $30 \mathrm{~m}$ in the rooms, establishing the need for models to account for a degree of 
surface diffusion as well as random incident absorption coefficients. The study also confirmed that Sabine-Eyring calculations could not be used to calculate the reverberation time in large, disproportionate rooms. [22].

Hodgson built on this study by modelling the rooms and scale models with image-source software that included a scattering coefficient. With the addition of scattering, he was able to use line-of-best-fit to establish values for surface scattering that led to RT prediction accurate within $5 \%$ of measured. The study proved that planar surfaces are responsible for more scattering than conventional knowledge suggested; $60-90 \%$ scattering on the ceilings and walls was found to produce the most accurate results [23].

A developed understanding of these rooms is summarized by B. Dalenbäck. He states that the non-linear decay curve is because, as is shown in Figure 2.3, sound reflected in the vertical plane attenuates much faster than sound reflected horizontally by virtue of hitting more reflecting surfaces for the same amount of time elapsed. The vertical reflections are absorbed quickly resulting in a steep decline in decibels, with the horizontal reflections prolonging the decay [24].

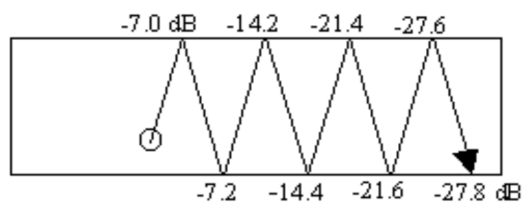

a) vertically reflected sound

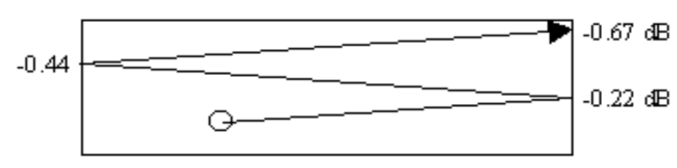

b) horizontally reflected sound

Figure 2.3: Diagram of Sound Attenuation in Large Shoebox Rooms [4] 
This problem is exacerbated by acoustical absorbers being placed on the ceiling and around the perimeter but the top of the walls, generally out of necessity. The installed absorption has an insignificant effect on late decay because the now-polarized sound field is stuck reflecting off hard, parallel surfaces [4].

\subsubsection{Speech intelligibility and Gymnasia}

A contemporary problem caused by the excessive reverberation in shoe-box rooms is the issue of poor speech intelligibility in school gymnasiums. These rooms are typically built with hard surfaces for durability and have dimensions in the range and geometry that are known to cause poor acoustics. Numerous studies have been conducted to investigate the extent of the problem as well as approaches to mitigate the reverberant nature of the spaces. As was discussed in Section 2.1, there are not many guidelines put in place to help schools create clear speech intelligibility, and the ones that exist in North America only mention reverberation time as the definitive metric for good acoustics [6] [7]. When looking for an acceptable range for RT values between 500-1000Hz, Gastmeier and Aitken [2] used measured RTs in gyms where users considered the environment adequate to establish a baseline recommended RT of between 2- 2.8 seconds. Reference 6 and 7, along with an additional 2 case studies was used to build a guideline recommendation for gym architectural acoustic treatments in schools [3]; the guidelines recommend a RT between 1.5-2 seconds at mid-range frequencies. Extensive data collection was undertaken in London to gauge schools' compliance with the countries building standards for acoustics. Schools in Great Britain are subject to Building Bulletin 93 which requires that indoor ambient noise levels to be below 40dB and have RTs below 1.5 seconds [25] 
In the process of designing, installing and testing the effect of absorbers in a gym, Packer and Faszer [1] found that there was a considerable difference between the modelled environment (ODEON) and the data collected after the installation of the absorbers. The discrepancy was rectified when plywood panels were positioned in the volume to increase diffusion. Their study brought up the question that computer models did not accurately predict the behaviour of sound when absorbers exacerbated the polarization of the sound field. 


\subsection{Aim of Current Investigation and Research Plan}

In the literature presented, there has not been any studies that took measurements above the $1.2 \mathrm{~m}$ specified by ISO 3882 to compare data collected in the upper portions of the gym to data modelled at the same height. The questions that this thesis aims to expand on are as follows:

- Does the Reverberation Time, Sound Pressure Level, and Speech Transmission Index change at different heights in a room?

- If there is a change, is it reflected in the computer model?

- Does ODEON predict the uneven sound field observed in the Packer and Faszer paper [1]

The research plan for the current investigation shown in Figure 2-5. 
Q: Analyze the sound field of school gymnasia and the effects of perimeter absorbers by characterizing the spaces with RT, SPL, and STI

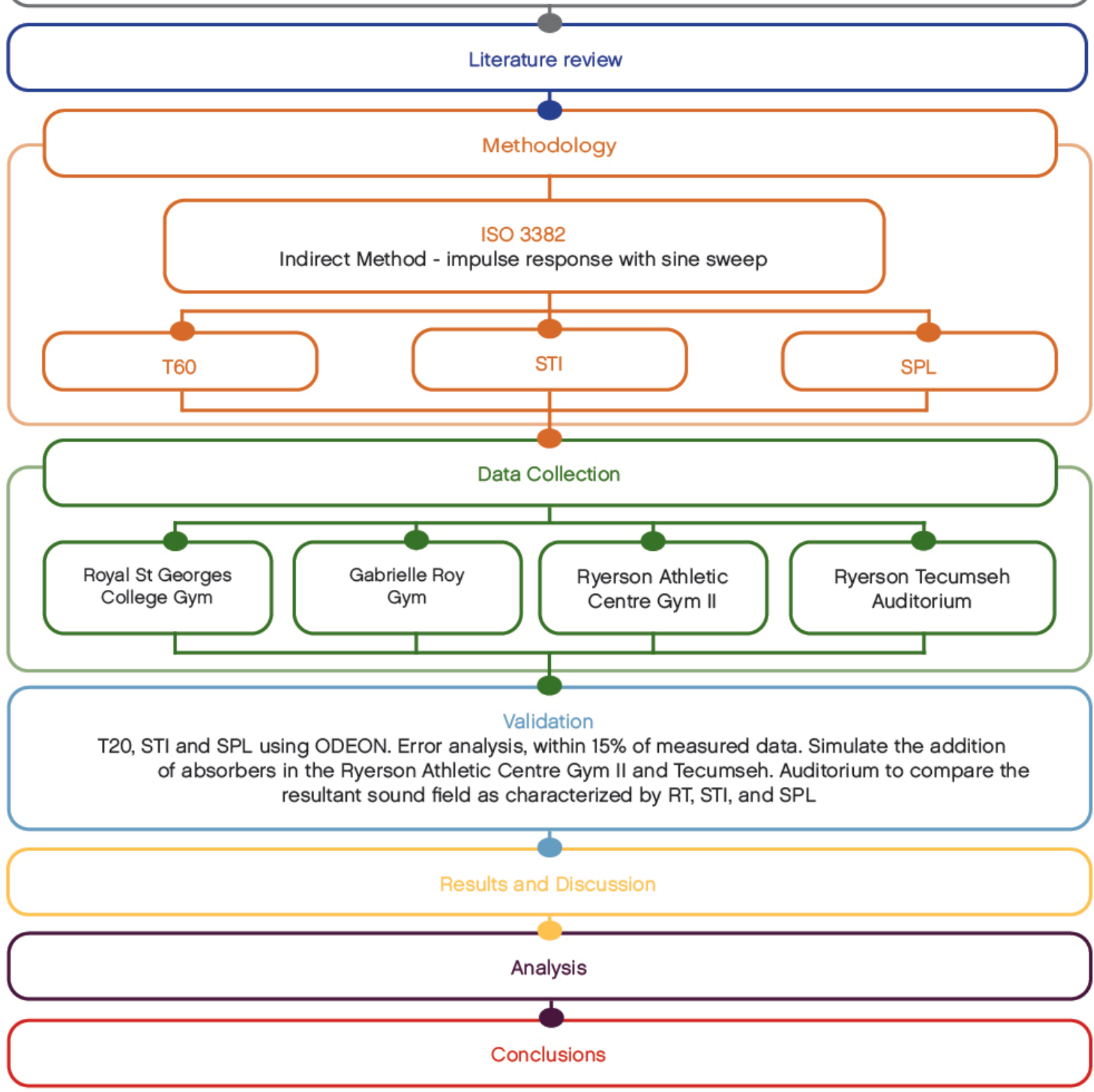

Figure 2.4: Research Plan Flow-Chart 


\section{Methodology}

The purpose of the current investigation is to analyze the sound field created by large, rectangular rooms where one dimension is substantially shorter than the others. These rooms are typically highly reverberant if little or no sound absorption has been installed and are historically difficult to accurately characterize with reverberation time alone, as was shown in studies [1] [22] [23] [21]. Four gyms of different sizes and surface types were selected and tested to collect data on reverberation time, sound pressure level, and speech transmission index to be compared to models calibrated from the measured RT. The research will use experimentation and computer simulation as investigation methods.

\subsection{Site Selection}

To be able to draw conclusions about characterizing gyms in general, locations had to meet certain criteria. The test rooms had to be large parallelepiped shapes with the floor-to-ceiling measurement being the shortest dimension. The surface materials had to be typical of school gymnasia; concrete, gypsum, steel, varnished wood floors, and glass. With regards to acoustical treatment; since it was not realistic to do pre and post installation of absorbers, two gyms were selected that were considered to have good acoustics and extensive sound absorption treatments. The remaining two should have little-to-no acoustical treatment with subjectively bad acoustics. All sites chosen fit the criteria for geometry and surface materials, making them suitable proxies for typical school gyms as a hole. They are all located in the Greater Toronto Area.

\subsection{Site Measurements}

The experiment involves both measured and modelled data. The first stage of testing involved field tests at the four test sites in accordance with ISO 3382. To achieve the highest accuracy 
possible, the testing was carried out on days with as-close-as-possible climate conditions, i.e. relative humidity and temperature since the density of air decreases with higher relative humidity and there is less energy lost to air resistance.

\subsubsection{Instrumentation and Set-up}

The purpose of this test is to collect data that can be analyzed and used to calibrate a room acoustics model that accurately represents the sound field found in large rectangular rooms. The same test was conducted in all four test locations. In accordance with ISO 3382, a signal was played over an omnidirectional sound source at locations that mimic typical activity in the gym. In this case, an eight-second-long sine sweep was used for greater accuracy at all frequencies.

\section{Instrumentation}

The sound source used for measurements was a

Brüel \& Kjær omnidirectional loudspeaker which played a sine-sweep. The impulse response was recorded by an omnidirectional microphone.

\section{Set-up}

For data collection at $1.2 \mathrm{~m}$, the receiver was attached to a $1.2 \mathrm{~m}$ high rod. To collect data at a 3.6m elevation, the same receiver points were used with the microphone attached to an extendable rod that measured $3.6 \mathrm{~m}$. Collecting field data at $6 \mathrm{~m}$ was prohibitively difficult without the aid of a scissor lift.

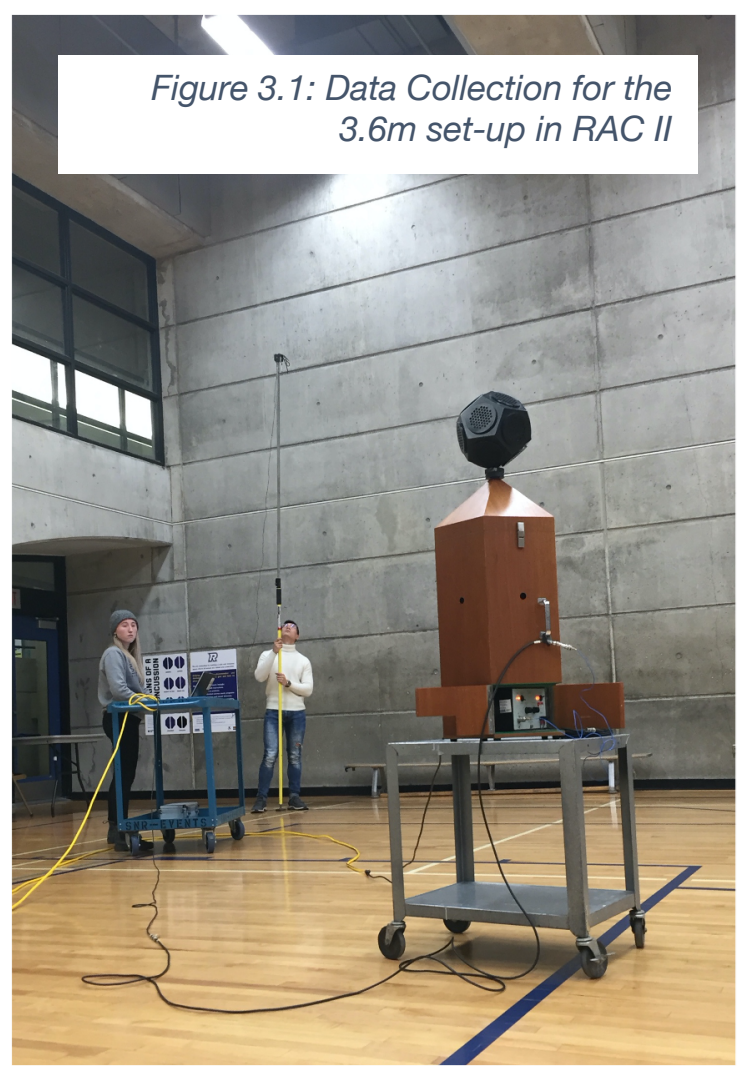




\subsection{Computer Simulation}

Once the data was collected, ODEON15 [26] was used to calibrate the models to accurately represent the sound field of the rooms. Each room was modelled in Sketchup and subsequently imported into the software. ODEON is an acoustical modeling software that uses a hybrid of image source, raytracing, and radiosity. Early predictions rely on image-source algorithms until a specified transition order is reached and the software switches to ray tracing for the purpose of modeling diffuse reflections. The software does not allow for frequencydependent scattering coefficients: a scattering coefficient is specified for $750 \mathrm{~Hz}$ and the software extrapolates the coefficient for all octave bands [27, 28].

Once the models were calibrated, RT, SPL, and STI data was generated for analysis. In the two gymnasia with minimal absorption, perimeter absorbers were added to the upper half of the gym to compare the simulated sound field of a reverberant gymnasium before and after acoustical treatment.

It is important to note that, since the purpose of this investigation is specifically concerned with intelligibility of gyms, the range of analysis is based on precedents [1] [2]. The studies included in the literature review all had problems over $250 \mathrm{~Hz}$, and guidelines only specify RTs for over $500 \mathrm{~Hz}$ [6] [7]. Given that there is no need for extensive analysis of the 125 and 63 octave bands, the lower frequency range will be adequately represented in simulations and will not be modeled with a finite element software. 


\section{Site Selection}

\subsection{Site Descriptions}

\subsubsection{Royal Saint Georges College Gym}
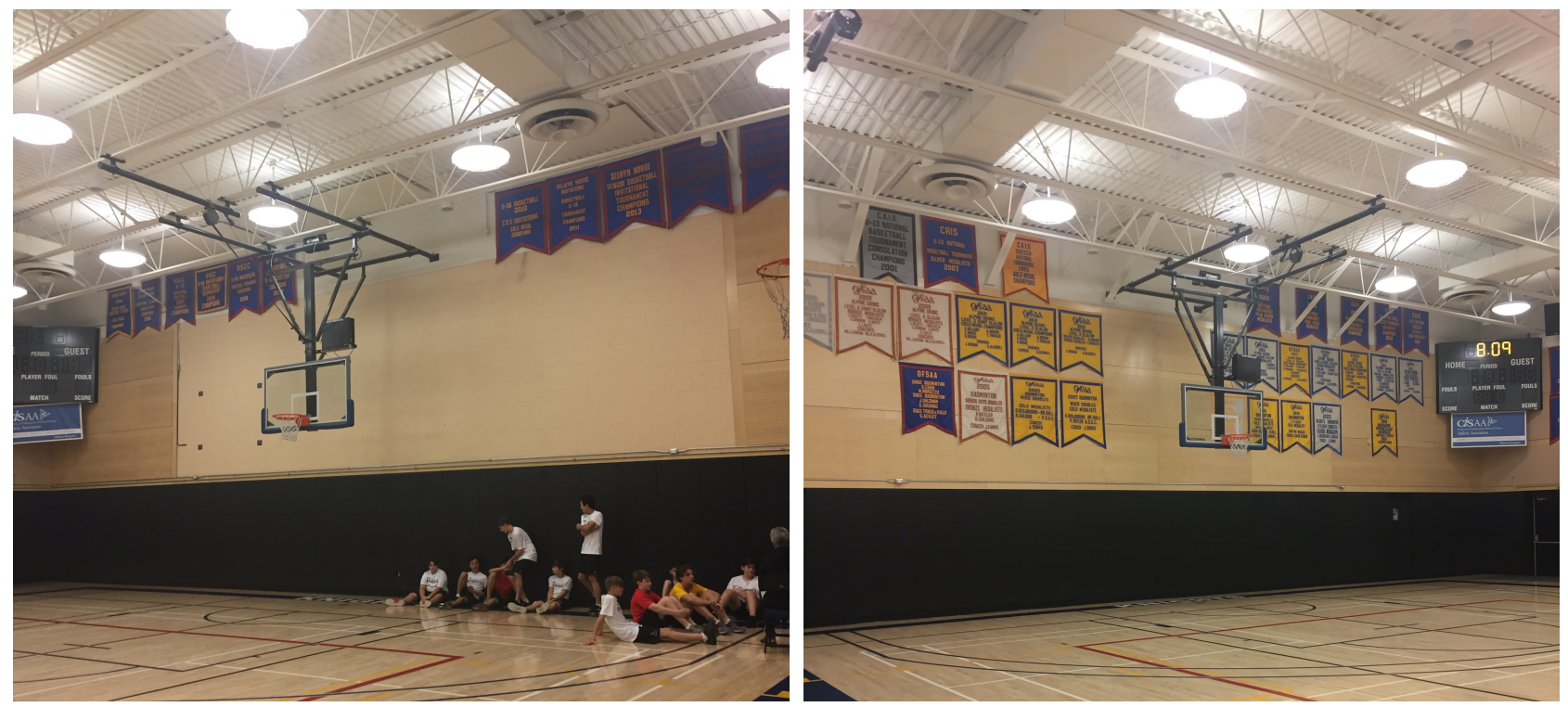

Figure 4.1: Site Photos of Royal St Georges College

The school is in the Annex neighborhood of Toronto and underwent renovations in 2010 to reduce echo [29]. The overall gym measures $20.9 \mathrm{~m} \times 27.6 \mathrm{~m} \times 7.0 \mathrm{~m}$, with an overall volume of $4,037.88 \mathrm{~m}^{3}$. The bottom $2.1 \mathrm{~m}$ of the walls covered in cushioning. In the remaining height of the gym, there is $160.1 \mathrm{~m}^{2}$ of fabric absorbers, $84.1 \mathrm{~m}^{2}$ of perforated wood panels, and $46.4 \mathrm{~m}^{2}$ of sound insulation. They ceiling is steel deck with open steel webbed joists and exposed HVAC. The remaining gym walls are painted concrete block with varnished wood floors. 


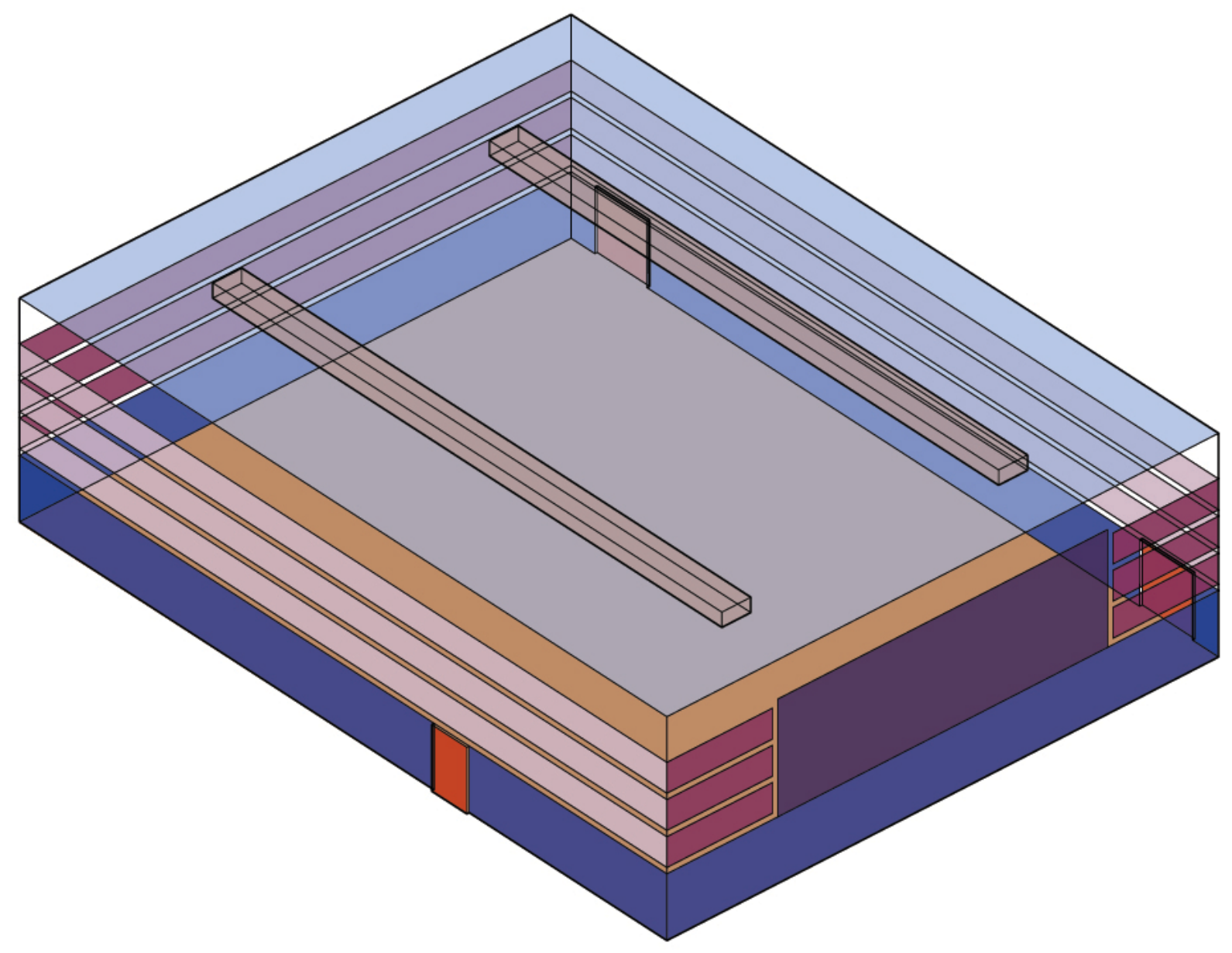

Figure 4.2: Schematic Representation of Royal St Georges Gym's Surfaces 


\subsubsection{Gabrielle Roy elementary school}

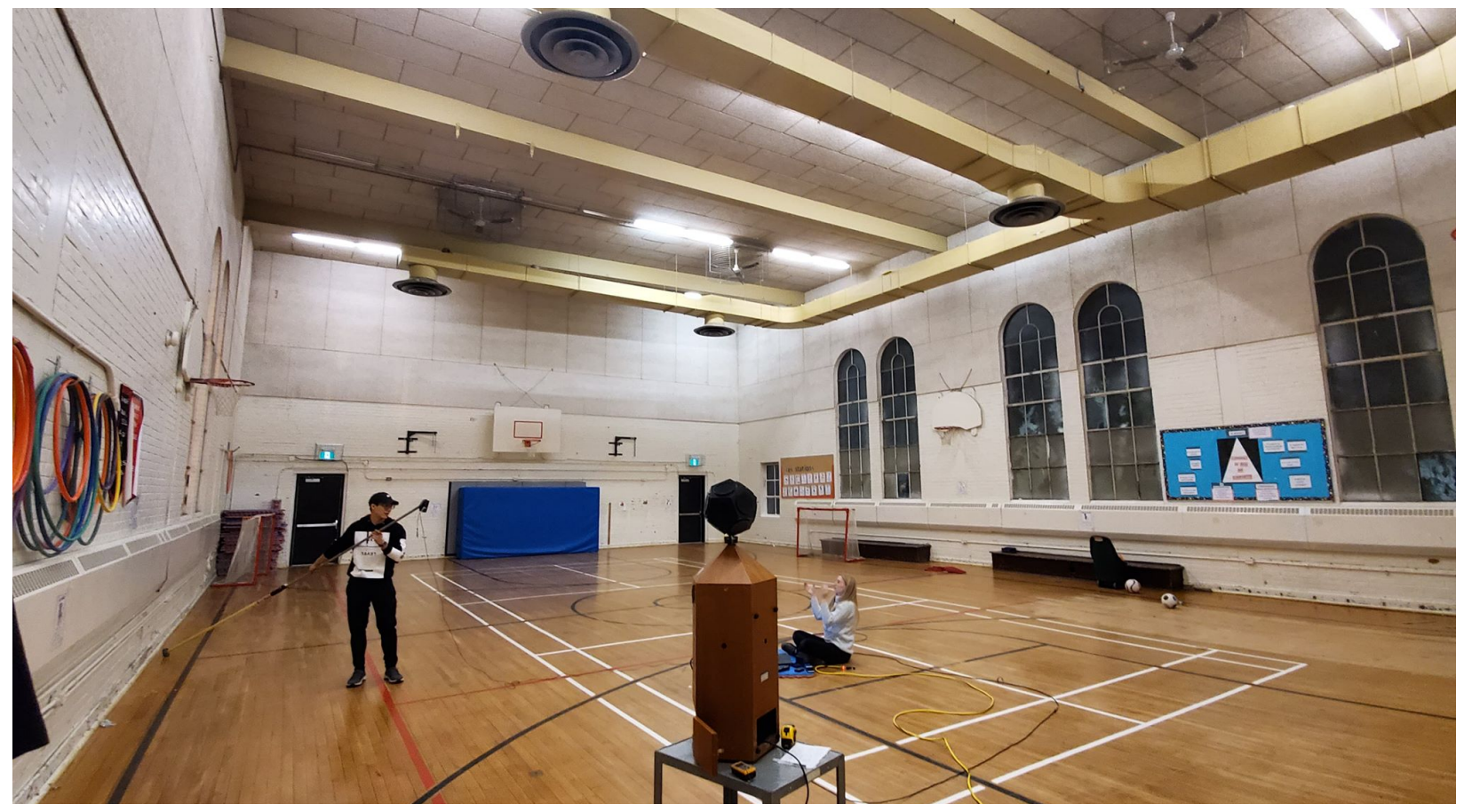

Figure 4.3: Site Photo of Gabrielle Roy Elementary School Gym

The school is in the downtown core of Toronto and is part of the French school board. It was originally built in 1929, with the additional sound absorbers added recently [30] . Its overall dimensions are $13.84 \mathrm{~m} \times 19.70 \mathrm{~m} \times 7.21 \mathrm{~m}$, with a total volume of $1,965 \mathrm{~m}^{3}$. The upper half of the walls and the entire ceiling are covered in $474.9 \mathrm{~m}^{2}$ of absorbers; the remaining wall is painted brick. 


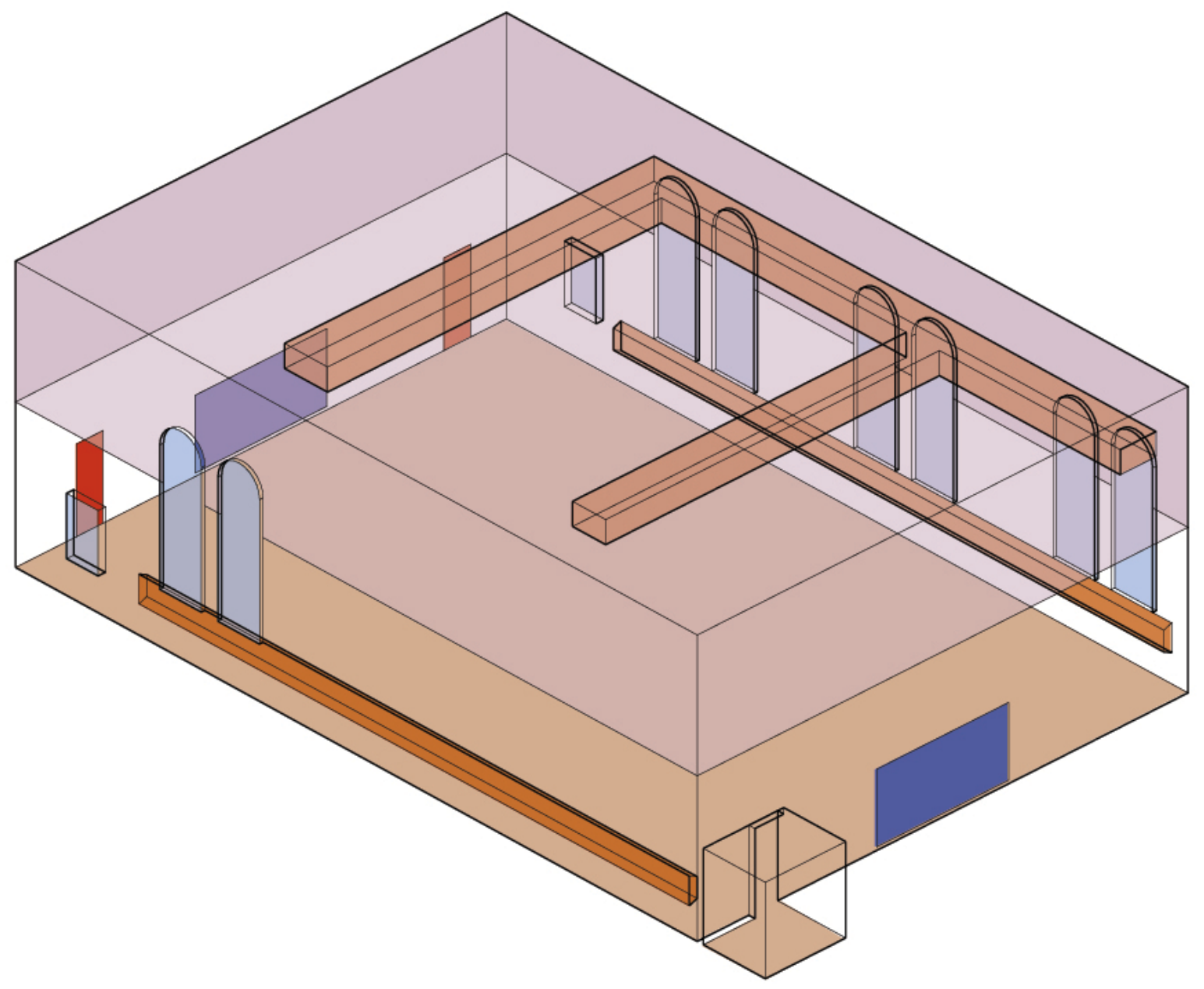

Figure 4.4: Schematic Representation of Gabrielle Roy's Gym Surface 


\subsubsection{Ryerson Athletic Centre Gym II}

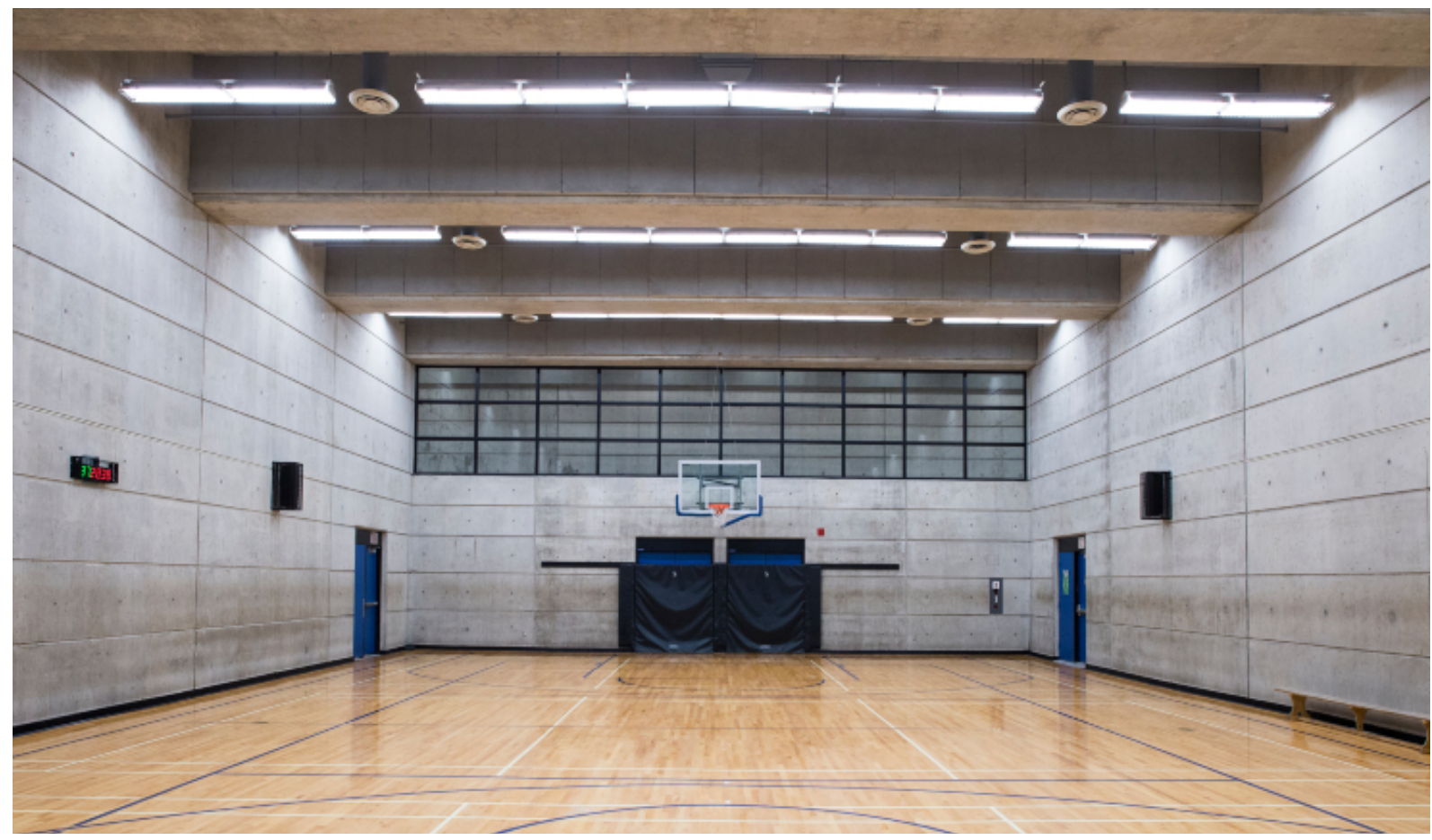

Figure 4.5: Photo of the Ryerson Athletic Facility Gym II [31]

The gym is part of Ryerson's athletic facilities in the downtown core. The gym's surface is mainly unfinished concrete, with glass windows looking in from a racetrack that runs along the top floor of the facility, and a varnished wood floor. There is $314.4 \mathrm{~m}^{2}$ of perforated metal panels with acoustic absorber backing installed on the vertical faced of the beams that run across the space. The gym measures $15.82 \mathrm{~m} \times 24.32 \mathrm{~m}$ with an overall celling height of $8.09 \mathrm{~m}$ and a floorto-beam height of $6.09 \mathrm{~m}$. The volume of the space including the beams is $2,971.91 \mathrm{~m}^{3}$. The space has noticeable distinct echoes and is considered by facilities to have subjectively poor intelligibility. 


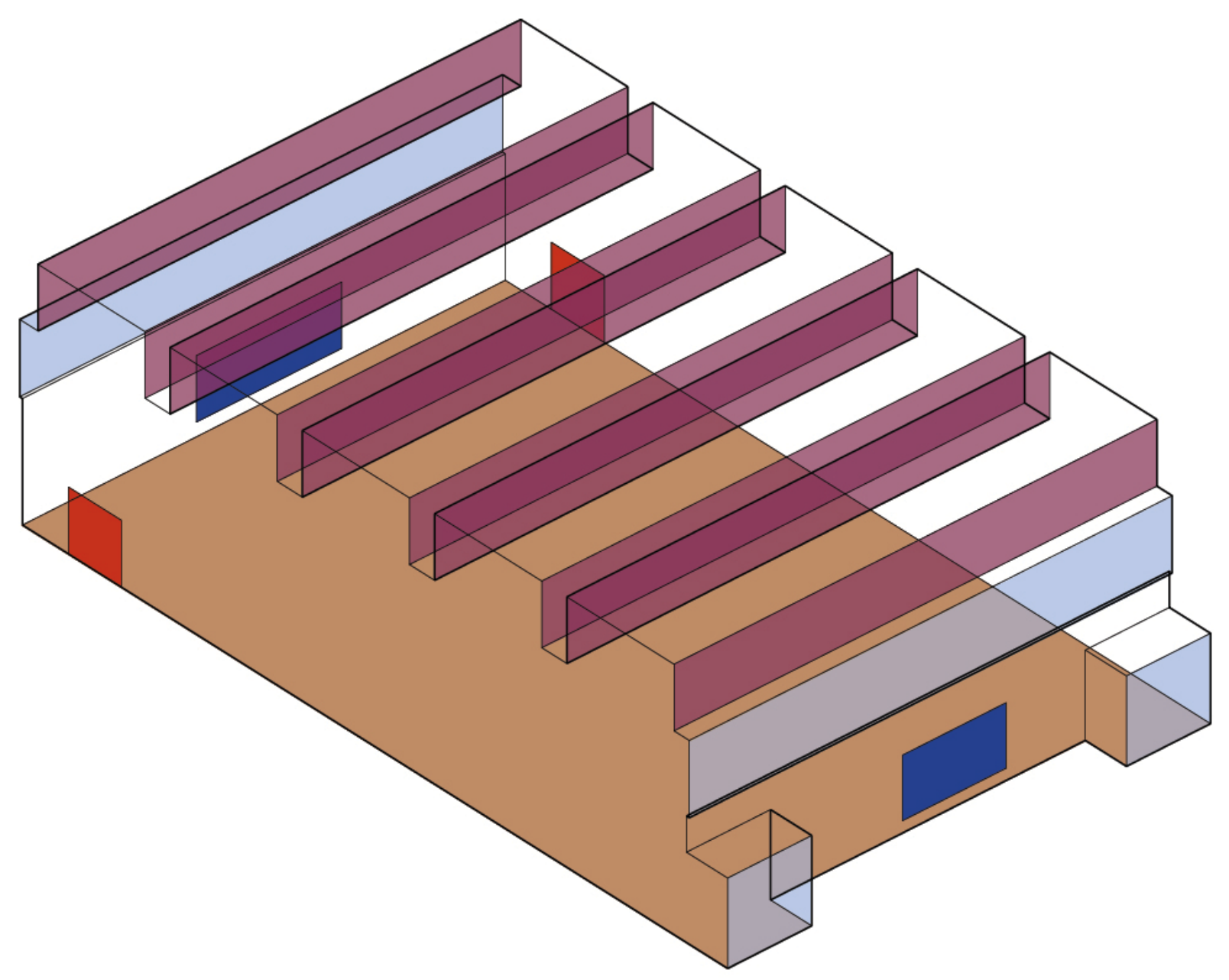

Figure 4.6: Schematic Representation of RAC II's Gym Surfaces 


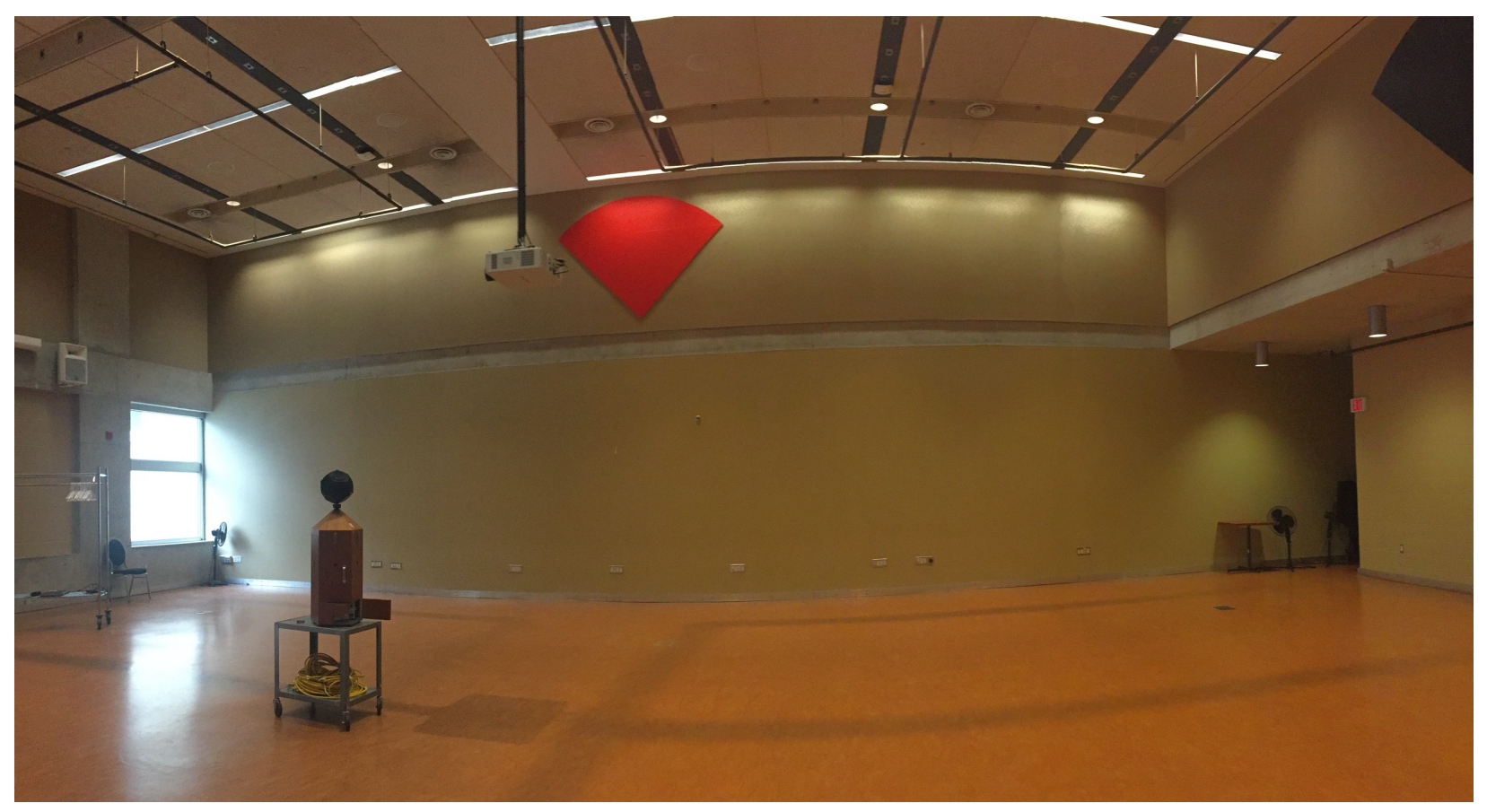

Figure 4.7: Site Photo of Tecumseh Auditorium

The Tecumseh Auditorium is part of the Student Service centre at Ryerson's downtown campus. The walls surface is mainly painted concrete block, drywall, and unfinished concrete. The floor is varnished hardwood and the ceiling is drywall and dropped acoustical ceiling tiles. The room measures $11.94 \mathrm{~m}$ by $17.73 \mathrm{~m}$ with the main ceiling being $5.9 \mathrm{~m}$ high and $3.36 \mathrm{~m}$ at a small area at one end of the gym. The approximate volume of the space is $1,260.98 \mathrm{~m} 3$. It has the most irregular surfaces which could contribute to a more diffuse sound field. The on-site subjective impression of the space is that it has a perceptible echo at mid-range frequencies. 


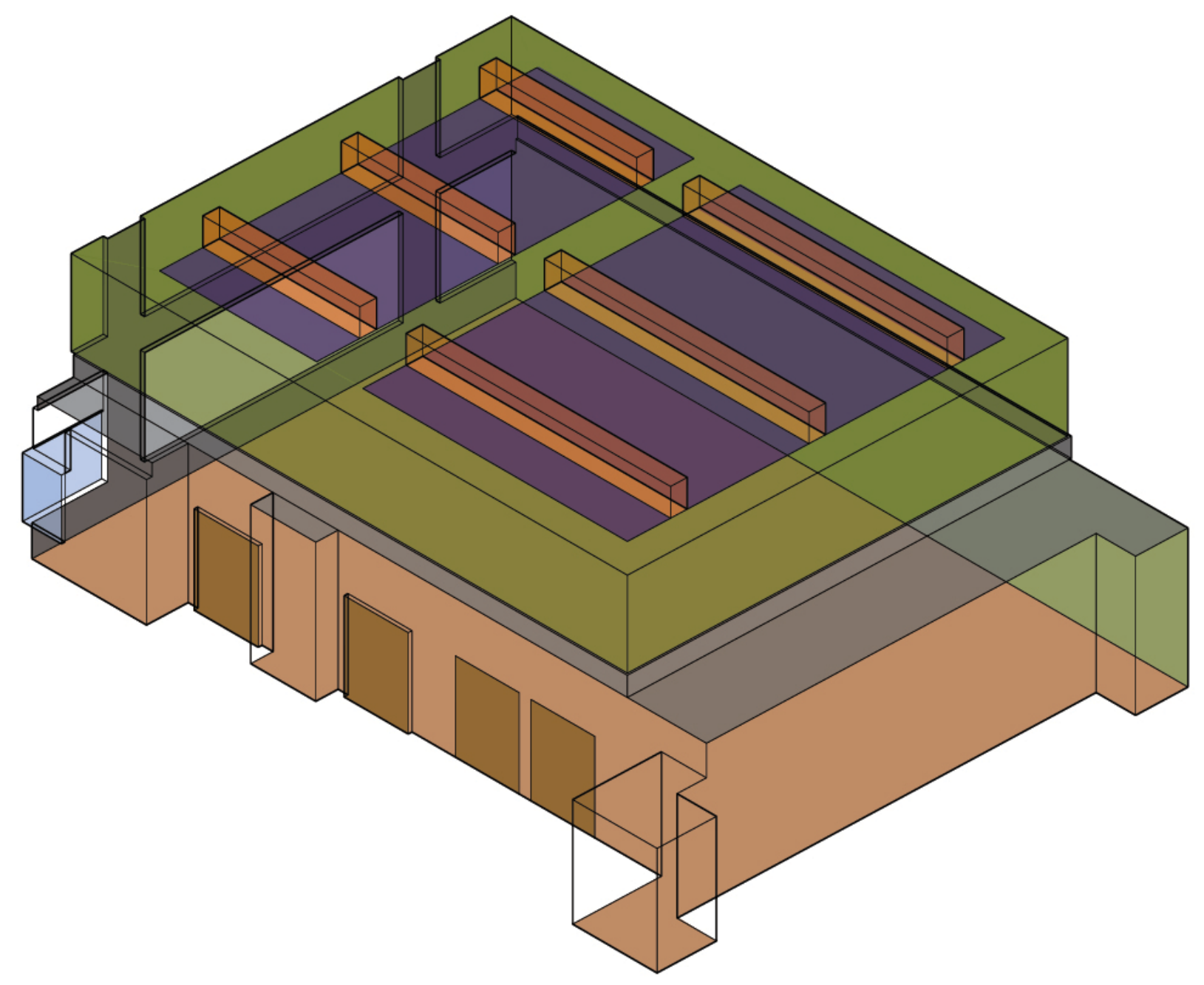

\begin{tabular}{|c|c|c|c|}
\hline $220.3 m^{2}$ & varnished wood floor & $216.4 m^{2}$ & gypsum board \\
\hline $88.7 m^{2}$ & smooth, unfinished concrete & $67.5 \mathrm{~m}^{2}$ & metal trim \\
\hline $5.5 \mathrm{~m}^{2}$ & painted concrete block & $9.3 m^{2}$ & double pane glazing \\
\hline $3 m^{2}$ & absorber panels & $15.2 \mathrm{~m}^{2}$ & wooden door \\
\hline
\end{tabular}

Figure 4.8: Schematic Representation of Tecumseh's Gym Surfaces 


\subsection{Source-Receiver Locations}

To achieve precision accuracy with the measured data, a minimum of 12 unique sourcereceiver locations are necessary [32]. Figures 3.11-14 indicate the source locations, labelled as S1 and S2, and the receiver points, labelled as R1-12. For Royal St. Georges College and RAC

Gym II, there is a total of 12 overall receiver locations. When data was being collected from $\mathrm{S} 1$, all receivers except $\mathrm{R} 4$ were used. When data was being collected at $\mathrm{S} 2$, all receivers except

R9 were used. In the smaller rooms, Gabrielle Roy's gym and Tecumseh auditorium, data from S1 excluded R3 and data from S2 excluded R6. 


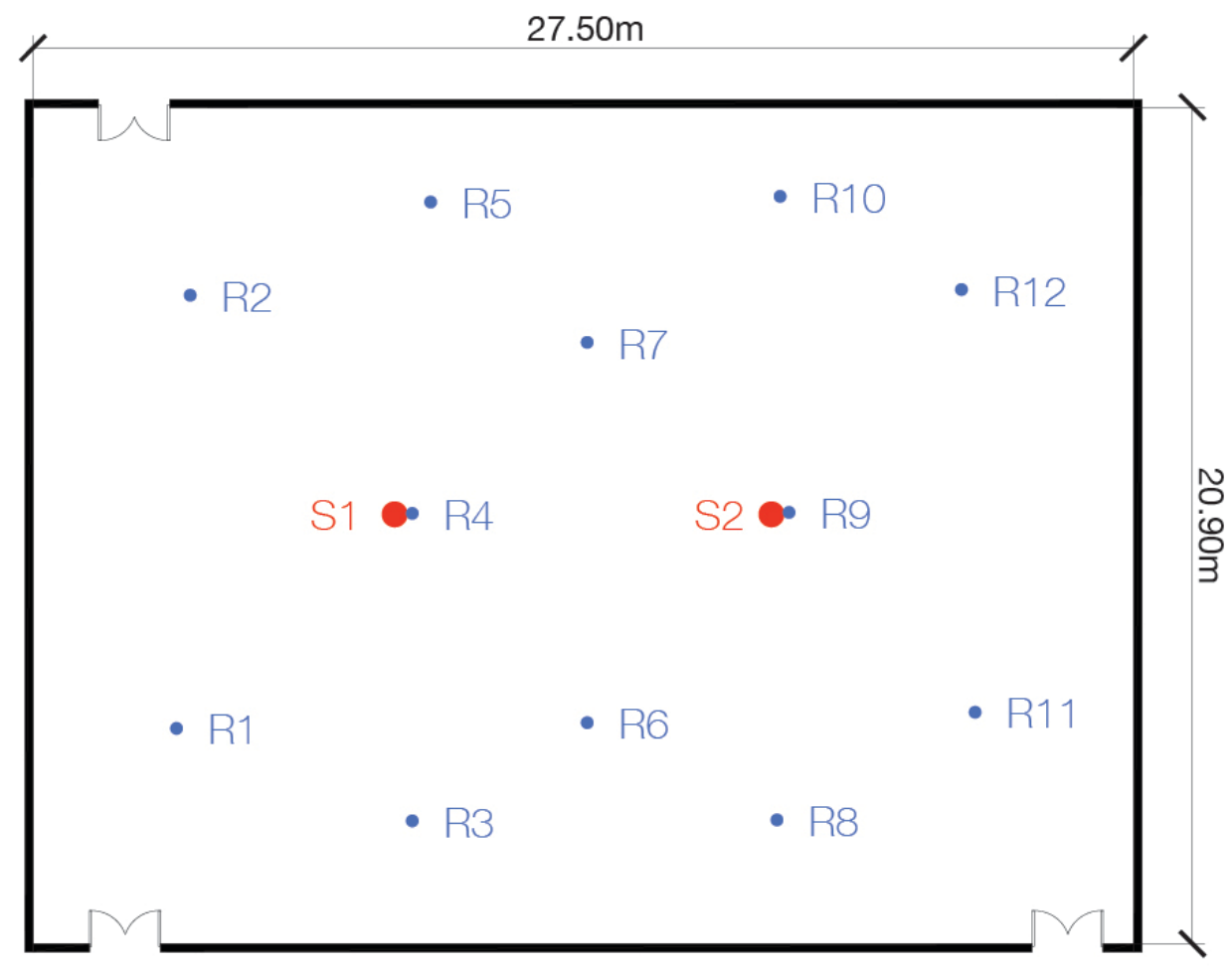

Figure 4.9: Royal St. Georges College source-receiver positions

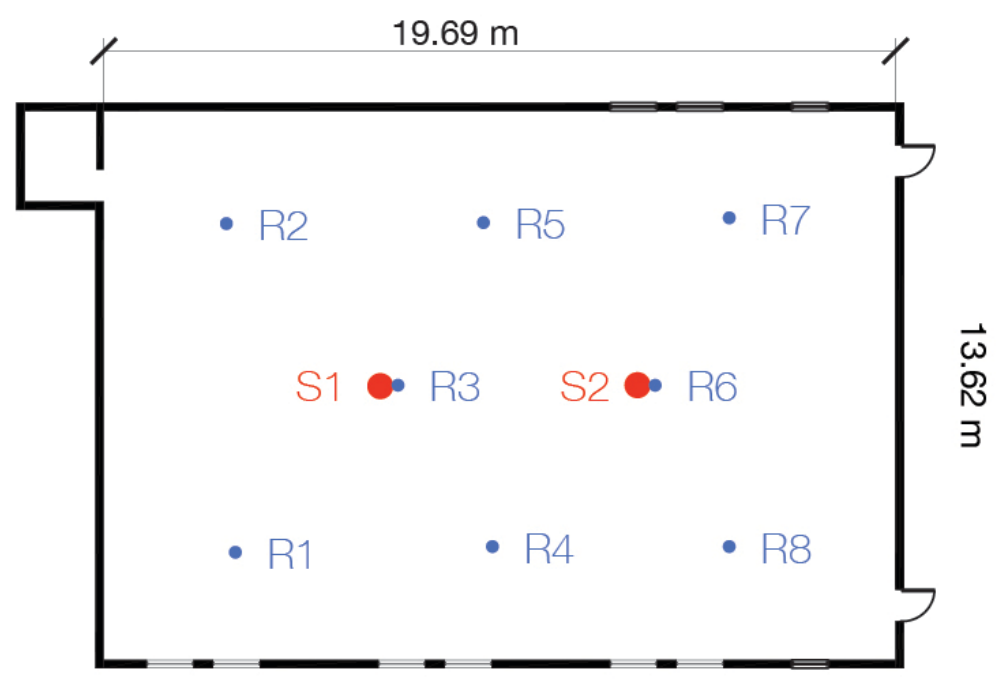

Figure 4.10: Gabrielle Roy source-receiver positions 


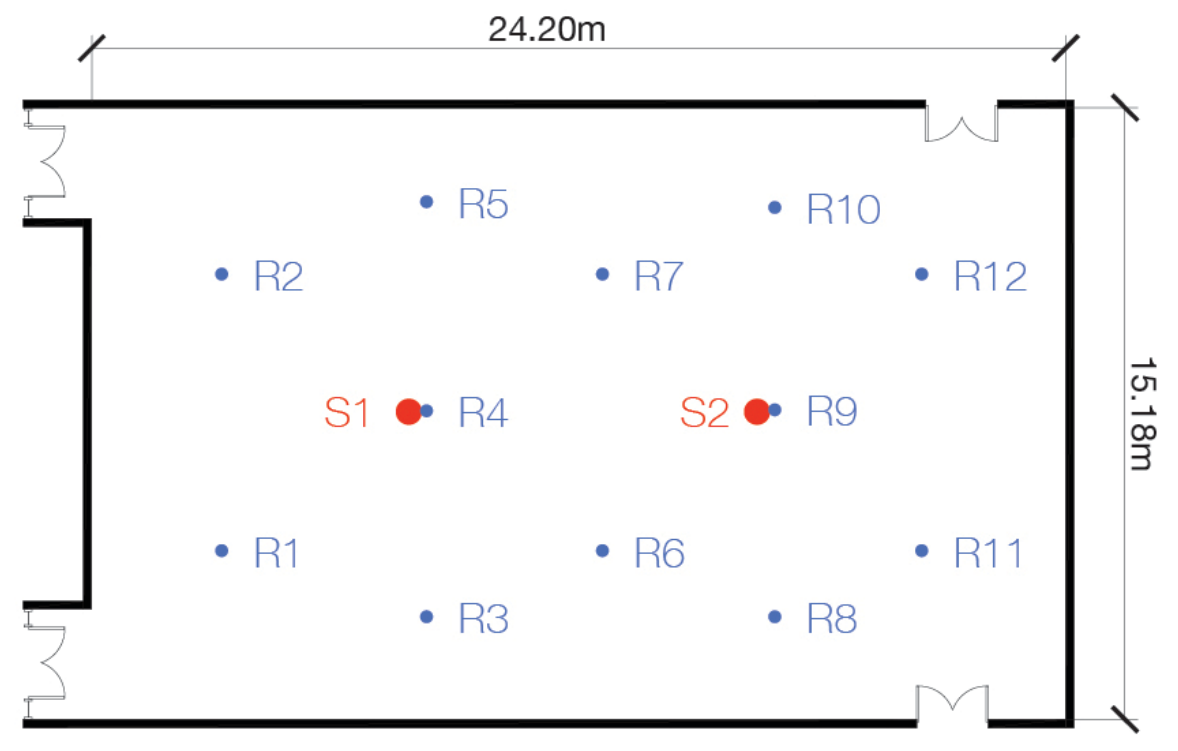

Figure 4.11: RAC I/ source-receiver positions

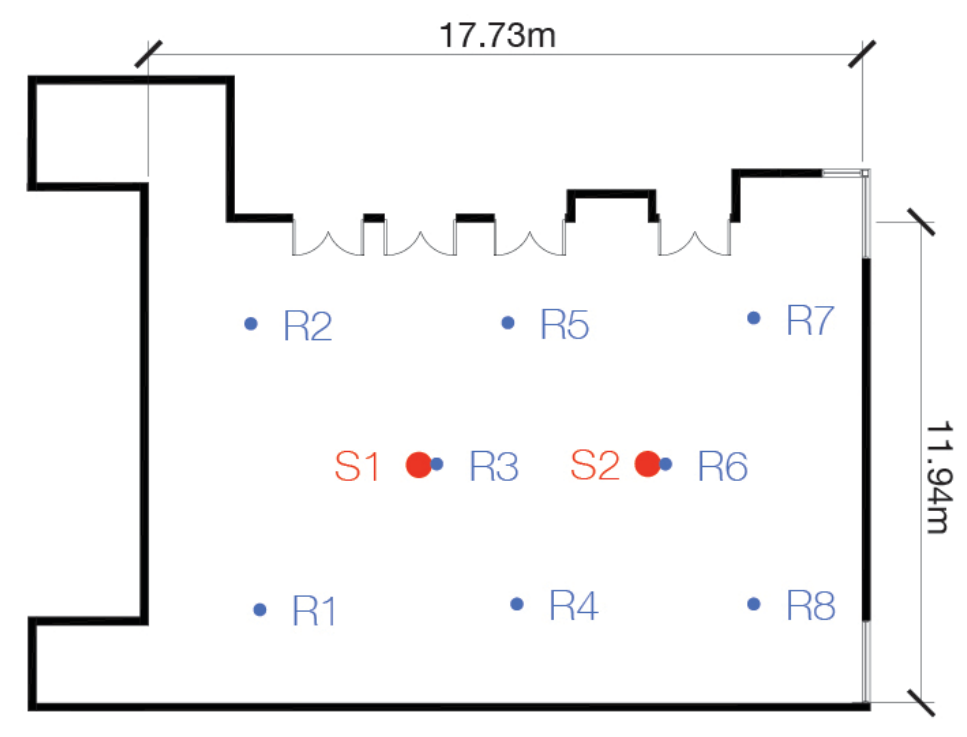

Figure 4.12: Tecumseh source-receiver positions 


\section{Results and Discussion}

Site measurement results and computer simulation result are presented below. The site data is first analysed in Section 5.1 for the effect of receiver height on sound field measurements. In Section 5.2, this data is compared to the calibrated computer models to gauge the prediction accuracy the computer simulation. Section 5.3 compares the sound field of the RAC Gym II and Tecumseh Auditorium with the addition of perimeter absorbers.

\subsection{Site Measurements}

Field test measurements are subject to limitations, the consequences of which are discussed more completely in the Analysis section. Some of those limitations are:

- In the case of RT, the measurement is based on a change in $\mathrm{dB}$ which enables accurate data collection provided the source noise can significantly exceed background noise. According to ISO 3382, T20 is the most commonly used reverberation time measurement. This means the T60 is estimated based on the amount of time it takes for the signal to decay by $20 \mathrm{~dB}$, which is multiplied by three.

- SPL measurements require a calibrated sound source. The data presented in the current investigation is in relative $\mathrm{dB}$ and therefore cannot be treated as absolute values.

- STI measurements require the input signal to be calibrated. 


\subsubsection{Royal Saint Georges College}

There was a total of 22 unique source-receiver locations used to calculate T20, SPL, and STI. Insufficient data could be collected at the $63 \mathrm{~Hz}$ octave band to give a confident T20 value; as such it has been omitted from the analysis. The background noise of the room was measured and is presented in Table 5.1.

\begin{tabular}{|l|l|l|l|l|l|l|l|l|}
\hline & $63 \mathrm{~Hz}$ & $125 \mathrm{~Hz}$ & $250 \mathrm{~Hz}$ & $500 \mathrm{~Hz}$ & $1000 \mathrm{~Hz}$ & $200 \mathrm{~Hz}$ & $4000 \mathrm{~Hz}$ & $8000 \mathrm{~Hz}$ \\
\hline \hline $\begin{array}{l}\text { Background } \\
\text { Noise [dB] }\end{array}$ & 29 & 31 & 34 & 37 & 35 & 33 & 29 & 24 \\
\hline
\end{tabular}

Table 5.1: Background Noise profile of RSGC

\section{$\underline{\text { Reverberation Time }}$}

Table 5.2 and Figure 5.1 show the average RT of Royal St Georges College gym, and indicate that there is a small difference in the average T20 measured at the $1.2 \mathrm{~m}$ and $3.2 \mathrm{~m}$ receiver heights. The difference is negligible below $500 \mathrm{~Hz}$ and becomes more pronounced at frequencies over $500 \mathrm{~Hz}$. At low frequencies, the two averages are within $1 \%$ of each other; at $500-1000 \mathrm{~Hz}$, the $3.6 \mathrm{~m}$ data is an average of 0.05 seconds longer than the $1.2 \mathrm{~m}$ data. The most significant difference is between $2000-8000 \mathrm{~Hz}$ where RT is $0.06 \mathrm{~s}$ shorter at $3.6 \mathrm{~m}$. At either height, the gymnasium satisfies the Alberta standard of having an RT below 2s and the CAM standard of an RT below 1.5s at key mid-frequencies.

\begin{tabular}{|c|c|c|c|c|c|c|c|c|}
\hline & $63 \mathrm{~Hz}$ & $125 \mathrm{~Hz}$ & $250 \mathrm{~Hz}$ & $500 \mathrm{~Hz}$ & $1000 \mathrm{~Hz}$ & $2000 \mathrm{~Hz}$ & $4000 \mathrm{~Hz}$ & $8000 \mathrm{~Hz}$ \\
\hline Measured T20 at $1.2 \mathrm{~m}$ & & 2.20 & 1.25 & 1.16 & 1.51 & 1.56 & 1.47 & 1.13 \\
\hline Measured T20 at 3.6m & & 2.22 & 1.23 & 1.20 & 1.57 & 1.52 & 1.40 & 1.04 \\
\hline \% Difference & & $1 \%$ & $-1 \%$ & $4 \%$ & $4 \%$ & $-3 \%$ & $-5 \%$ & $-8 \%$ \\
\hline
\end{tabular}

Table 5.2: Mean Measured T20 for RSGC at 1.2m and 3.6m 


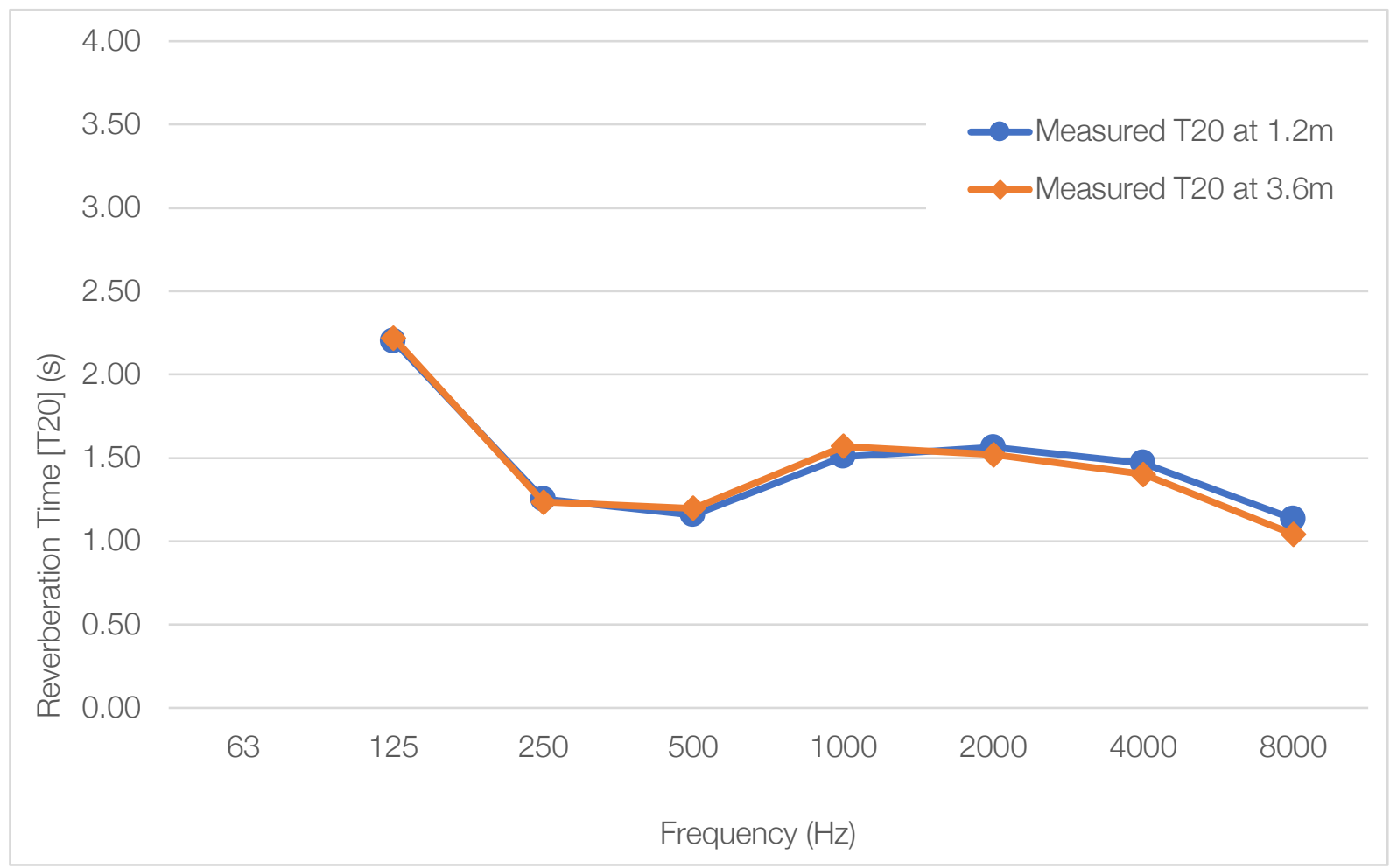

Figure 5.1: Measured T20 for 1.2m and 3.6m for RSGC

\begin{tabular}{|r|rr|r|r|r|r|r|r|}
\hline & \multicolumn{1}{|c}{$63 \mathrm{~Hz}$} & \multicolumn{1}{l}{$125 \mathrm{~Hz}$} & \multicolumn{1}{l}{$250 \mathrm{~Hz}$} & \multicolumn{1}{l}{$500 \mathrm{~Hz}$} & $1000 \mathrm{~Hz}$ & $2000 \mathrm{~Hz}$ & \multicolumn{1}{l}{$4000 \mathrm{~Hz}$} & $8000 \mathrm{~Hz}$ \\
\hline \hline Stdev 1.2m & & 0.22 & 0.08 & 0.06 & 0.06 & 0.09 & 0.08 & 0.06 \\
\hline Stdev 3.6m & & 0.18 & 0.10 & 0.06 & 0.06 & 0.04 & 0.03 & 0.03 \\
\hline
\end{tabular}

Table 5.3: Standard Deviation of RSGC's T20 measurements at $1.2 \mathrm{~m}$ and $3.6 \mathrm{~m}$

Figures 5.2 and 5.3 are plots of the T20 data at each individual receiver point. The graphs show that the equipment was incapable of collecting $\mathrm{RT}$ at $63 \mathrm{~Hz}$ and was highly variable at $125 \mathrm{~Hz}$. This could be due to the loudspeaker not being able to generate a loud enough signal at lower frequencies. As such, it should be regarded as less reliable. Table 5.3 shows that the standard deviation of the data generally went down as the frequency increased. 


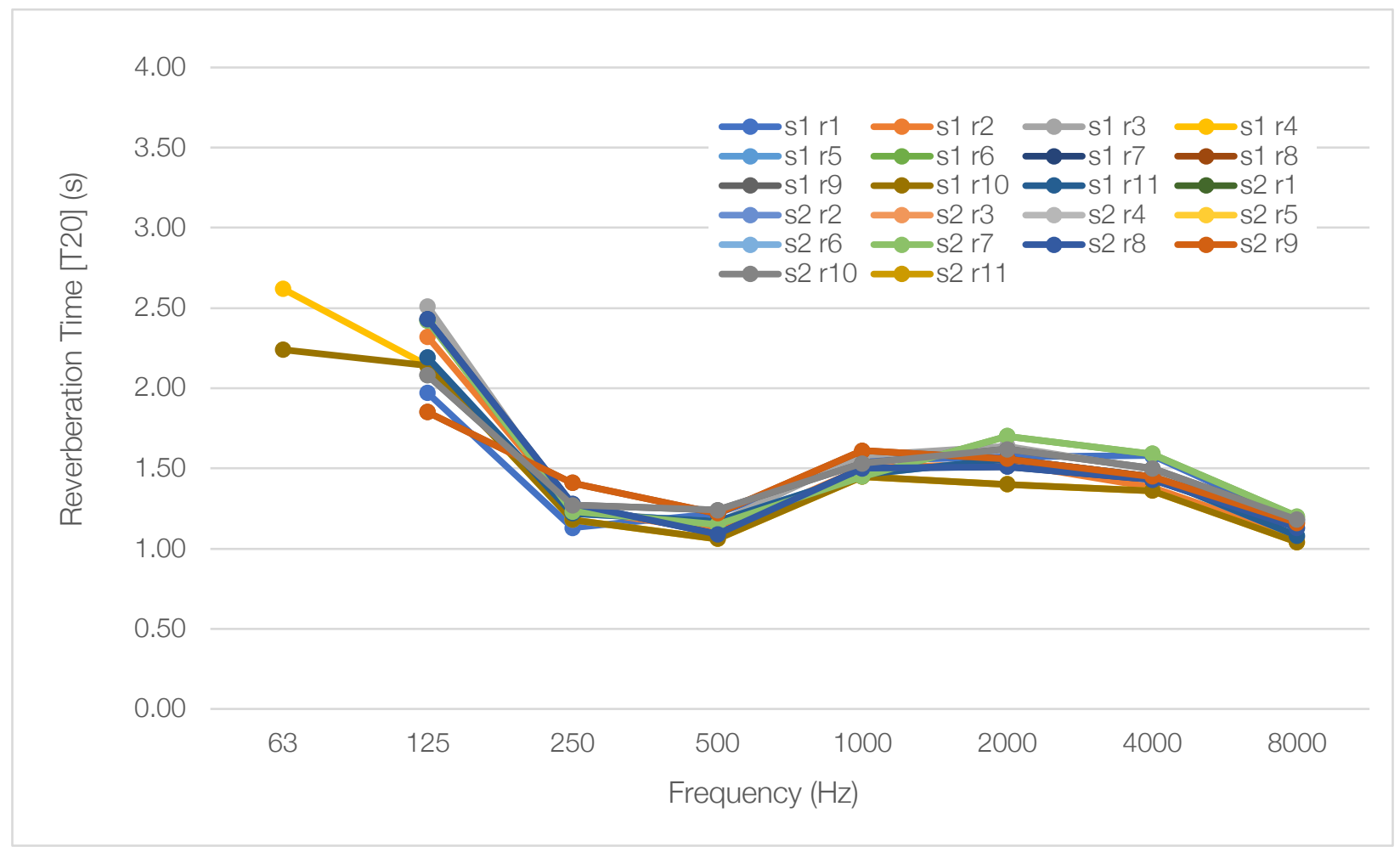

Figure 5.2: T20 data for all 1.2m receiver points for $R S G C$

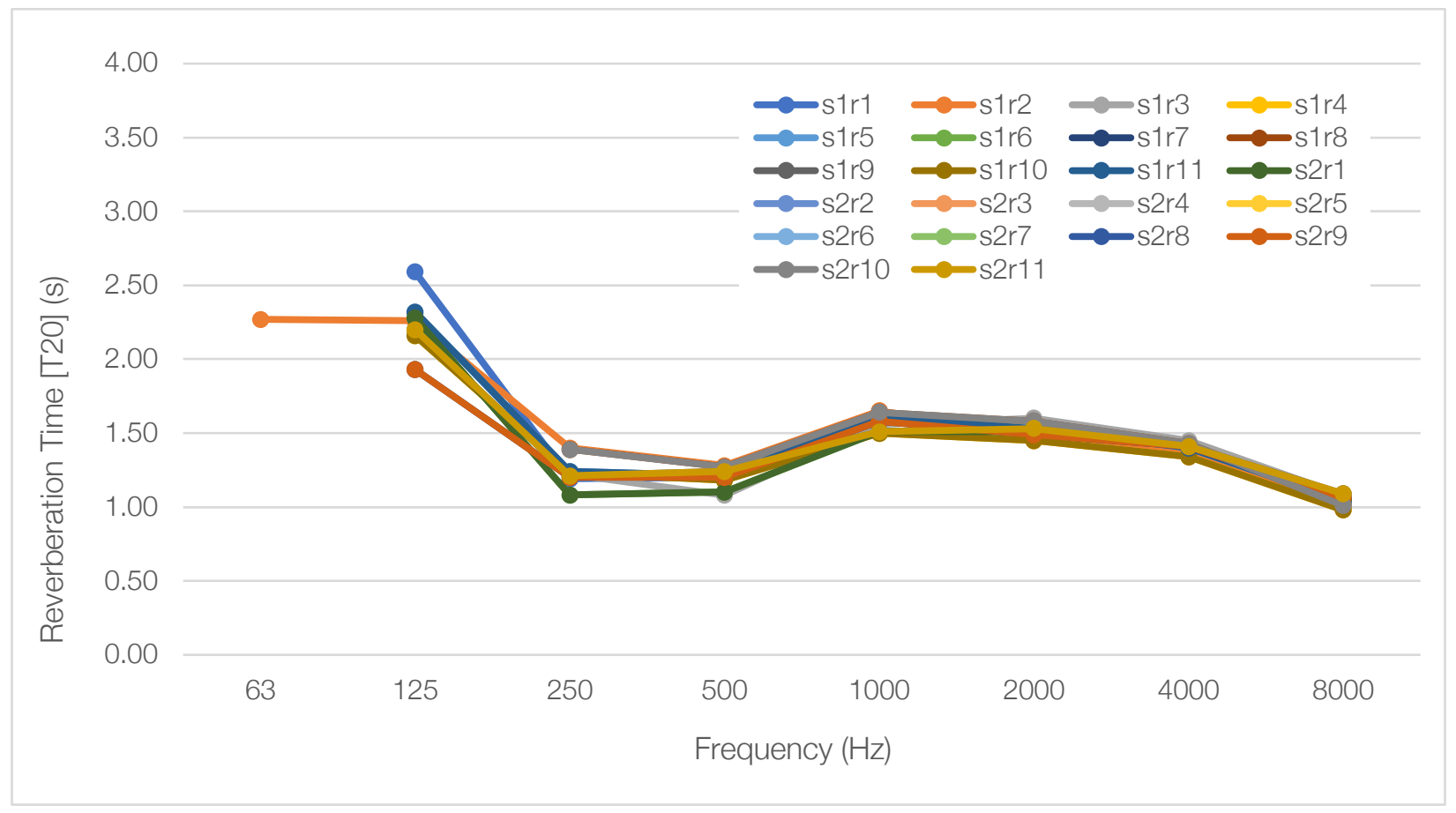

Figure 5.3: T20 data for all 3.6m receiver points for $R S G C$ 


\section{Sound Pressure Level}

Figure 5.4 shows the relative SPL distribution in the RSGC gymnasium. There is significant difference between the SPL at the two receiver heights, reaching a $6 \mathrm{~dB}$ difference at $500 \mathrm{~Hz}$. At $125 \mathrm{~Hz}$ and above, the $3.6 \mathrm{~m}$ data exceeds the $1.2 \mathrm{~m}$ data at some receiver points. Within the respective receiver heights, SPL varies up to $10 \mathrm{~dB}$. Across different frequencies, the plot does not retain a similar shape with some points being relatively higher at some frequencies and lower at others. This is most pronounced between $63 \mathrm{~Hz}$ and $125 \mathrm{~Hz}$ and could indicate the presence of interference like a room mode. The overall SPL is lower $63 \mathrm{~Hz}$ and $125 \mathrm{~Hz}$, likely due to the loudspeaker not being able to produce a strong enough signal at lower frequencies. There is also a significant reduction in $\mathrm{dB}$ at $8000 \mathrm{~Hz}$, which can be attributed to high frequencies attenuating more quickly from air resistance. 

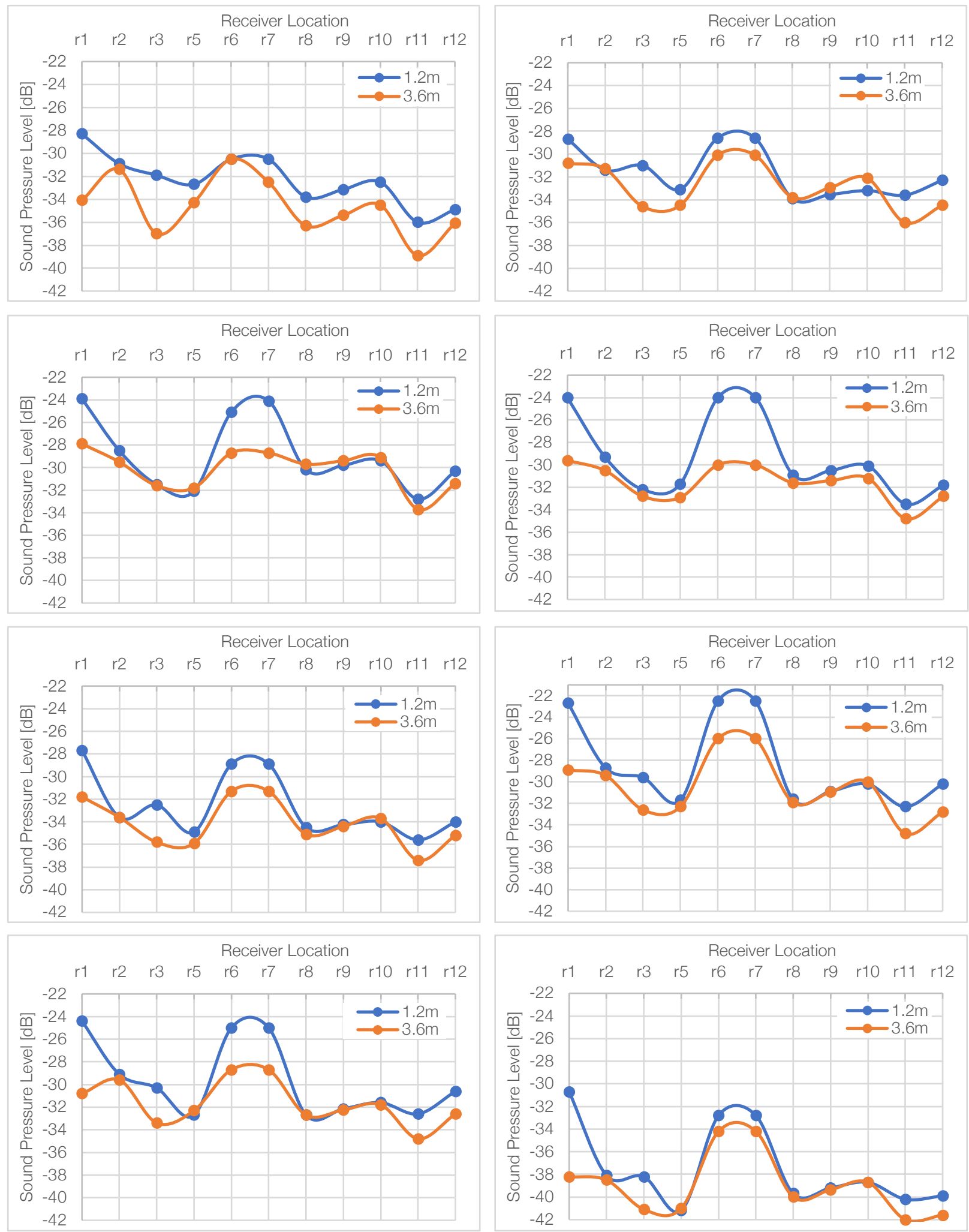

Figure 5.4: RSGC SPL distribution for all S1 receiver points at (left to right) $63 \mathrm{~Hz}, 125 \mathrm{~Hz}, 250 \mathrm{~Hz}, 500 \mathrm{~Hz}$, $1000 \mathrm{~Hz}, 2000 \mathrm{~Hz}, 40000 \mathrm{~Hz}$, and $8000 \mathrm{~Hz}$ 


\section{Speech Transmission Index}

At both heights, the measured STI was 0.51 with the STI at $3.6 \mathrm{~m}$ being $0.03 \%$ lower, which was considered negligible. This measurement is above the required STI of 0.5 from the CAM.

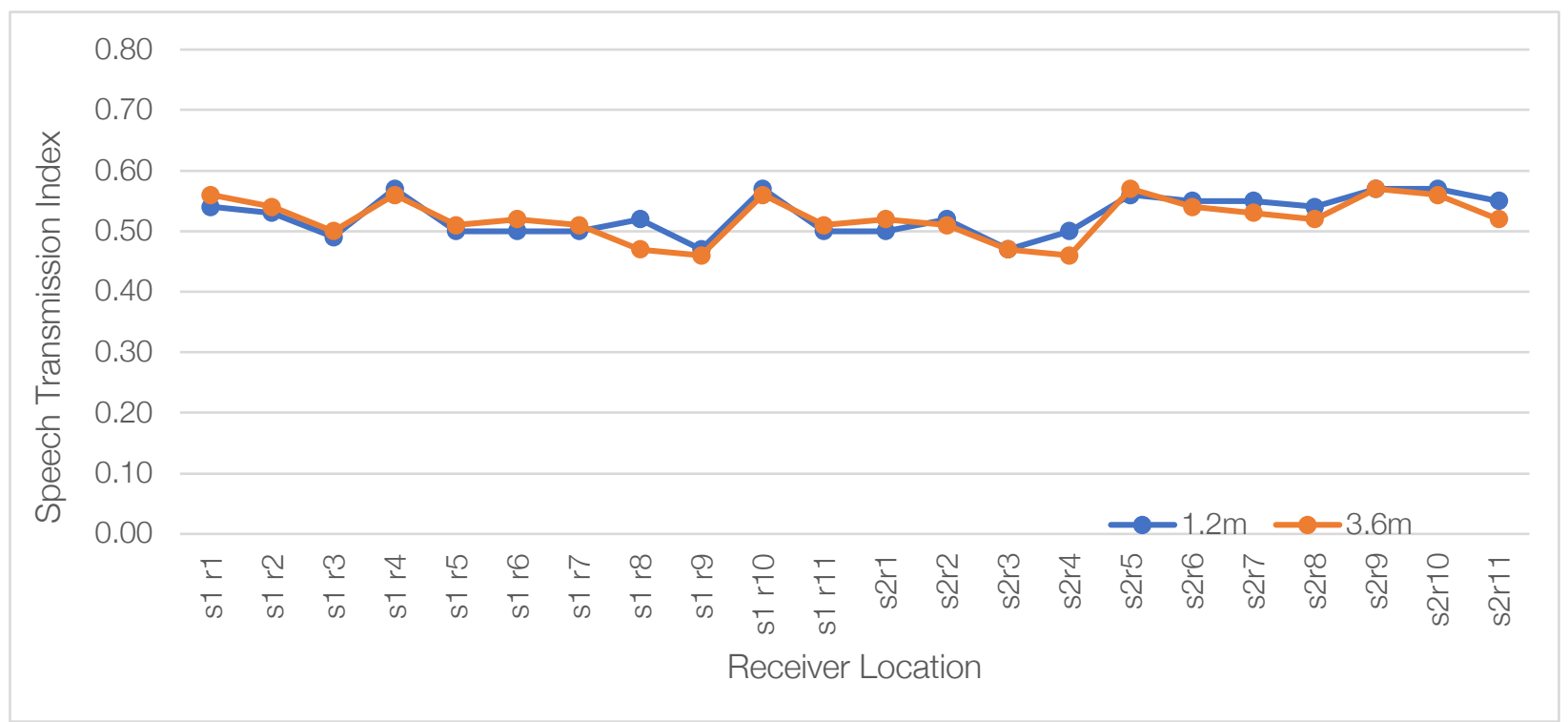

Figure 5.5: STI at 1.2m and 3.6m for RSGC 


\subsubsection{Gabrielle Roy Elementary School}

There was a total of 14 unique source-receiver locations used to calculate T20, SPL, and STI.

The background noise of the room was measured and is presented in Table 5.4.

\begin{tabular}{|l|l|l|l|l|l|l|l|l|}
\hline & $63 \mathrm{~Hz}$ & $125 \mathrm{~Hz}$ & $250 \mathrm{~Hz}$ & $500 \mathrm{~Hz}$ & $1000 \mathrm{~Hz}$ & $2000 \mathrm{~Hz}$ & $4000 \mathrm{~Hz}$ & $8000 \mathrm{~Hz}$ \\
\hline \hline $\begin{array}{l}\text { Background } \\
\text { Noise [dB] }\end{array}$ & 32 & 35 & 38 & 38 & 39 & 35 & 29 & 25 \\
\hline
\end{tabular}

Table 5.4: Background Noise profile of Gabrielle Roy

\section{$\underline{\text { Reverberation Time }}$}

Table 5.5 and Figure 5.13 show the average RT of Gabrielle Roy gym and indicate that from $63-1000 \mathrm{~Hz}$, the two averages are within $\pm 4 \%$ of each other. The most significant difference is between $2000-8000 \mathrm{~Hz}$ where RT is an average of $0.1 \mathrm{~s}$ shorter at $3.6 \mathrm{~m}$. At either height, the gymnasium satisfies the Alberta standard of having an RT below 2s but does not meet the CAM standard of an RT below $1.5 \mathrm{~s}$ at key mid-frequencies.

\begin{tabular}{|r|r|r|r|r|r|r|r|r|}
\hline & $63 \mathrm{~Hz}$ & \multicolumn{1}{c}{$125 \mathrm{~Hz}$} & \multicolumn{1}{c}{$250 \mathrm{~Hz}$} & \multicolumn{1}{c}{$500 \mathrm{~Hz}$} & $1000 \mathrm{~Hz}$ & $2000 \mathrm{~Hz}$ & $4000 \mathrm{~Hz}$ & $8000 \mathrm{~Hz}$ \\
\hline \hline Measured T20 at $1.2 \mathrm{~m}$ & 1.22 & 1.62 & 1.78 & 1.61 & 1.26 & 1.25 & 1.14 & 0.80 \\
\hline Measured T20 at 3.6m & 1.28 & 1.66 & 1.73 & 1.64 & 1.30 & 1.14 & 1.01 & 0.75 \\
\hline \% Difference & $4 \%$ & $2 \%$ & $-3 \%$ & $2 \%$ & $3 \%$ & $-9 \%$ & $-11 \%$ & $-7 \%$ \\
\hline
\end{tabular}

Table 5.5: Mean Measured T20 for Gabrielle Roy at 1.2m and 3.6m 


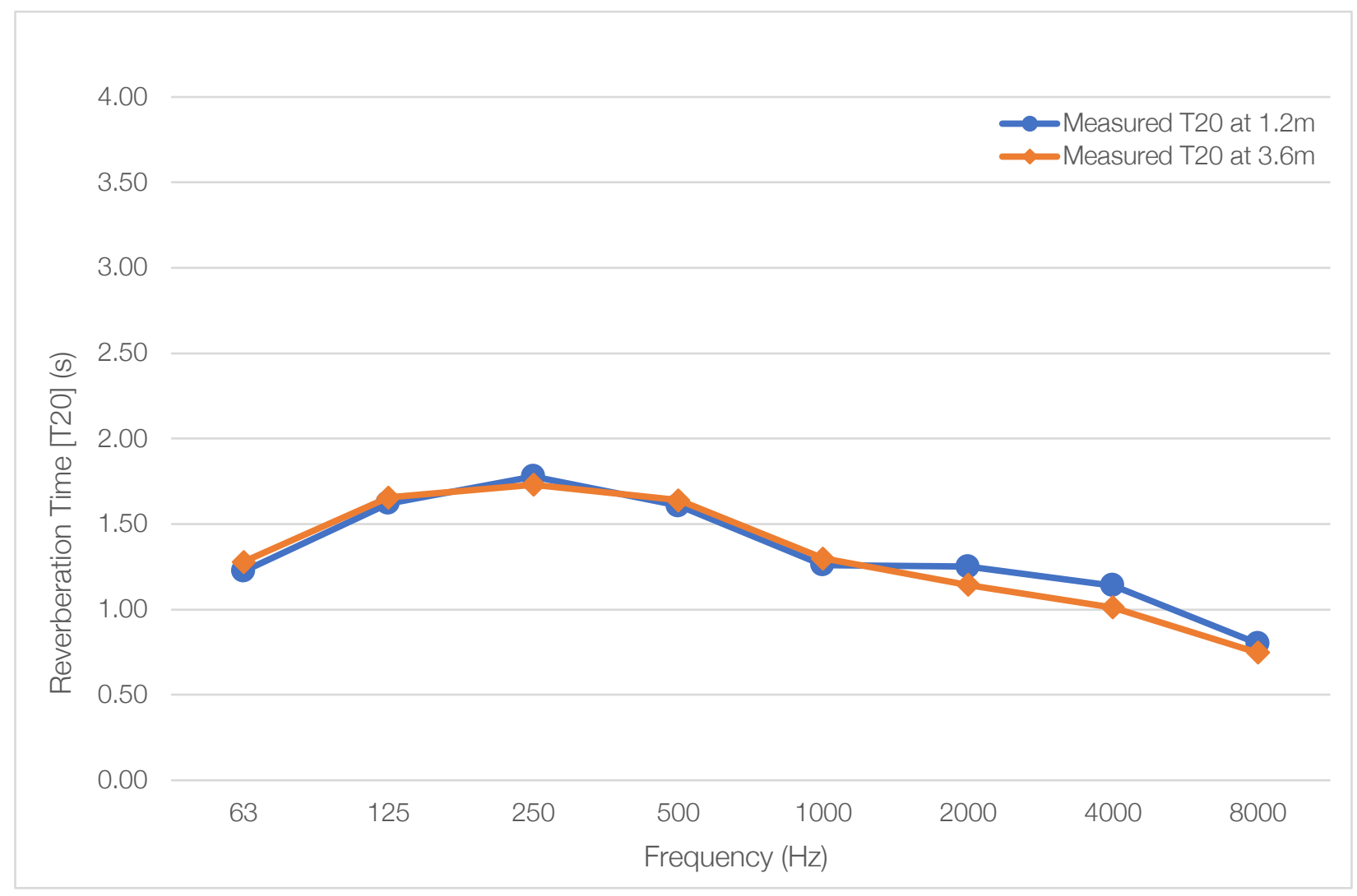

Figure 5.6: Gabrielle Roy Measured T20 for $1.2 \mathrm{~m}$ and 3.6m

\begin{tabular}{|c|c|c|c|c|c|c|c|c|}
\hline & $63 \mathrm{~Hz}$ & $125 \mathrm{~Hz}$ & $250 \mathrm{~Hz}$ & $500 \mathrm{~Hz}$ & $1000 \mathrm{~Hz}$ & $2000 \mathrm{~Hz}$ & $4000 \mathrm{~Hz}$ & $8000 \mathrm{~Hz}$ \\
\hline Stdev $1.2 \mathrm{~m}$ & 0.16 & 0.12 & 0.06 & 0.09 & 0.03 & 0.02 & 0.02 & 0.02 \\
\hline Stdev 3.6m & 0.17 & 0.12 & 0.06 & 0.07 & 0.02 & 0.02 & 0.02 & 0.02 \\
\hline
\end{tabular}

Table 5.6: Standard Deviation of T20 data from Gabrielle Roy at 1.2m and 3.6m

Figures 5.7 and 5.8 are plots of the T20 data at each individual receiver point. The graphs show that the equipment was incapable of consistently collecting $\mathrm{RT}$ at $63 \mathrm{~Hz}$, and was relatively variable at $125 \mathrm{~Hz}$; as such, it should be regarded as less reliable. Table 5.6 shows that the standard deviation of the data generally went down as the frequency increased. 


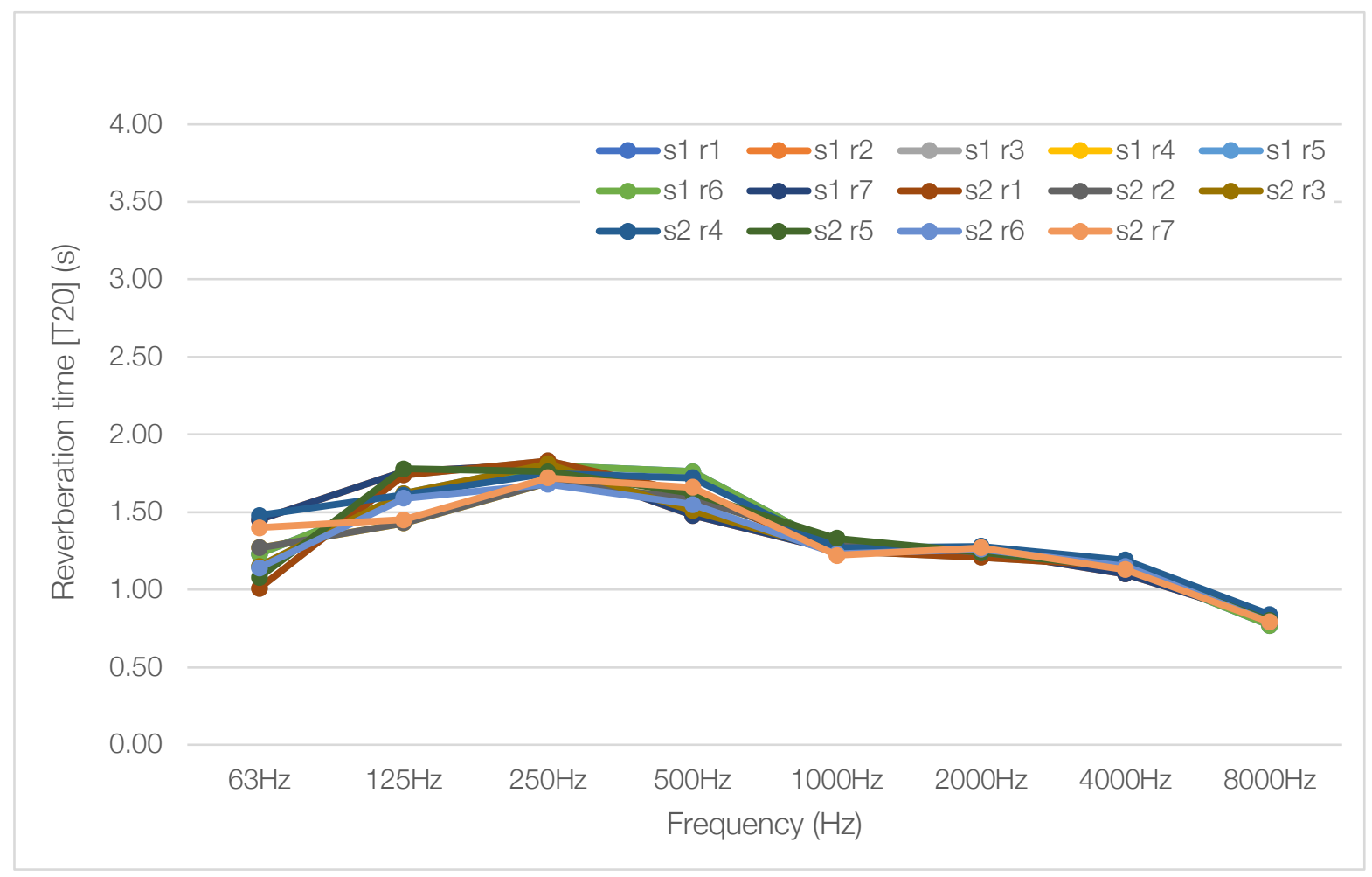

Figure 5.7: T20 data for all 1.2m receiver points for Gabrielle Roy

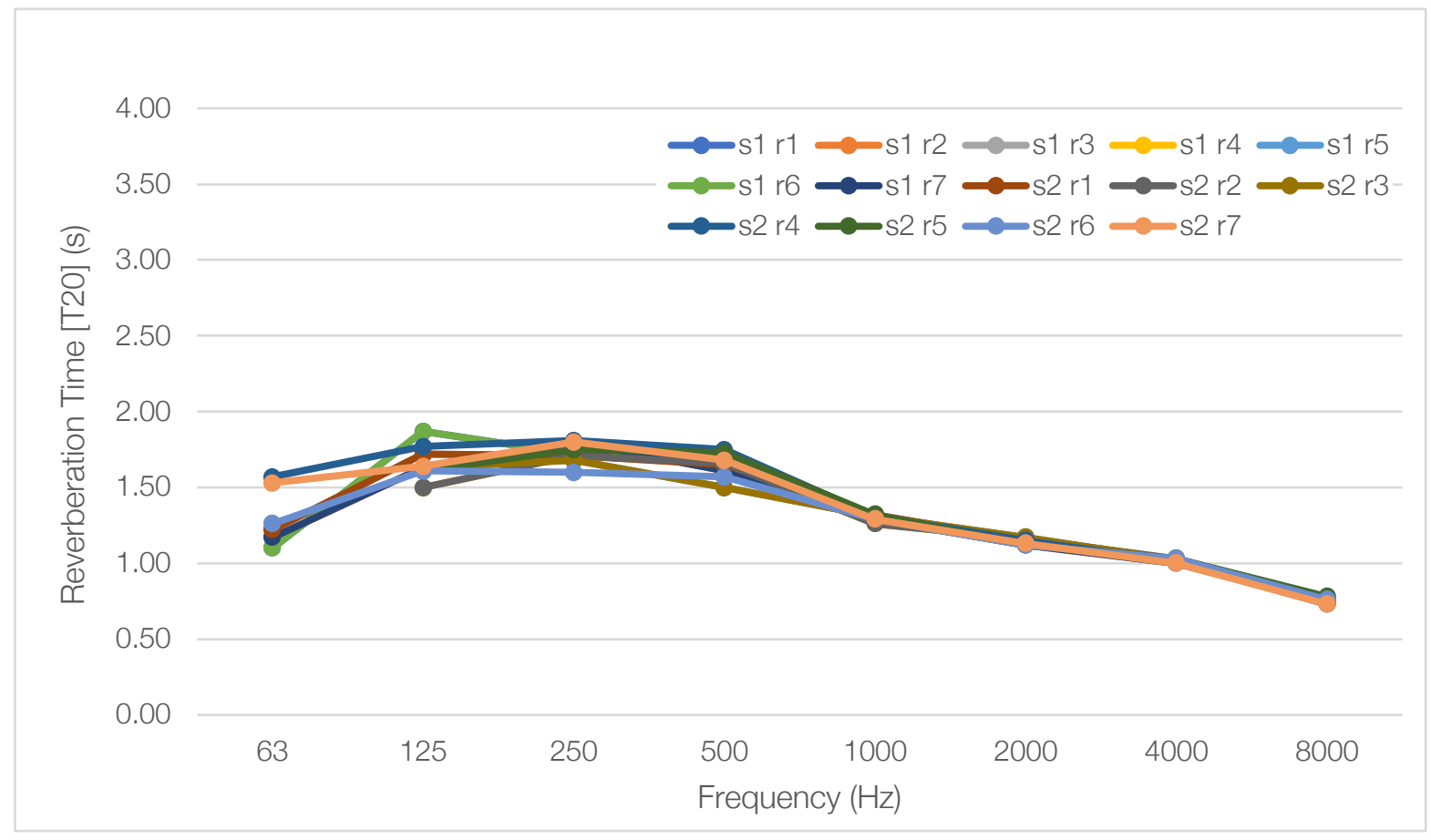

Figure 5.8: T20 data for all 3.6m receiver points for Gabrielle Roy 


\section{Sound Pressure Level}

Figure 5.9 shows the relative SPL distribution in the Gabrielle Roy gymnasium. There is a difference between the SPL at the two receiver heights, reaching a maximum $4 \mathrm{~dB}$ difference at $63 \mathrm{~Hz}$. At $250 \mathrm{~Hz}$ and above, the $3.6 \mathrm{~m}$ data exceeds the $1.2 \mathrm{~m}$ data at most receiver points. Across different frequencies, the plot does not retain a similar shape. At $63 \mathrm{~Hz}, 125 \mathrm{~Hz}$, and $250 \mathrm{~Hz}$, the plots are quite dissimilar with some points being relatively higher at some frequencies and lower at others. Above $250 \mathrm{~Hz}$, the plots become more similar as the frequency increases, indicating some interference. Within the respective receiver heights, SPL varies around $2 \mathrm{~dB}$. 

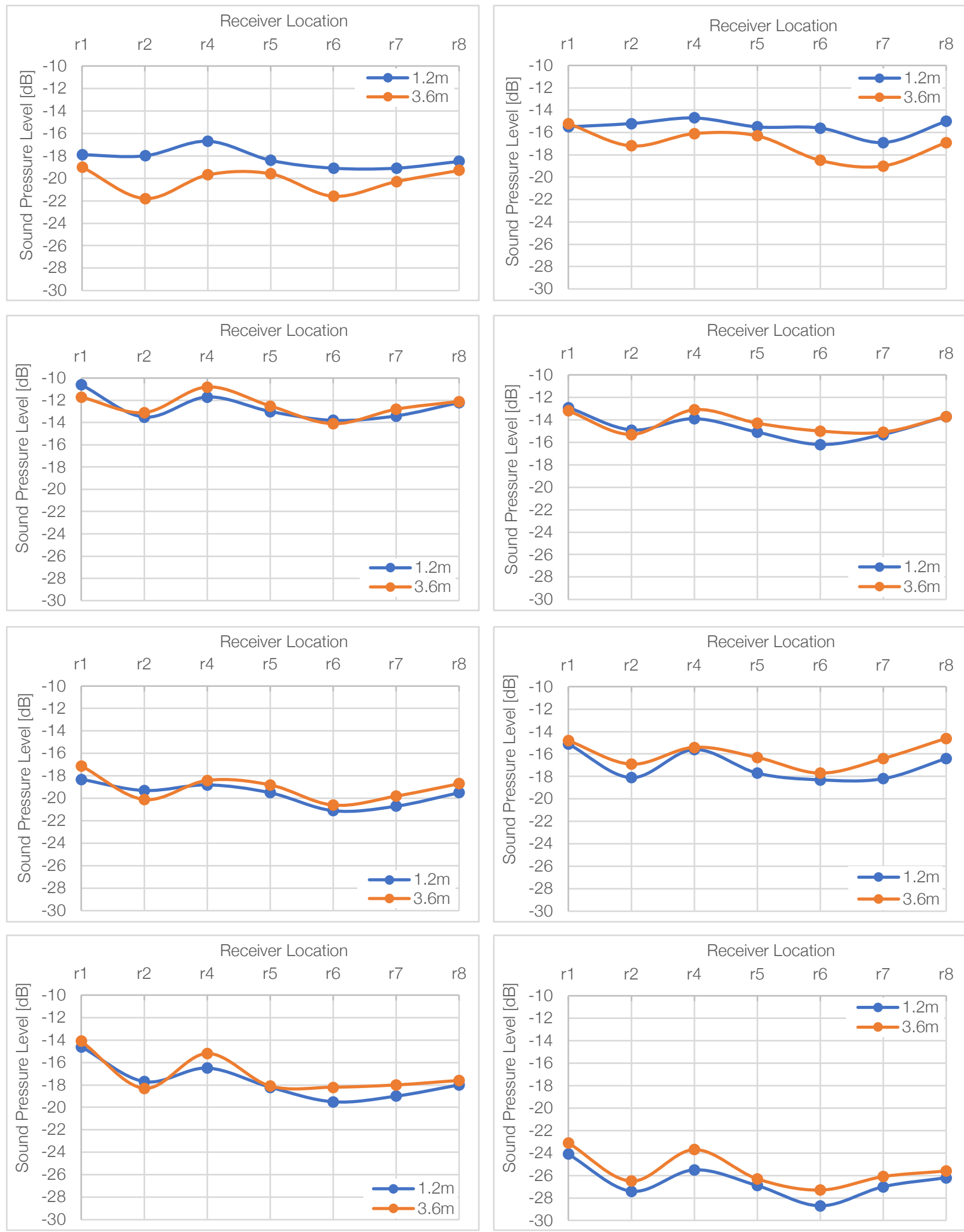

Figure 5.9: Gabrielle Roy SPL distribution for all S1 receiver points at (left to right) $63 \mathrm{~Hz}, 125 \mathrm{~Hz}, 250 \mathrm{~Hz}$, $500 \mathrm{~Hz}, 1000 \mathrm{~Hz}, 2000 \mathrm{~Hz}, 40000 \mathrm{~Hz}$, and $8000 \mathrm{~Hz}$ 


\section{Speech Transmission Index}

The average measured STI at $1.2 \mathrm{~m}$ was 0.54 and 0.53 at $3.6 \mathrm{~m}$, a $1 \%$ reduction. This measurement is above the required STI of 0.5 from the CAM.

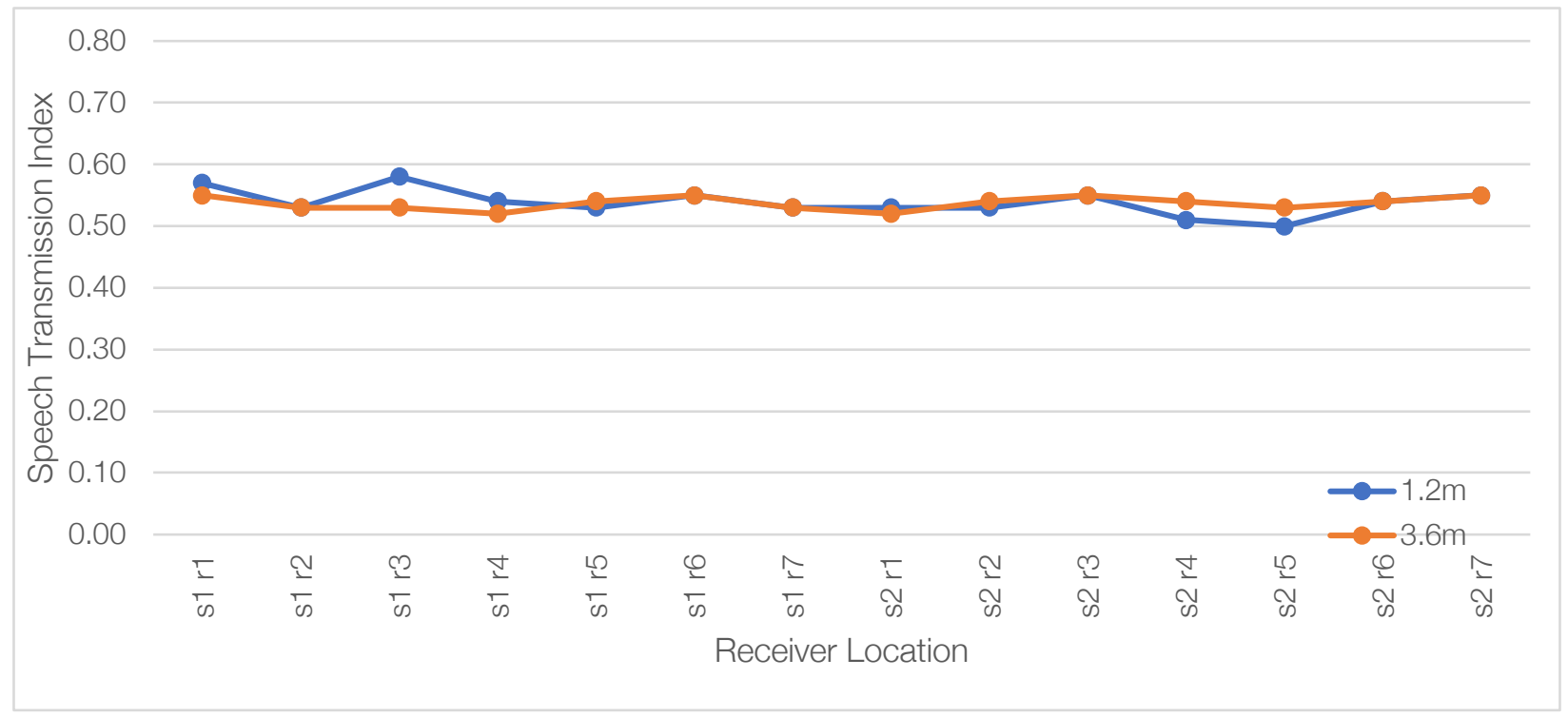

Figure 5.10: STI at 1.2m and 3.6m for Gabrielle Roy 


\subsubsection{Ryerson Athletics Centre Gym II}

There was a total of 22 unique source-receiver locations used to calculate T20, SPL, and STI. Insufficient data could be collected at the $63 \mathrm{~Hz}$ octave band to give a confident T20 value; as such it has been omitted from the analysis. The background noise of the room was measured and is presented in Table 5.7.

\begin{tabular}{|l|l|l|l|l|l|l|l|l|}
\hline & $63 \mathrm{~Hz}$ & $125 \mathrm{~Hz}$ & $250 \mathrm{~Hz}$ & $500 \mathrm{~Hz}$ & $1000 \mathrm{~Hz}$ & $2000 \mathrm{~Hz}$ & $4000 \mathrm{~Hz}$ & $8000 \mathrm{~Hz}$ \\
\hline \hline $\begin{array}{l}\text { Background } \\
\text { Noise [dB] }\end{array}$ & 15 & 19 & 28 & 30 & 28 & 26 & 25 & 24 \\
\hline
\end{tabular}

Table 5.7: Background Noise profile for RAC II

\section{$\underline{\text { Reverberation Time }}$}

Table 5.8 and Figure 5.11 indicate that from $125-500 \mathrm{~Hz}$, the RT for the $3.6 \mathrm{~m}$ data is $0.13 \mathrm{~s}$ shorter than that measured at $1.2 \mathrm{~m}$. At $1000 \mathrm{~Hz}$ and up, the two averages are within $2 \%$ of each other. At either height, the gymnasium does not satisfy the Alberta standard of having an $\mathrm{RT}$ below $2 \mathrm{~s}$, nor does it meet the CAM standard of an RT below $1.5 \mathrm{~s}$ at key mid-frequencies. As was noted in the gym description, the room has subjectively bad acoustics with a perceptible echo. The discrepancy at lower frequencies can be accounted for by the high variability of RTs measured, as shown in figure 5.12 and 5.13 . Because of the degree of experimental variation, no conclusions can be drawn about the difference in RTs below $500 \mathrm{~Hz}$.

\begin{tabular}{|c|c|c|c|c|c|c|c|c|}
\hline & $63 \mathrm{~Hz}$ & $125 \mathrm{~Hz}$ & $250 \mathrm{~Hz}$ & $500 \mathrm{~Hz}$ & $1000 \mathrm{~Hz}$ & $2000 \mathrm{~Hz}$ & $4000 \mathrm{~Hz}$ & $8000 \mathrm{~Hz}$ \\
\hline Measured T20 at $1.2 \mathrm{~m}$ & & 3.06 & 2.56 & 2.87 & 2.46 & 1.98 & 1.56 & 0.96 \\
\hline Measured T20 at 3.6m & & 2.93 & 2.42 & 2.74 & 2.52 & 1.99 & 1.55 & 0.95 \\
\hline \% Difference & & $-4 \%$ & $-5 \%$ & $-4 \%$ & $2 \%$ & $0 \%$ & $0 \%$ & $-1 \%$ \\
\hline
\end{tabular}

Table 5.8: Mean measured T20 data for RAC II at 1.2m and 3.6m 


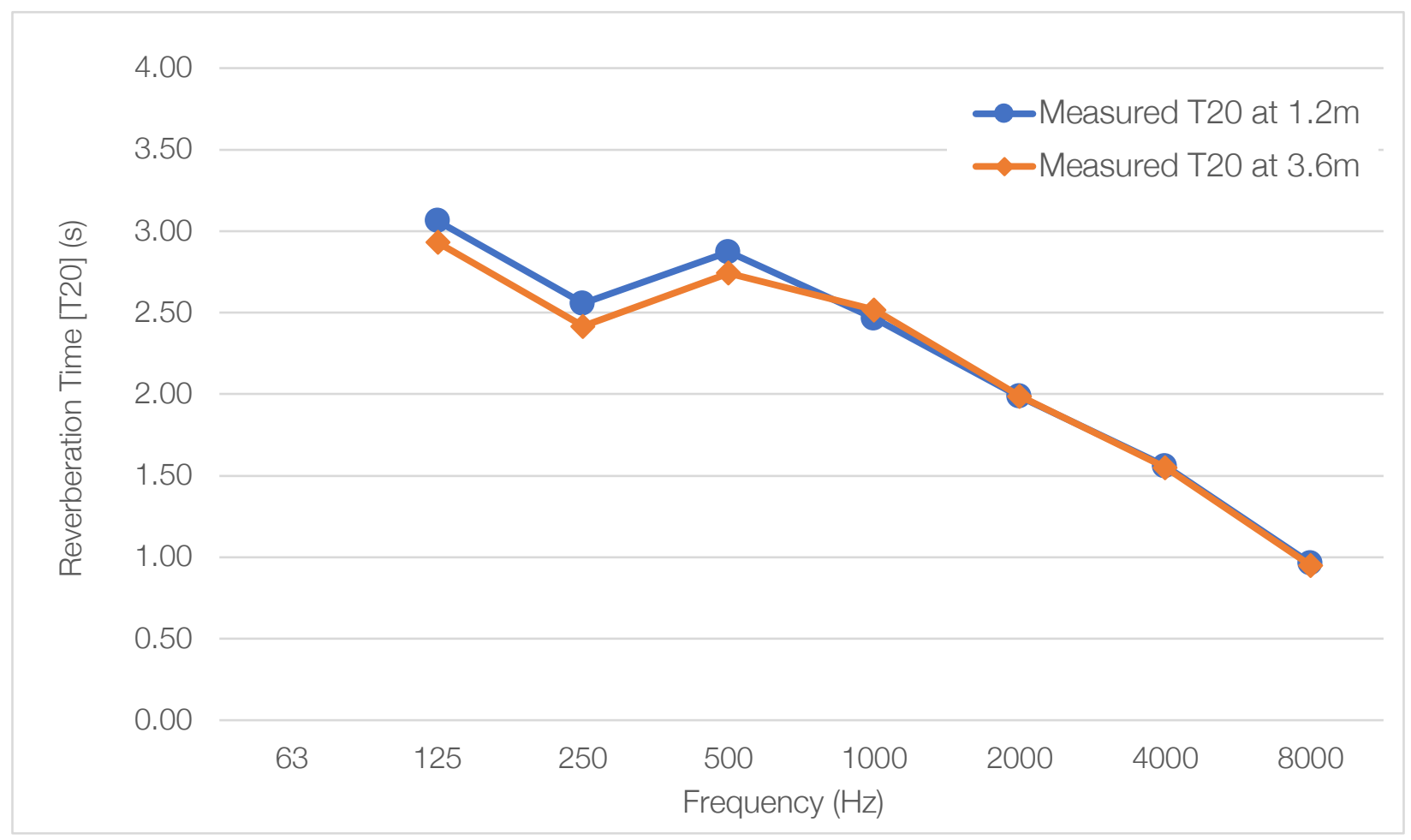

Figure 5.11: RAC II Measured T20 at 1.2m and 3.6m

\begin{tabular}{|r|r|r|r|r|r|r|r|r|}
\hline & \multicolumn{1}{|c}{$63 \mathrm{~Hz}$} & $125 \mathrm{~Hz}$ & \multicolumn{1}{l}{$250 \mathrm{~Hz}$} & \multicolumn{1}{l}{$500 \mathrm{~Hz}$} & $1000 \mathrm{~Hz}$ & $2000 \mathrm{~Hz}$ & $4000 \mathrm{~Hz}$ & $8000 \mathrm{~Hz}$ \\
\hline \hline Stdev $1.2 \mathrm{~m}$ & & 0.40 & 0.28 & 0.23 & 0.08 & 0.06 & 0.05 & 0.04 \\
\hline Stdev 3.6m & & 0.27 & 0.16 & 0.15 & 0.07 & 0.05 & 0.05 & 0.03 \\
\hline
\end{tabular}

Table 5.9: Standard deviation of T20 data from RAC /l at $1.2 \mathrm{~m}$ and $3.6 \mathrm{~m}$

Figures 5.12 and 5.13 are plots of the T20 data at each individual receiver point. The graphs show that the equipment was incapable of collecting $\mathrm{RT}$ at $63 \mathrm{~Hz}$ and was highly variable at $125 \mathrm{~Hz}$ and $250 \mathrm{~Hz}$. As such, it should be regarded as less reliable. Table 5.9 shows that the standard deviation of the data generally went down as the frequency increased. 


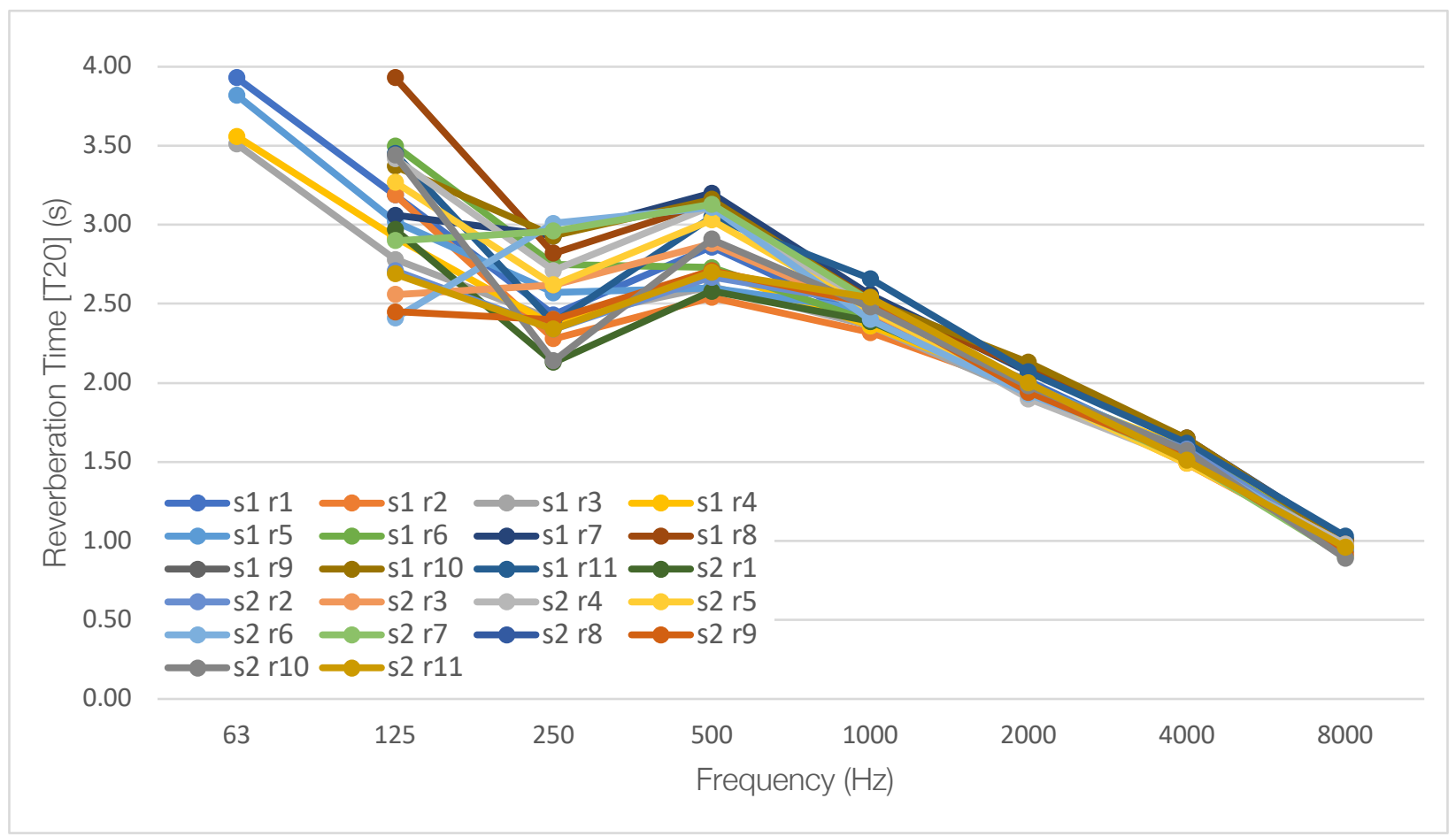

Figure 5.12: T20 data for all $1.2 m$ receiver points for $R A C$ II

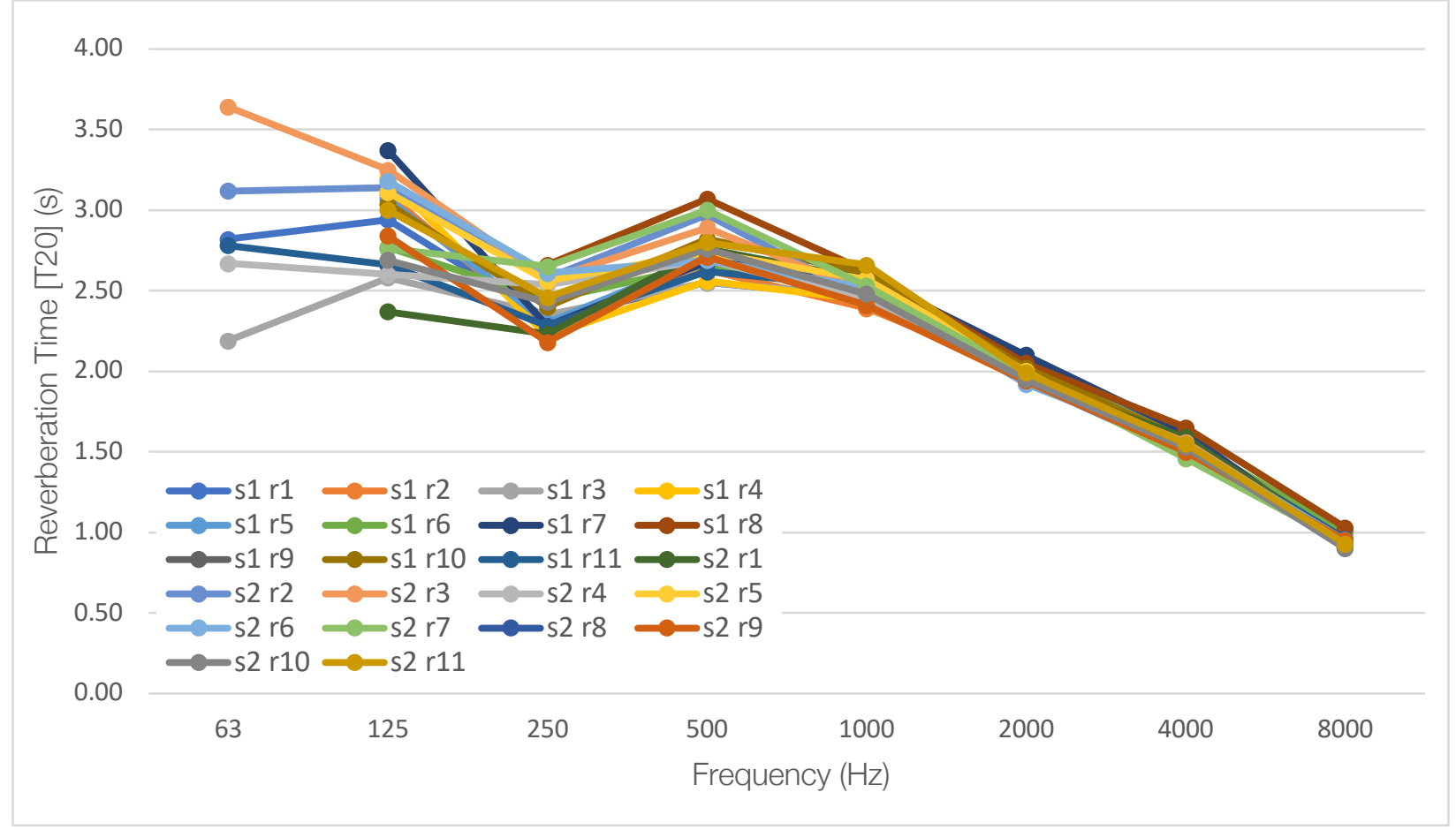

Figure 5.13: T20 data for all 3.6m receiver points for RAC II 


\section{Sound Pressure Level}

Figure 5.14 shows the relative SPL distribution in the RAC II gymnasium. There is significant difference between the SPL at the two receiver heights, reaching a $5 \mathrm{~dB}$ difference at $2000 \mathrm{~Hz}$. At $1000 \mathrm{~Hz}$ and above, the $3.6 \mathrm{~m}$ data exceeds the $1.2 \mathrm{~m}$ data at some receiver points. Within the respective receiver heights, SPL varies up to $6 \mathrm{~dB}$. Across different frequencies, the plots do not retain a similar shape from $63 \mathrm{~Hz}$ to $500 \mathrm{hz}$, after which the plots become more similar as the frequency increases. This is likely due to interference. 

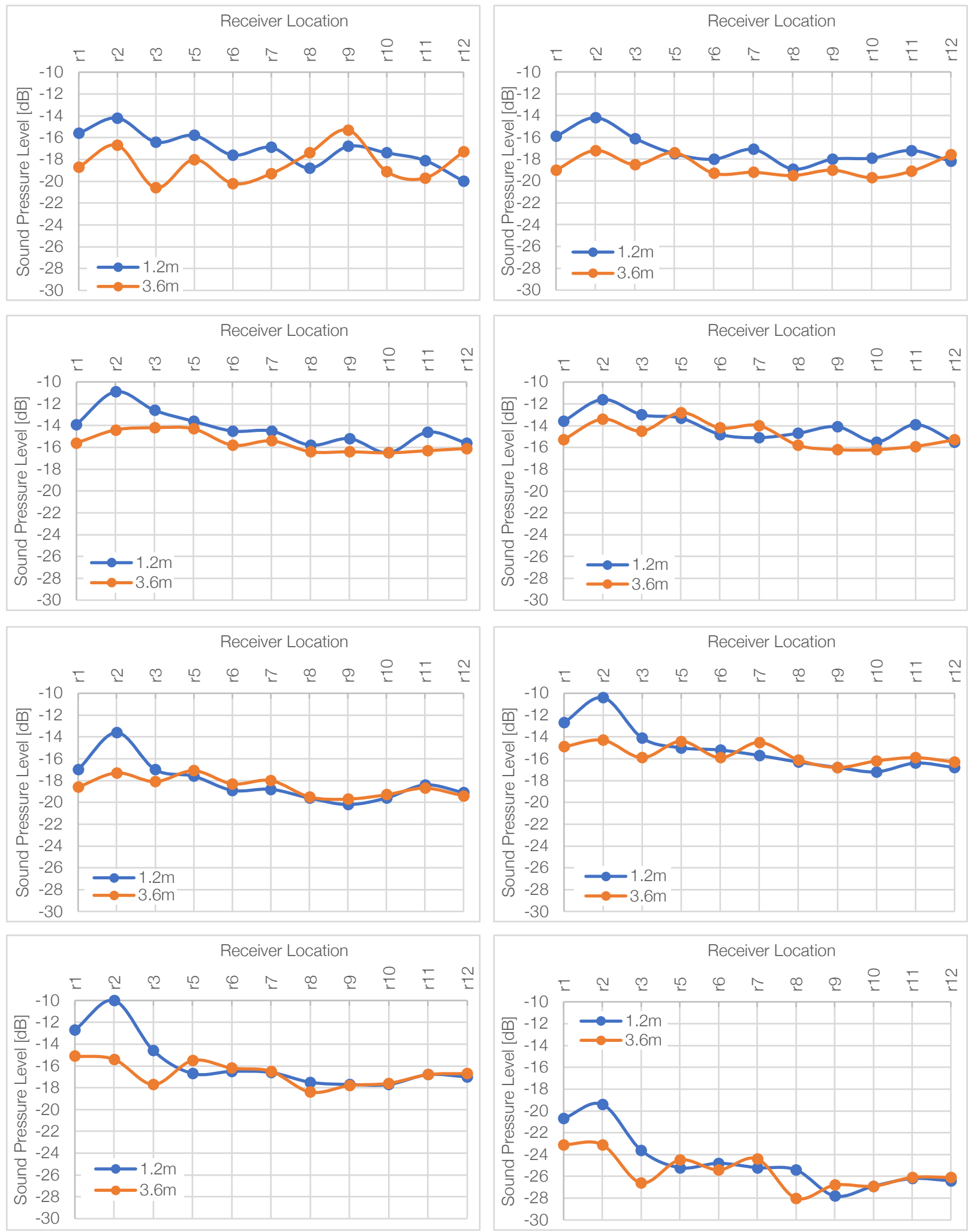

Figure 5.14: RAC II SPL distribution for all S1 receiver points at (left to right) $63 \mathrm{~Hz}, 125 \mathrm{~Hz}, 250 \mathrm{~Hz}, 500 \mathrm{~Hz}$, $1000 \mathrm{~Hz}, 2000 \mathrm{~Hz}, 40000 \mathrm{~Hz}$, and $8000 \mathrm{~Hz}$ 


\section{Speech Transmission Index}

At both heights, the measured STI was 0.48 with the STI at $3.6 \mathrm{~m}$ being $0.8 \%$ higher. This measurement is below the required STI of 0.5 from the CAM while still being considered "fair".

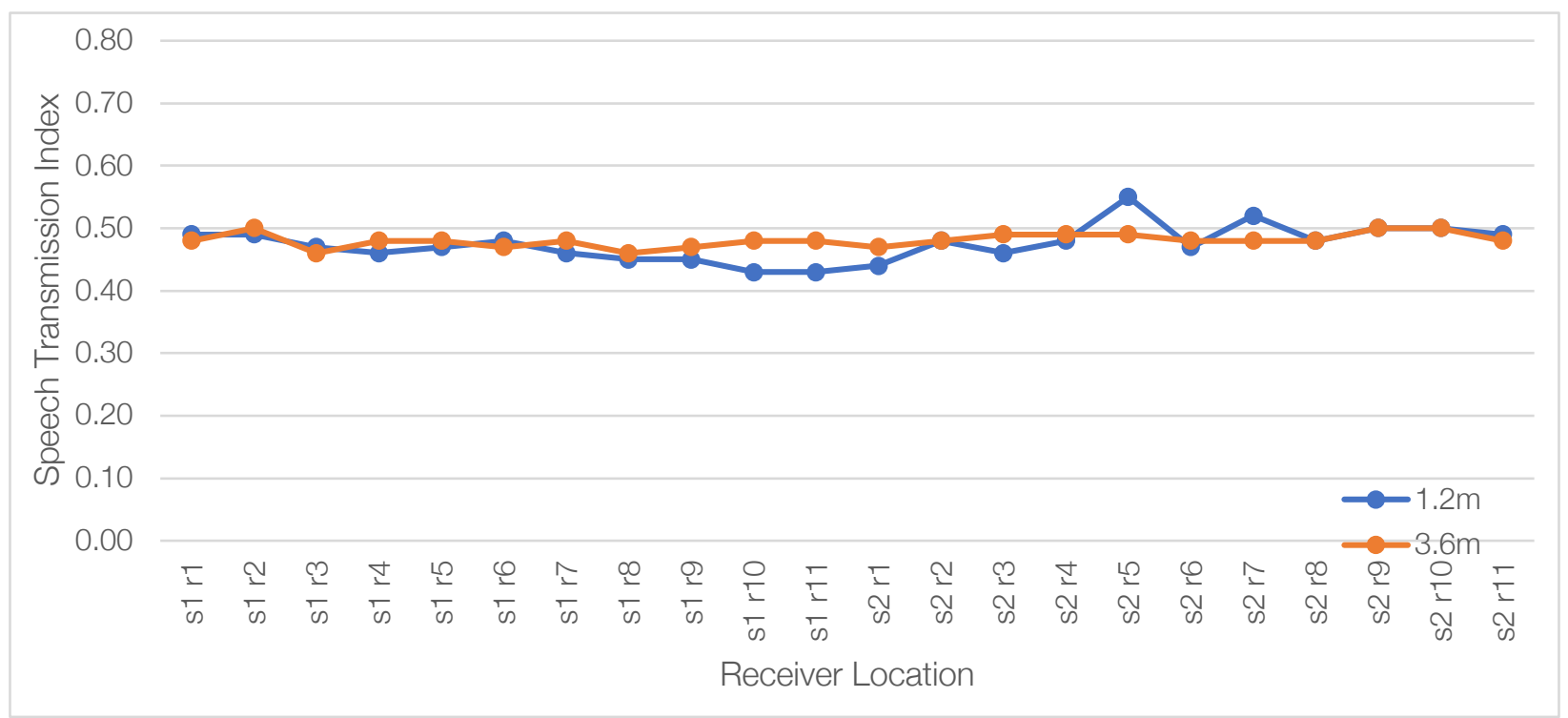

Figure 5.15: STI at 1.2m and 3.6m for RAC II 


\subsubsection{Ryerson's Tecumseh Auditorium}

There was a total of 14 unique source-receiver locations used to calculate T20, SPL, and STI. Insufficient data could be collected at the $63 \mathrm{~Hz}$ octave band to give a confident T20 value; as such it has been omitted from the analysis. The background noise of the room was measured and is presented in Table 5.10.

\begin{tabular}{|l|l|l|l|l|l|l|l|l|}
\hline & $63 \mathrm{~Hz}$ & $125 \mathrm{~Hz}$ & $250 \mathrm{~Hz}$ & $500 \mathrm{~Hz}$ & $1000 \mathrm{~Hz}$ & $2000 \mathrm{~Hz}$ & $4000 \mathrm{~Hz}$ & $8000 \mathrm{~Hz}$ \\
\hline \hline $\begin{array}{l}\text { Background } \\
\text { Noise [dB] }\end{array}$ & 20 & 23 & 26 & 27 & 26 & 26 & 25 & 25 \\
\hline
\end{tabular}

Table 5.10: Background Noise profile of Tecumseh Auditorium

\section{$\underline{\text { Reverberation Time }}$}

Table 5.11 and Figure 5.16 indicate that there is a small difference in the average T20 measured at the $1.2 \mathrm{~m}$ and $3.6 \mathrm{~m}$ receiver heights; the RT at $3.6 \mathrm{~m}$ is consistently lower than that at $1.2 \mathrm{~m}$ at all frequencies measured. Below $1000 \mathrm{~Hz}$, the $3.6 \mathrm{~m}$ data is an average of 0.06 seconds shorter than the $1.2 \mathrm{~m}$ data. At $1000 \mathrm{~Hz}$ and above, the $3.6 \mathrm{~m} \mathrm{RT}$ data is an average of $0.03 \mathrm{~s}$ shorter. At either height, the gymnasium does not satisfy the Alberta standard of having an RT below 2s, nor does it meet the CAM standard of an RT below 1.5s at key midfrequencies. As was noted in the gym description, the room has subjectively bad acoustics with a perceptible echo.

\begin{tabular}{|r|rrrrrrr|r|r|}
\hline & \multicolumn{1}{|c}{$63 \mathrm{~Hz}$} & $125 \mathrm{~Hz}$ & \multicolumn{2}{l}{$250 \mathrm{~Hz}$} & \multicolumn{1}{l}{$500 \mathrm{~Hz}$} & $1000 \mathrm{~Hz}$ & $2000 \mathrm{~Hz}$ & $4000 \mathrm{~Hz}$ & $8000 \mathrm{~Hz}$ \\
\hline \hline Measured T20 at $1.2 \mathrm{~m}$ & & 2.63 & 2.18 & 1.99 & 1.92 & 1.58 & 1.27 & 0.77 \\
\hline Measured T20 at 3.6m & & 2.59 & 2.10 & 1.94 & 1.89 & 1.56 & 1.22 & 0.73 \\
\hline \% Difference & & $-1 \%$ & $-3 \%$ & $-3 \%$ & $-2 \%$ & $-1 \%$ & $-4 \%$ & $-5 \%$ \\
\hline
\end{tabular}

Table 5.11: Mean measured T20 for Tecumseh Auditorium at 1.2m and 3.6m 


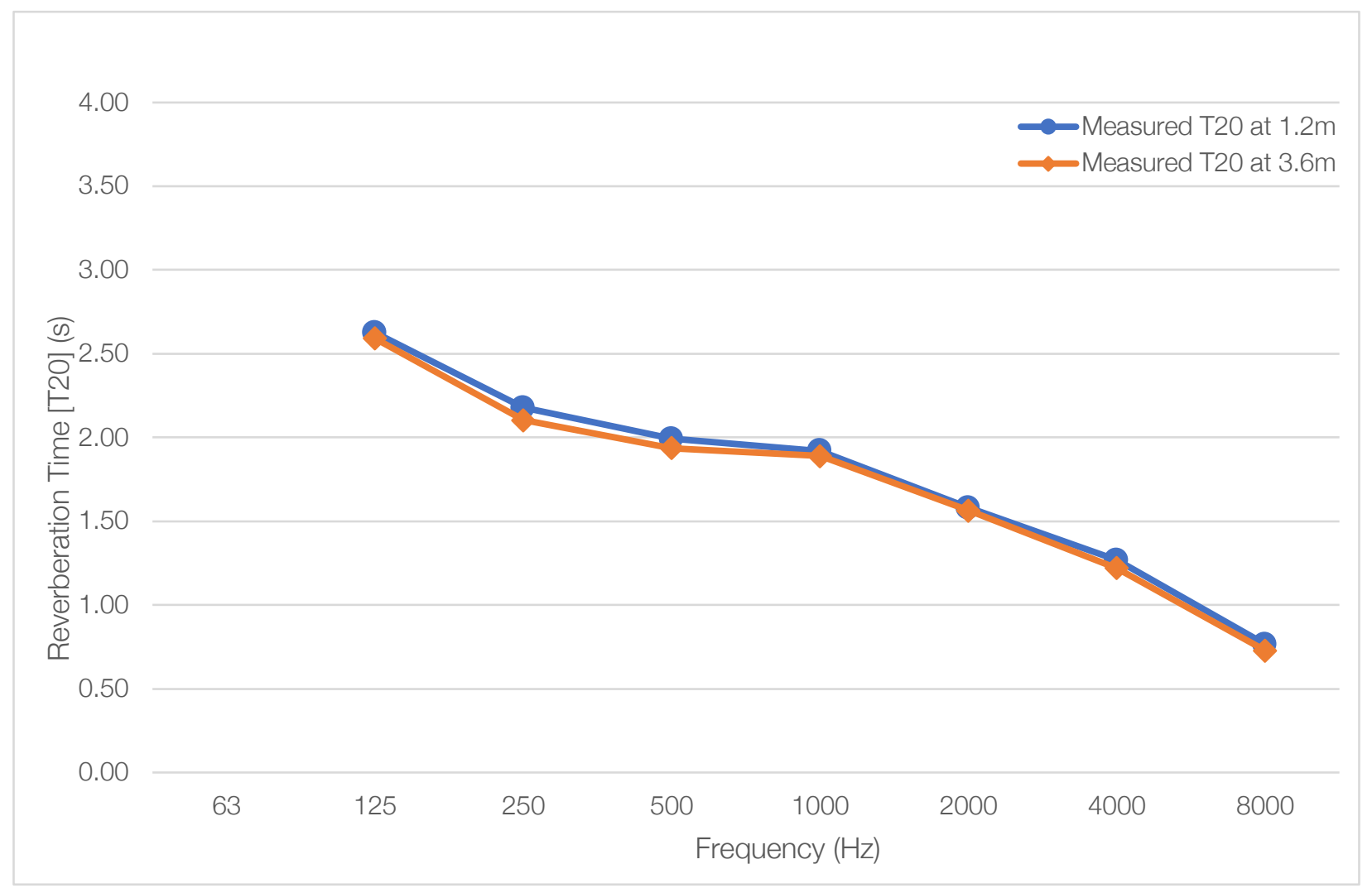

Figure 5.16: Tecumseh Measured T20 at 1.2m and 3.6m

\begin{tabular}{|c|c|c|c|c|c|c|c|c|}
\hline & $63 \mathrm{~Hz}$ & $125 \mathrm{~Hz}$ & $250 \mathrm{~Hz}$ & $500 \mathrm{~Hz}$ & $1000 \mathrm{~Hz}$ & $2000 \mathrm{~Hz}$ & $4000 \mathrm{~Hz}$ & $8000 \mathrm{~Hz}$ \\
\hline Stdev $1.2 \mathrm{~m}$ & & 0.28 & 0.09 & 0.07 & 0.05 & 0.03 & 0.03 & 0.03 \\
\hline Stdev 3.6m & & 0.29 & 0.09 & 0.06 & 0.05 & 0.03 & 0.03 & 0.03 \\
\hline
\end{tabular}

Table 5.12: Standard deviation for T20 data for Tecumseh Auditorium at 1.2m and $3.6 \mathrm{~m}$

Figures 5.17 and 5.18 are plots of the T20 data at each individual receiver point. The graphs show that the equipment was incapable of collecting $\mathrm{RT}$ at $63 \mathrm{~Hz}$ and was highly variable at $125 \mathrm{~Hz}$ and $250 \mathrm{~Hz}$. As such, it should be regarded as less reliable. Table 5.12 shows that the standard deviation of the data generally went down as the frequency increased. 


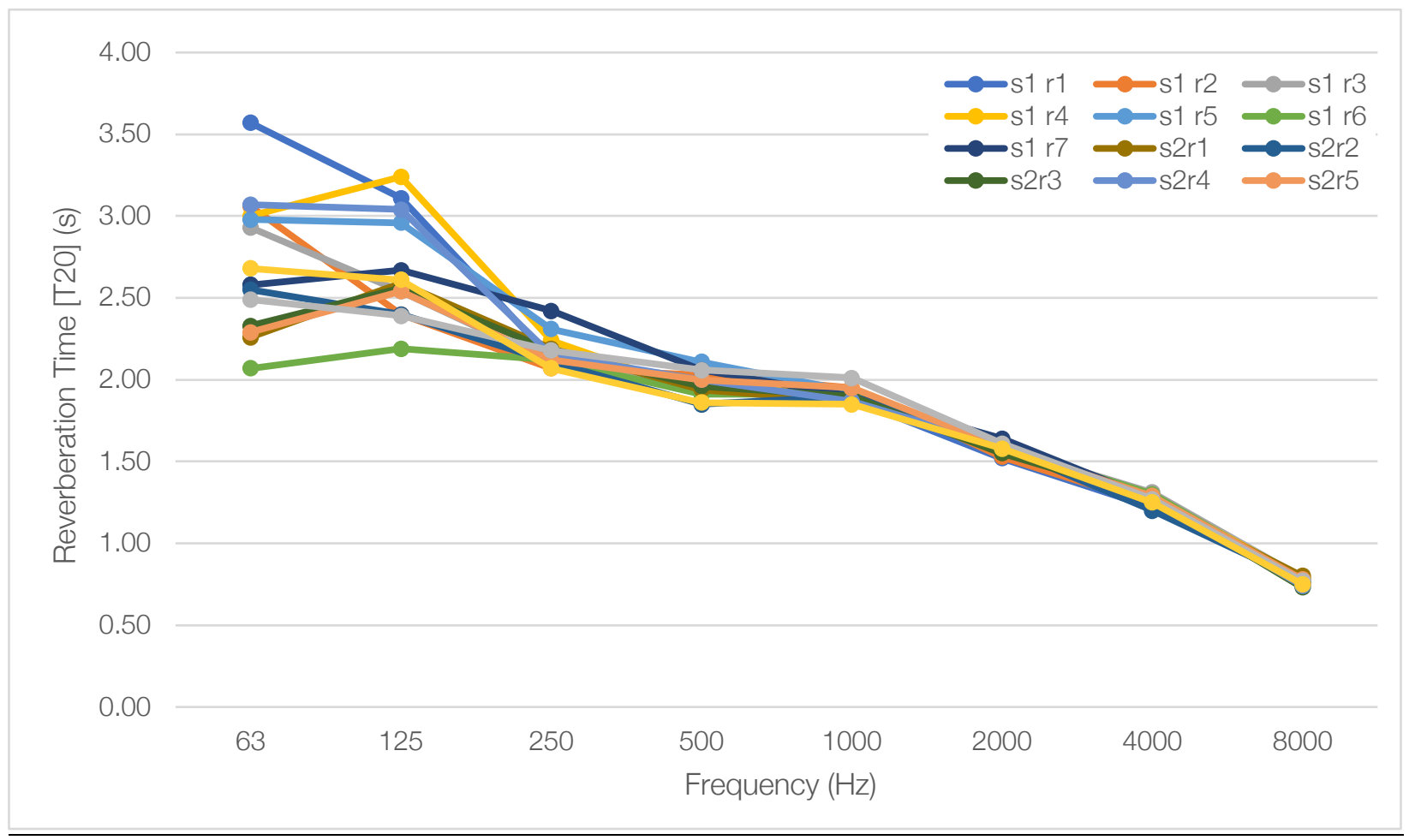

Figure 5.17: All 1.2m receiver points T20 data for Tecumseh Auditorium

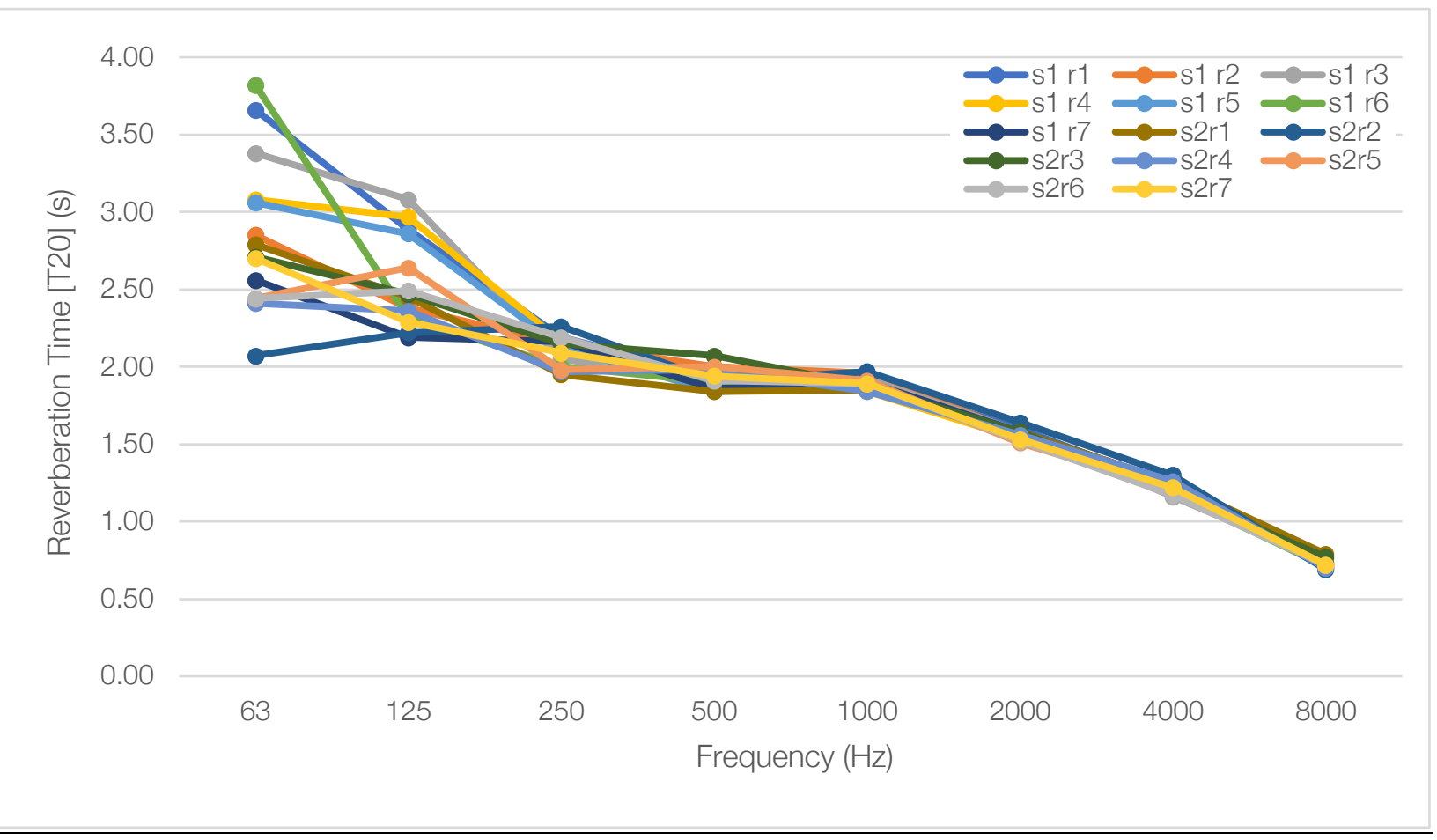

Figure 5.18: All 3.6m receiver points T20 data for Tecumseh Auditorium 


\section{Sound Pressure Level}

Figure 5.19 shows the relative SPL distribution in the Tecumseh Auditorium. There is a difference between the SPL at the two receiver heights, reaching a maximum $4 \mathrm{~dB}$ difference at $63 \mathrm{~Hz}$. At $1000 \mathrm{~Hz}$ and above, the $3.6 \mathrm{~m}$ data exceeds the $1.2 \mathrm{~m}$ data at some receiver points. Within the respective receiver heights, SPL varies up to $4 \mathrm{~dB}$. Across different frequencies, the plots do not retain a similar shape from $63 \mathrm{~Hz}$ to $125 \mathrm{hz}$, after which the plots become more similar as the frequency increases. This is likely due to interference. 

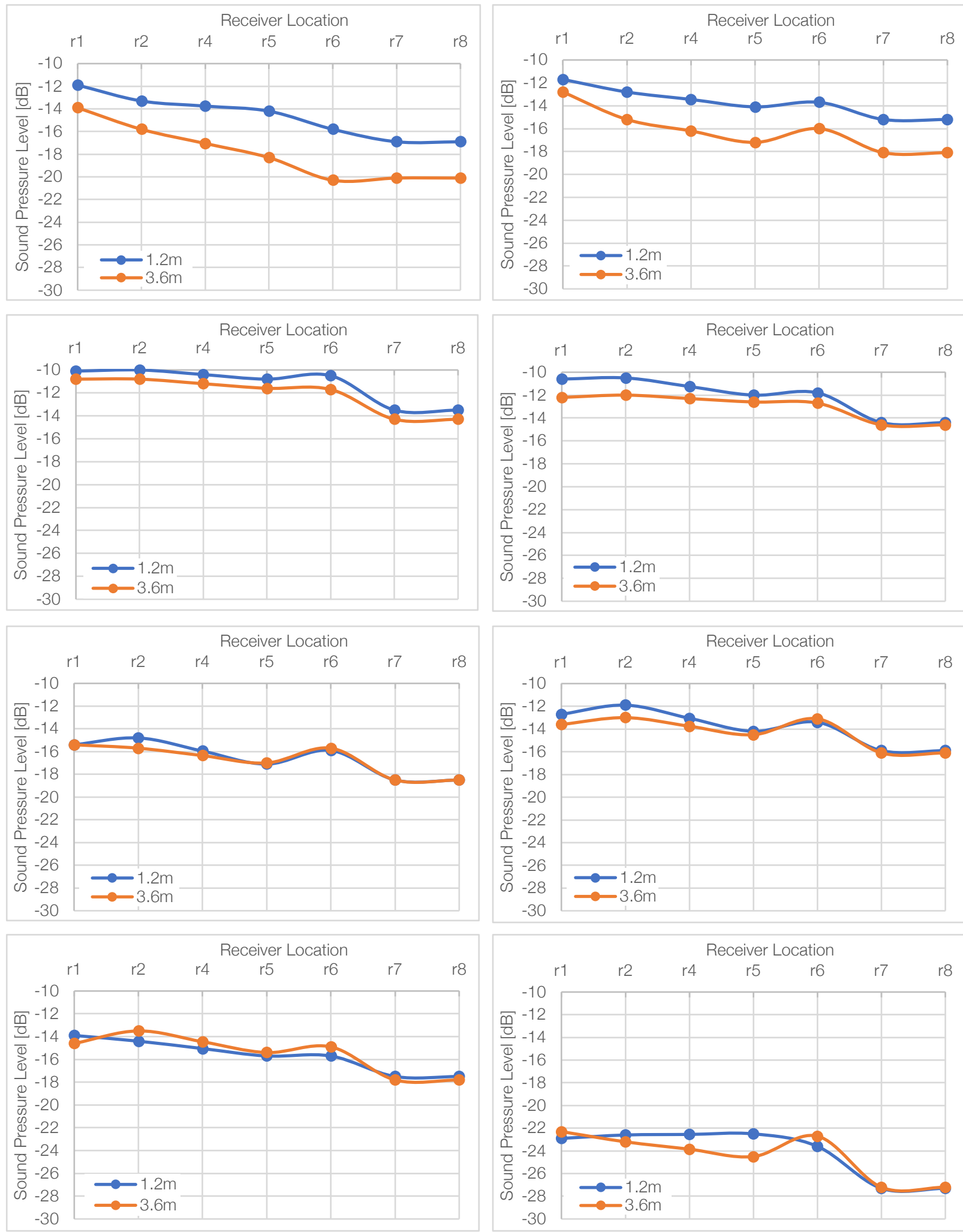

Figure 5.19: Tecumseh SPL distribution for all S1 receiver points at (left to right) $63 \mathrm{~Hz}, 125 \mathrm{~Hz}, 250 \mathrm{~Hz}$, $500 \mathrm{~Hz}, 1000 \mathrm{~Hz}, 2000 \mathrm{~Hz}, 40000 \mathrm{~Hz}$, and $8000 \mathrm{~Hz}$ 


\section{Speech Transmission Index}

The average measured STI at $1.2 \mathrm{~m}$ was 0.49 and 0.50 at $3.6 \mathrm{~m}$, a $3 \%$ reduction. This measurement is below the required STI of 0.5 from the CAM at the $1.2 \mathrm{~m}$ height ISO 3382 specifies.

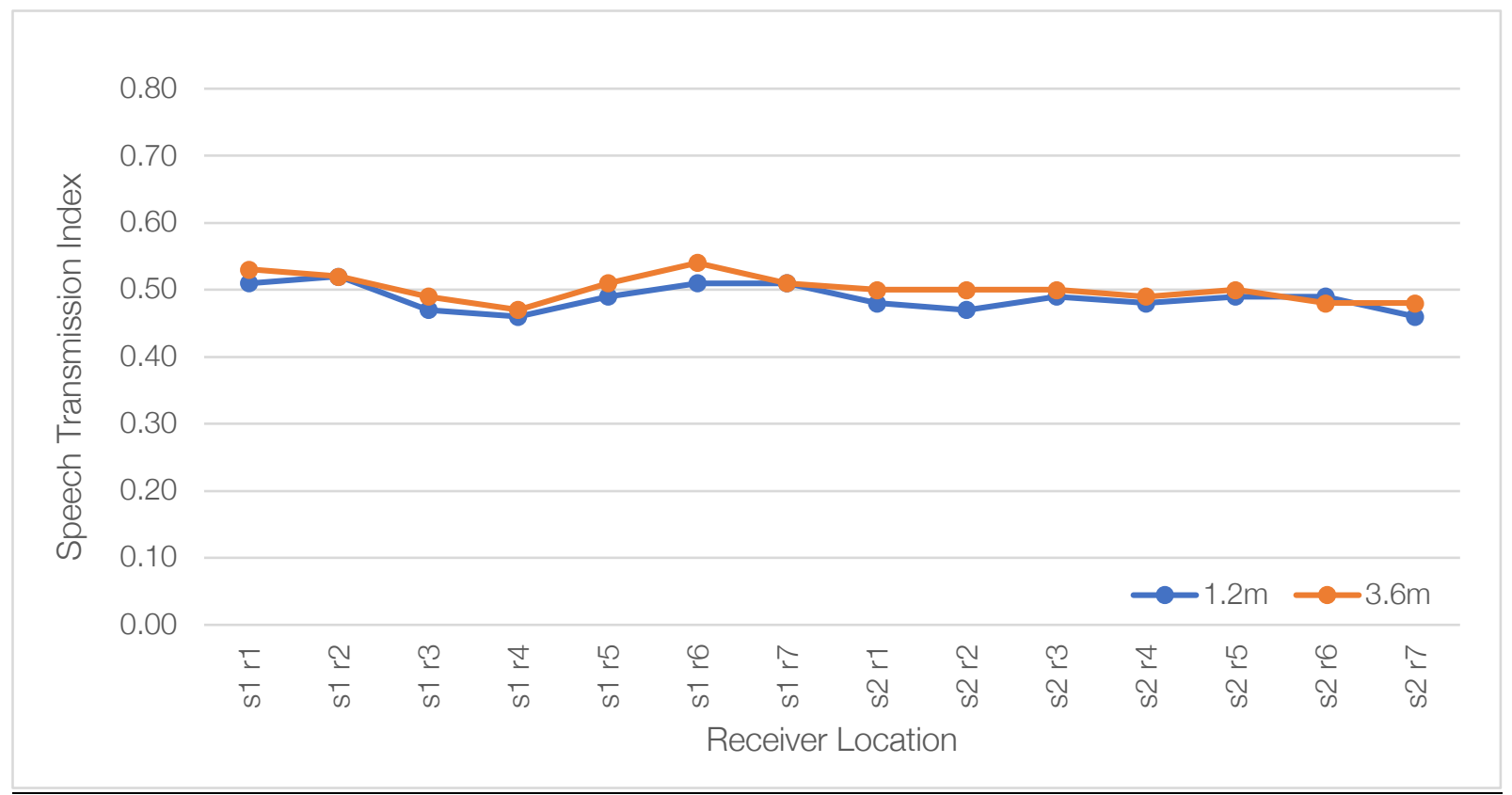

Figure 5.20: STI at 1.2m and 3.6m for Tecumseh 


\subsection{Simulation Results}

Digital 3D models of the spaces were imported into the simulation software from Sketchup. The same source-receiver arrangements used in the field tests were set up in the simulations with the addition of a receiver array at $6 \mathrm{~m}$. A single point's T20 data was used to calibrate the simulations. Surface properties were assigned from the software's material library, apart from steel doors [33] and HVAC [34] which were assigned values from textbooks or research papers. To reach closer agreement between the modeled and the measured data, surface properties were modified using values from textbooks [33] or from published material tests [13]. All the models' simulated RT were within the $15 \%$ range necessary for engineering accuracy, in accordance with ISO 3382.

Simulations are subject to limitations which were taken into consideration when drawing conclusions. The simulation does not allow for frequency-specific diffusion coefficients; a single value is input at $750 \mathrm{~Hz}$ and extrapolated for other frequencies. ODEON is also a hybrid image-source and ray-tracing software which means it doesn't account for the wave properties of sound. This is primarily an issue at low frequencies where diffraction and interference are significant. 


\subsubsection{Royal Saint Georges College}

Table 5.13 summarizes the adjusted absorption coefficients of all the surfaces present in the digital model of RSGC. The room has open web steel joists which are not included in the model but could diffuse sound at higher frequencies.

\begin{tabular}{l|llllllll}
\hline & $63 \mathrm{~Hz}$ & $125 \mathrm{~Hz}$ & $250 \mathrm{~Hz}$ & $500 \mathrm{~Hz}$ & $1000 \mathrm{~Hz}$ & $2000 \mathrm{~Hz}$ & $4000 \mathrm{~Hz}$ & $8000 \mathrm{~Hz}$ \\
\hline \hline Wood Floor & 0.15 & 0.15 & 0.11 & 0.10 & 0.07 & 0.06 & 0.70 & 0.70 \\
Painted Concrete Block & 0.10 & 0.10 & 0.05 & 0.06 & 0.07 & 0.09 & 0.08 & 0.10 \\
Steel Door [33] & 0.05 & 0.05 & 0.05 & 0.05 & 0.06 & 0.04 & 0.02 & 0.02 \\
Steel Deck Ceiling & 0.30 & 0.30 & 0.25 & 0.20 & 0.10 & 0.10 & 0.15 & 0.15 \\
Absorber Type 1 & 0.08 & 0.15 & 0.90 & 0.94 & 0.99 & 0.99 & 0.60 & 0.15 \\
Absorber Type 2 & 0.08 & 0.08 & 0.40 & 0.50 & 0.40 & 0.40 & 0.20 & 0.08 \\
Absorber Type 3 & 0.15 & 0.15 & 0.56 & 0.88 & 0.99 & 0.99 & 0.95 & 0.30 \\
HVAC [35] & 0.04 & 0.07 & 0.06 & 0.05 & 0.04 & 0.05 & 0.04 & 0.04 \\
Rubber Mat & 0.04 & 0.04 & 0.04 & 0.08 & 0.12 & 0.10 & 0.10 & 0.10 \\
\hline
\end{tabular}

Table 5.13: Calibrated Material Absorption Coefficients for Royal St Georges College

Source 1 receiver 8 was used for model calibration; the pre and post calibration RTs are shown in Table 5.14.

\begin{tabular}{|c|c|c|c|c|c|c|c|c|}
\hline & $63 \mathrm{~Hz}$ & $125 \mathrm{~Hz}$ & $250 \mathrm{~Hz}$ & $500 \mathrm{~Hz}$ & $1000 \mathrm{~Hz}$ & $2000 \mathrm{~Hz}$ & $4000 \mathrm{~Hz}$ & $8000 \mathrm{~Hz}$ \\
\hline S1 R8 measured & & 2.43 & 1.28 & 1.15 & 1.50 & 1.51 & 1.43 & 1.13 \\
\hline S1 R8 simulation & & 2.80 & 1.67 & 1.58 & 1.82 & 1.76 & 1.52 & 1.09 \\
\hline S1 R8 calibrated simulation & & 2.13 & 1.33 & 1.29 & 1.54 & 1.49 & 1.39 & 1.06 \\
\hline
\end{tabular}

Table 5.14: Calibration point T20 data for RSGC

\section{Reverberation Time}

\begin{tabular}{|c|c|c|c|c|c|c|c|c|}
\hline & $63 \mathrm{~Hz}$ & $125 \mathrm{~Hz}$ & $250 \mathrm{~Hz}$ & $500 \mathrm{~Hz}$ & $1000 \mathrm{~Hz}$ & $2000 \mathrm{~Hz}$ & $4000 \mathrm{~Hz}$ & $8000 \mathrm{~Hz}$ \\
\hline Measured T20 at $1.2 \mathrm{~m}$ & & 2.20 & 1.25 & 1.16 & 1.51 & 1.56 & 1.47 & 1.13 \\
\hline Modelled T20 at $1.2 \mathrm{~m}$ & 2.25 & 2.15 & 1.35 & 1.32 & 1.62 & 1.58 & 1.43 & 1.06 \\
\hline \% Difference & & $-2 \%$ & $8 \%$ & $14 \%$ & $7 \%$ & $1 \%$ & $-2 \%$ & $-7 \%$ \\
\hline Measured T20 at 3.6m & & 2.22 & 1.23 & 1.20 & 1.57 & 1.52 & 1.40 & 1.04 \\
\hline Modelled T20 at 3.6m & 2.27 & 2.17 & 1.35 & 1.33 & 1.62 & 1.58 & 1.44 & 1.06 \\
\hline \% Difference & & $-2 \%$ & $10 \%$ & $11 \%$ & $3 \%$ & $4 \%$ & $3 \%$ & $2 \%$ \\
\hline Modelled T20 at $6.0 \mathrm{~m}$ & 2.26 & 2.17 & 1.36 & 1.33 & 1.62 & 1.58 & 1.44 & 1.05 \\
\hline
\end{tabular}

Table 5.15: Comparison of measured and modelled T20 data from RSGC

Unlike the measured data, the T20 outputs from the simulation were all within $1 \%$ of each

other at all heights. The simulated data does not reflect the change in RT at an increased height; it predicts a more uniform sound field than was measured. 


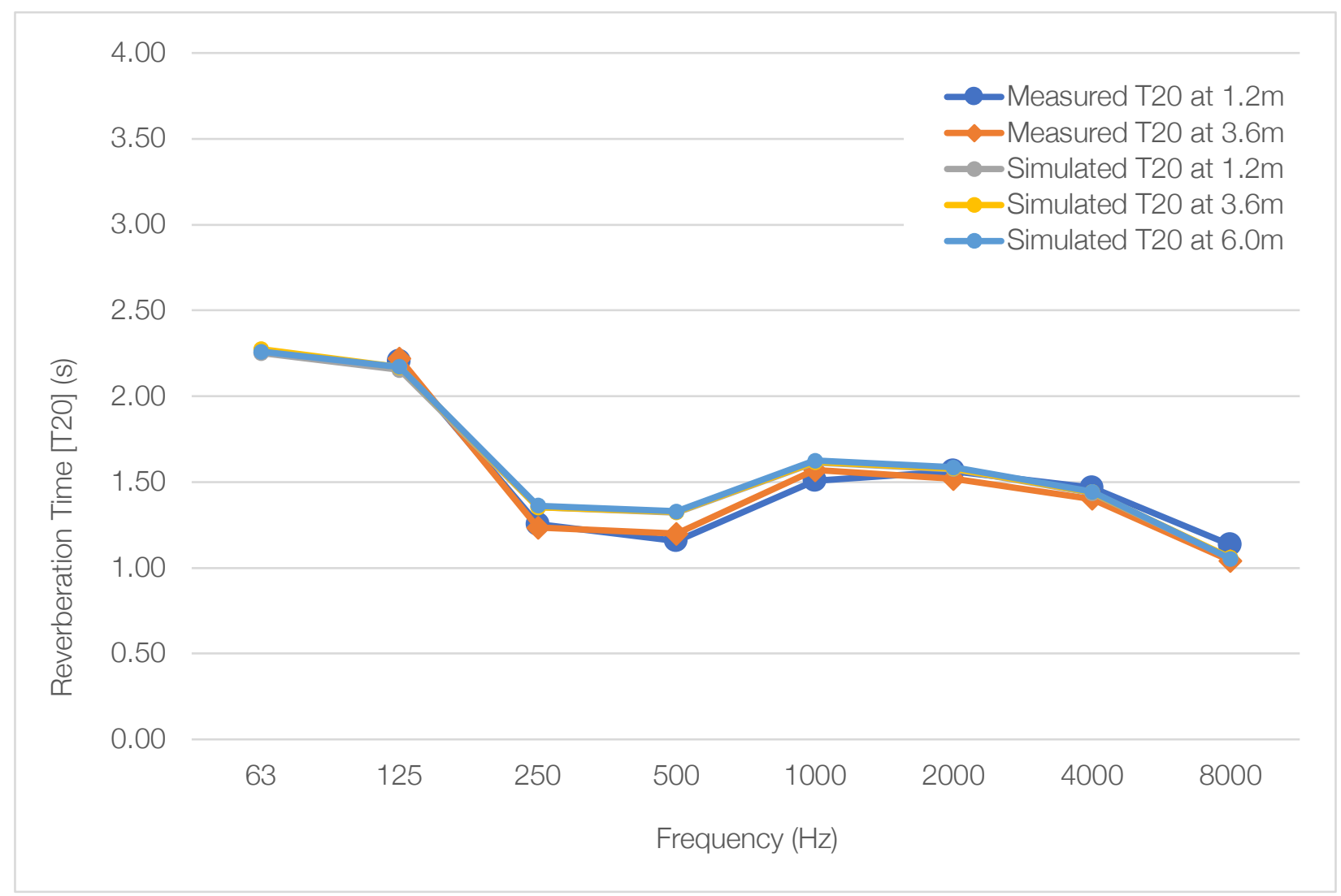

Figure 5.21: RSGC T20 Measured vs Simulated

\begin{tabular}{|c|c|c|c|c|c|c|c|c|}
\hline & $63 \mathrm{~Hz}$ & $125 \mathrm{~Hz}$ & $250 \mathrm{~Hz}$ & $500 \mathrm{~Hz}$ & $1000 \mathrm{~Hz}$ & $2000 \mathrm{~Hz}$ & $4000 \mathrm{~Hz}$ & $8000 \mathrm{~Hz}$ \\
\hline Stdev $1.2 \mathrm{~m}$ & & 0.22 & 0.08 & 0.06 & 0.06 & 0.09 & 0.08 & 0.06 \\
\hline Stdev 3.6m & & 0.18 & 0.10 & 0.06 & 0.06 & 0.04 & 0.03 & 0.03 \\
\hline Modelled Stdev 1.2m & & 0.07 & 0.07 & 0.08 & 0.13 & 0.12 & 0.05 & 0.03 \\
\hline Modelled Stdev 3.6m & & 0.04 & 0.05 & 0.06 & 0.09 & 0.08 & 0.04 & 0.02 \\
\hline Modelled Stdev 6.0m & & 0.05 & 0.08 & 0.09 & 0.13 & 0.12 & 0.06 & 0.02 \\
\hline
\end{tabular}

Table 5.16: Standard deviation of all T20 data at RSGC

Figures 5.22, 5.23, and 5.24 are plots of the T20 data at each simulated receiver point. The graphs show that, unlike in the measured data, the greatest variability in $\mathrm{RT}$ comes at $500 \mathrm{~Hz}$ to $2000 \mathrm{~Hz}$. This could be because the digital model cannot account for all the small scattering elements found in the physical room and therefore simulates a less diffuse environment. RSGC was also quite large and would inherently have larger variability in RT at different receiver points if a less diffuse sound field was predicted. 


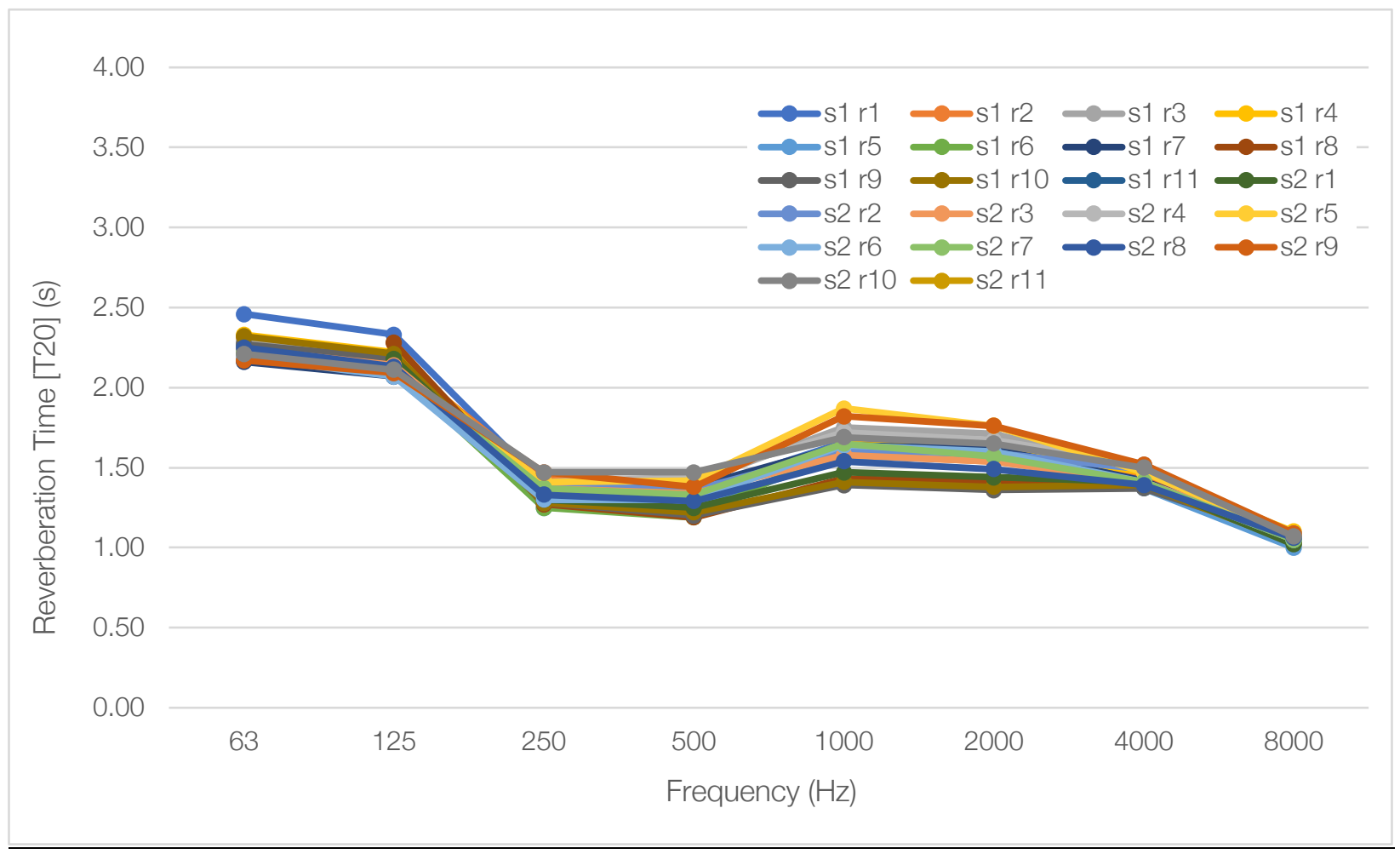

Figure 5.22: All simulated $1.2 m$ receiver points T20 data for $R S G C$

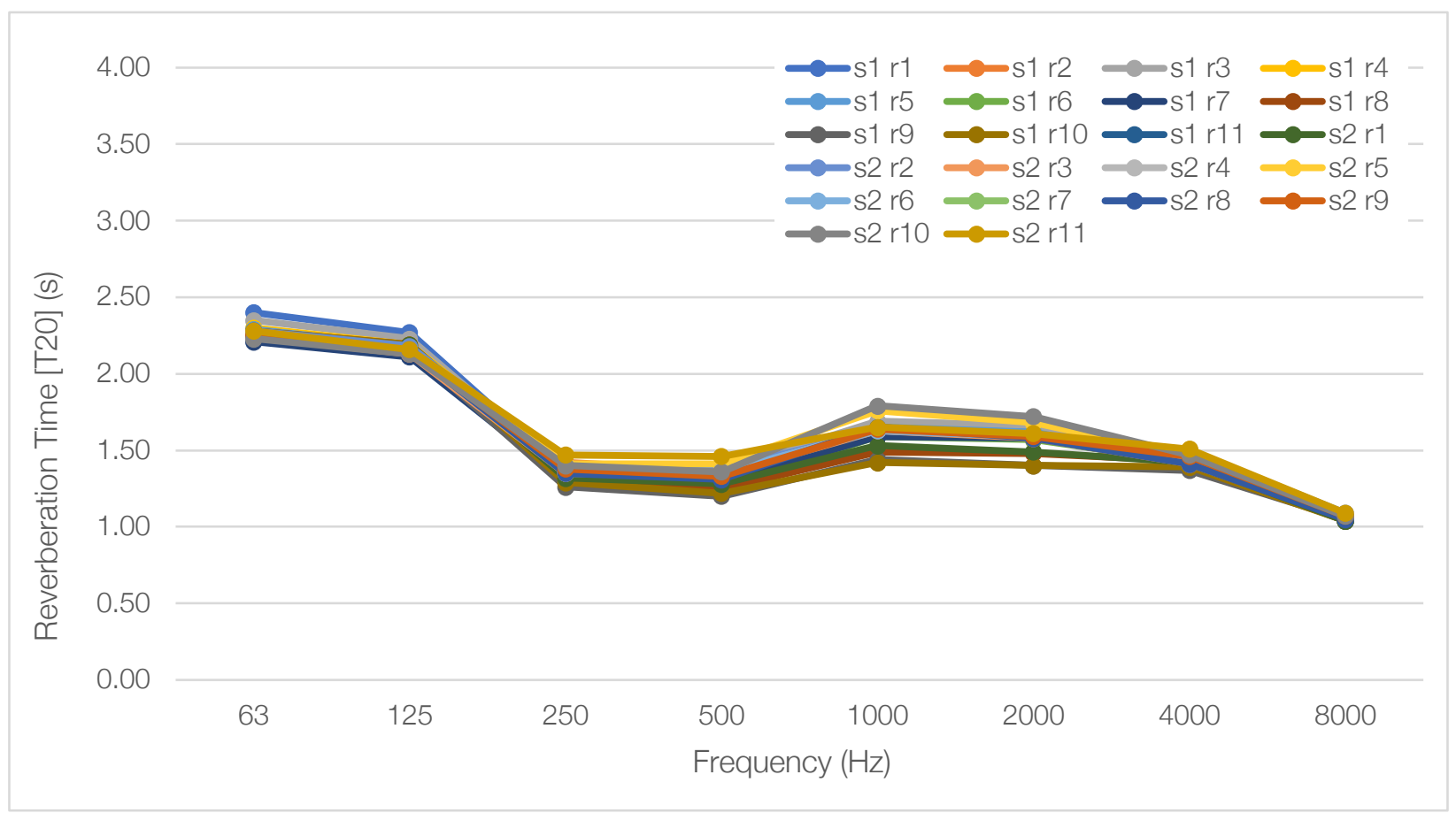

Figure 5.23: All simulated 3.6m receiver points T20 data for RSGC 


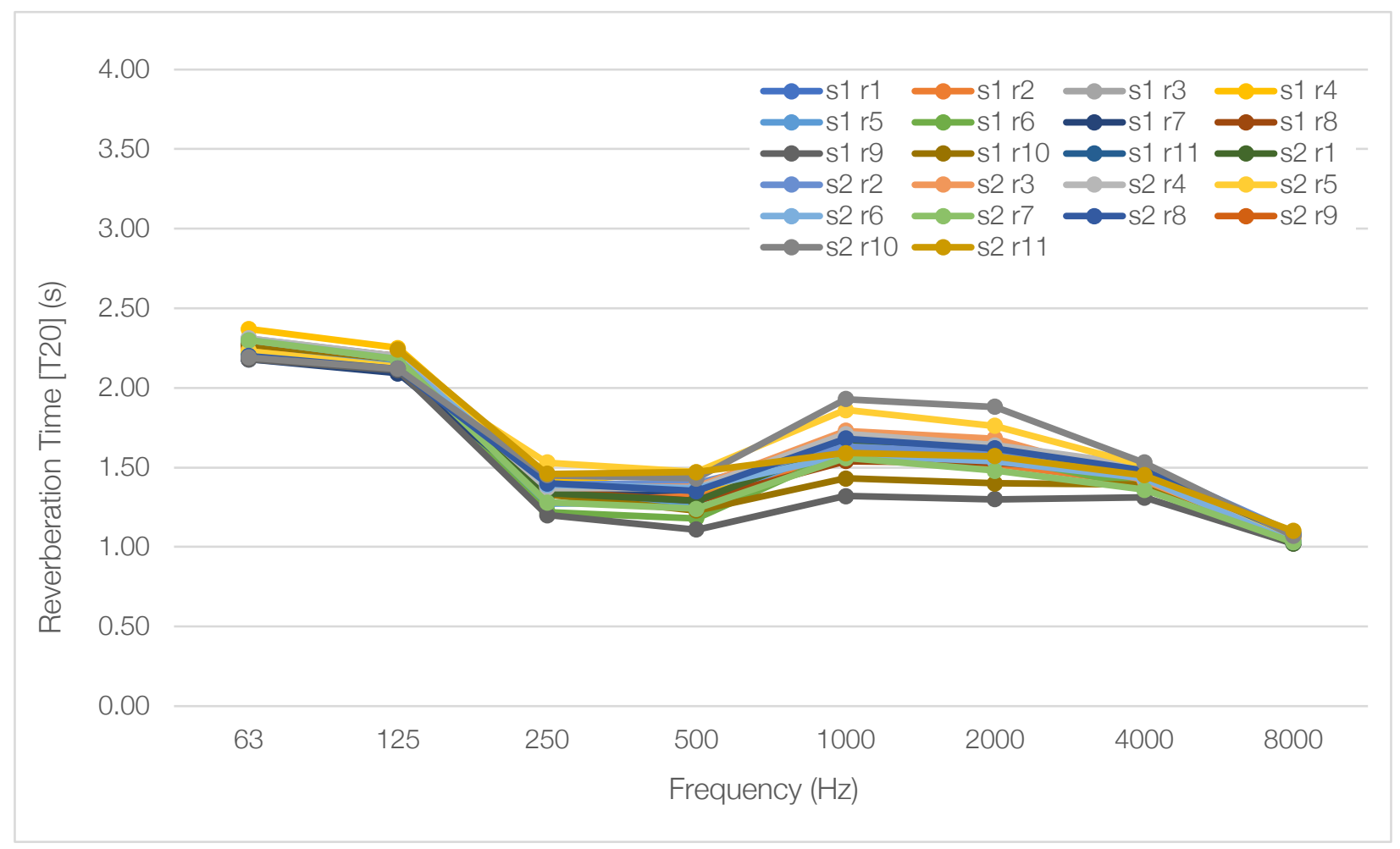

Figure 5.24: All simulated 6.0m receiver points T20 data for RSGC

\section{Sound Pressure Level}

Figures 5.25 shows the simulated relative SPL distribution in the RSGC gymnasium. There is a small difference between the SPL at the two receiver heights, not exceeding a $2 \mathrm{~dB}$ difference at any frequency. Within the respective receiver heights, SPL varies up to $2 \mathrm{~dB}$. Across different frequencies, the plot retains a similar shape and there is not a significant change in SPL from one frequency to another. Unlike the measured data, the simulated 3.6m SPL does not go above the $1.2 \mathrm{~m}$ SPL. 

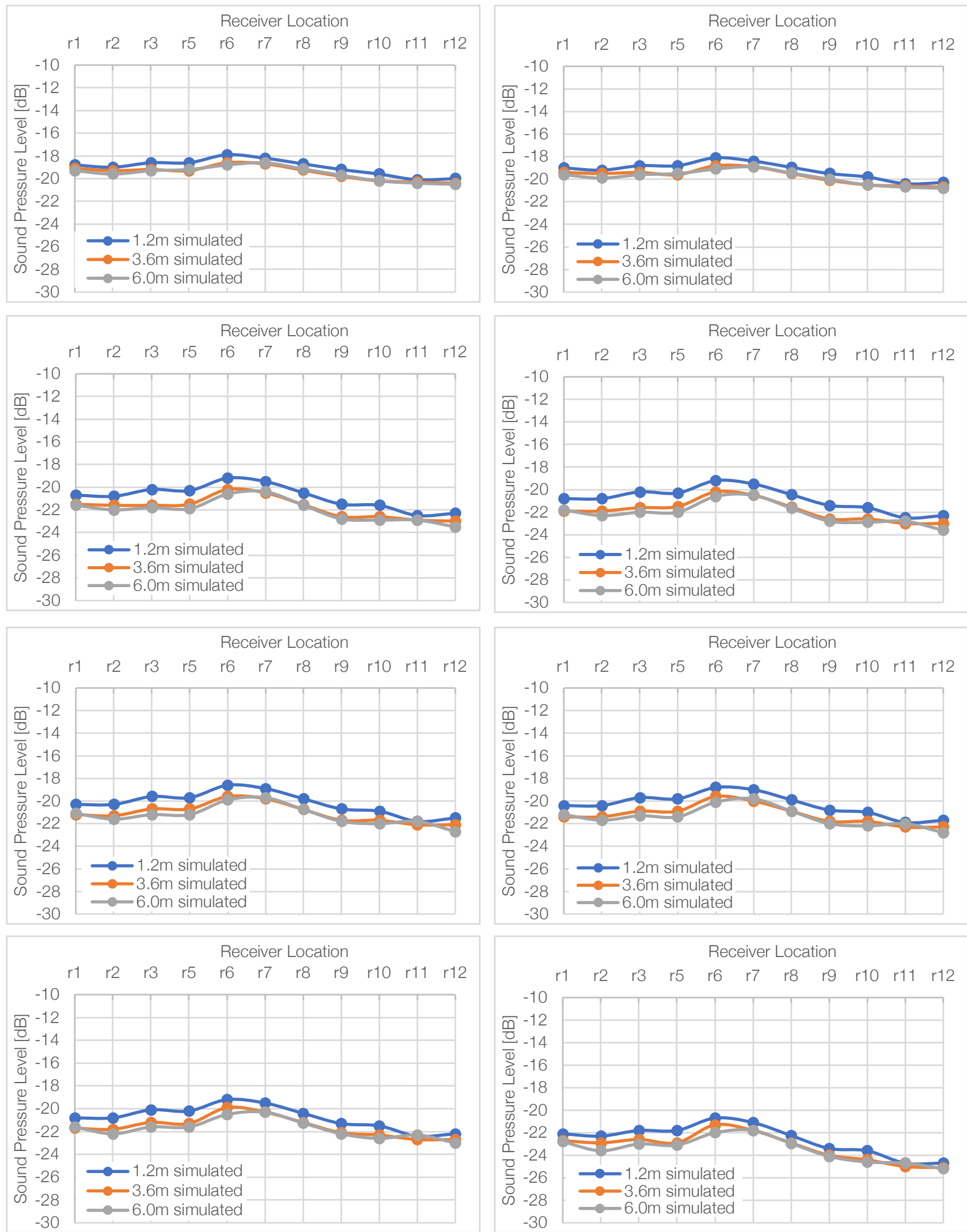

Figure 5.25: RSGC simulated SPL distribution for all S1 receiver points at (left to right) $63 \mathrm{~Hz}, 125 \mathrm{~Hz}$, $250 \mathrm{~Hz}, 500 \mathrm{~Hz}, 1000 \mathrm{~Hz}, 2000 \mathrm{~Hz}, 40000 \mathrm{~Hz}$, and $8000 \mathrm{~Hz}$ 


\section{Speech Transmission Index}

The simulation's output for STI was 0.52 at $1.2 \mathrm{~m}, 0.51$ at $3.6 \mathrm{~m}$ and $6.0 \mathrm{~m}$. The model overpredicted STI by $2 \%$ at the ISO 3382 height but confirmed that the model meets CAM standards.

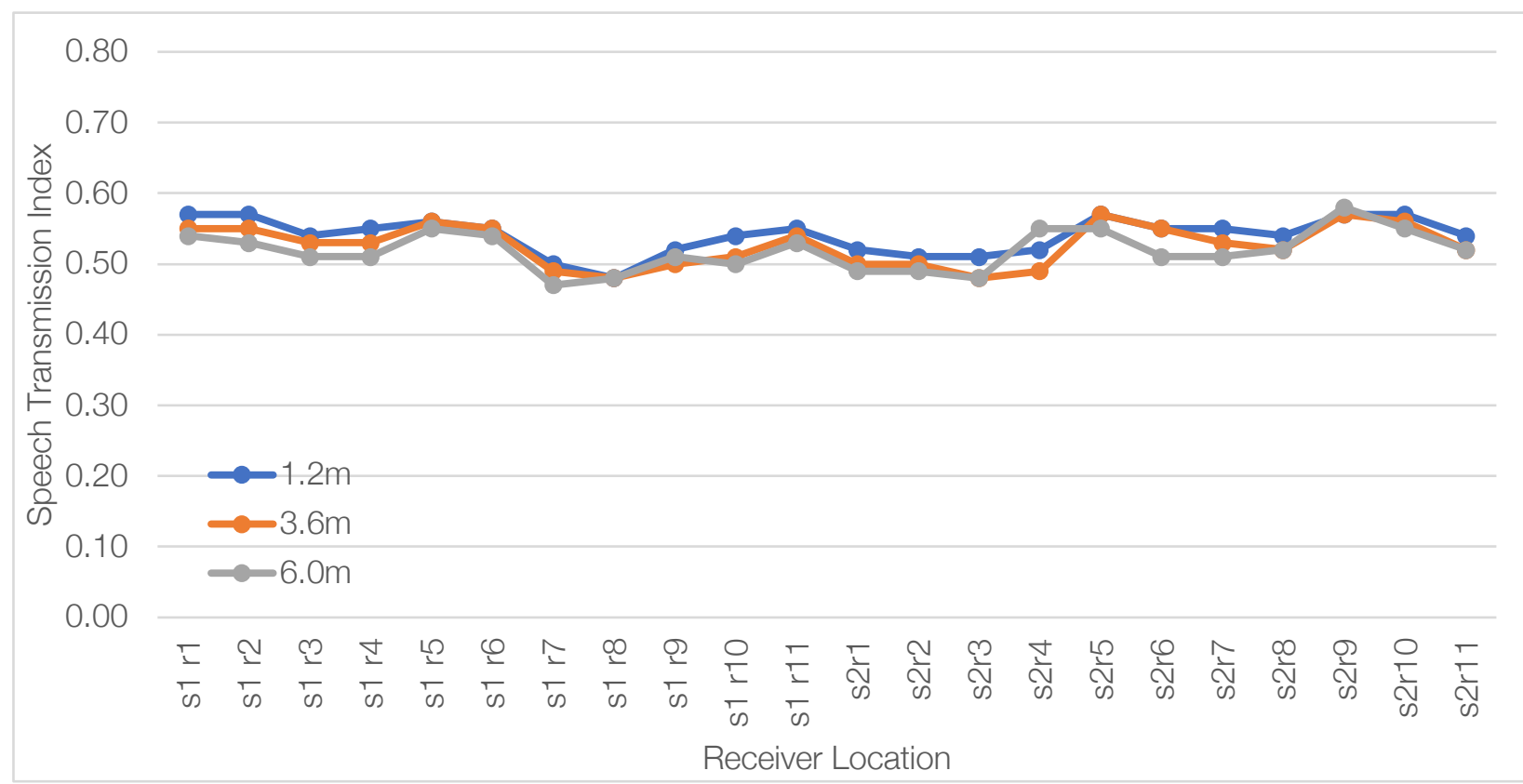

Figure 5.26: Simulated STI at 1.2m, 3.6m, and 6.0m for RSGC 


\subsubsection{Gabrielle Roy Elementary School}

Table 5.17 summarizes the adjusted absorption coefficients of all the surfaces present in the digital model of Gabrielle Roy. The only element not present in the 3D model used for simulation is 3 steel joists across the ceiling and athletic equipment in the corners.

\begin{tabular}{l|llllllll}
\hline & $63 \mathrm{~Hz}$ & $125 \mathrm{~Hz}$ & $250 \mathrm{~Hz}$ & $500 \mathrm{~Hz}$ & $1000 \mathrm{~Hz}$ & $2000 \mathrm{~Hz}$ & $4000 \mathrm{~Hz}$ & $8000 \mathrm{~Hz}$ \\
\hline \hline Wood Floor & 0.15 & 0.15 & 0.11 & 0.10 & 0.07 & 0.06 & 0.70 & 0.70 \\
Painted Concrete Block & 0.10 & 0.10 & 0.05 & 0.06 & 0.07 & 0.09 & 0.08 & 0.10 \\
Steel Door [33] & 0.05 & 0.05 & 0.05 & 0.05 & 0.06 & 0.04 & 0.02 & 0.02 \\
Single Pane Glazing & 0.18 & 0.18 & 0.06 & 0.04 & 0.03 & 0.02 & 0.02 & 0.02 \\
Absorption Panels & 0.37 & 0.23 & 0.27 & 0.30 & 0.42 & 0.42 & 0.42 & 0.40 \\
HVAC [35] & 0.04 & 0.07 & 0.06 & 0.05 & 0.04 & 0.05 & 0.04 & 0.04 \\
Rubber Mat & 0.04 & 0.04 & 0.04 & 0.08 & 0.12 & 0.10 & 0.10 & 0.10 \\
\hline
\end{tabular}

Table 5.17: Calibrated Material Absorption Coefficients for Gabrielle Roy

Source 1 receiver 4 was used for model calibration; the pre and post calibration RTs are shown in Table 5.18.

\begin{tabular}{|l|l|l|l|l|l|l|l|l|}
\hline & $63 \mathrm{~Hz}$ & $125 \mathrm{~Hz}$ & $250 \mathrm{~Hz}$ & $500 \mathrm{~Hz}$ & $1000 \mathrm{~Hz}$ & $2000 \mathrm{~Hz}$ & $4000 \mathrm{~Hz}$ & $8000 \mathrm{~Hz}$ \\
\hline \hline S1 R4 measured & 1.14 & 1.59 & 1.68 & 1.55 & 1.23 & 1.26 & 1.15 & 0.79 \\
\hline S1 R4 simulation & 1.32 & 1.75 & 1.80 & 1.62 & 1.42 & 1.38 & 1.42 & 1.09 \\
\hline S1 R4 calibrated simulation & 1.25 & 1.67 & 1.75 & 1.62 & 1.26 & 1.20 & 1.06 & 0.73 \\
\hline
\end{tabular}

Table 5.18: Calibration point T20 data for Gabrielle Roy

\section{Reverberation Time}

\begin{tabular}{|c|c|c|c|c|c|c|c|c|}
\hline & $63 \mathrm{~Hz}$ & $125 \mathrm{~Hz}$ & $250 \mathrm{~Hz}$ & $500 \mathrm{~Hz}$ & $1000 \mathrm{~Hz}$ & $2000 \mathrm{~Hz}$ & $4000 \mathrm{~Hz}$ & $8000 \mathrm{~Hz}$ \\
\hline Measured T20 at $1.2 \mathrm{~m}$ & 1.22 & 1.62 & 1.78 & 1.61 & 1.26 & 1.25 & 1.14 & 0.80 \\
\hline Modelled T20 at 1.2m & 1.25 & 1.68 & 1.76 & 1.62 & 1.26 & 1.19 & 1.05 & 0.73 \\
\hline \% Difference & & $3 \%$ & $-1 \%$ & $1 \%$ & $0 \%$ & $-5 \%$ & $-8 \%$ & $-9 \%$ \\
\hline Measured T20 at 3.6m & 1.28 & 1.66 & 1.73 & 1.64 & 1.30 & 1.14 & 1.01 & 0.75 \\
\hline Modelled T20 at 3.6m & 1.28 & 1.69 & 1.79 & 1.65 & 1.29 & 1.21 & 1.06 & 0.72 \\
\hline \% Difference & & $2 \%$ & $3 \%$ & $1 \%$ & $-1 \%$ & $6 \%$ & $5 \%$ & $-4 \%$ \\
\hline Modelled T20 at $6.0 \mathrm{~m}$ & 1.28 & 1.69 & 1.79 & 1.65 & 1.29 & 1.21 & 1.06 & 0.72 \\
\hline
\end{tabular}

Table 5.19: Comparison of measure and modelled T20 data at Gabrielle Roy

The T20 outputs from the simulation are within $1 \%$ at different height for each octave band.

The simulated data does not reflect the change in RT at an increased height; it predicts a more uniform sound field than was measured. 


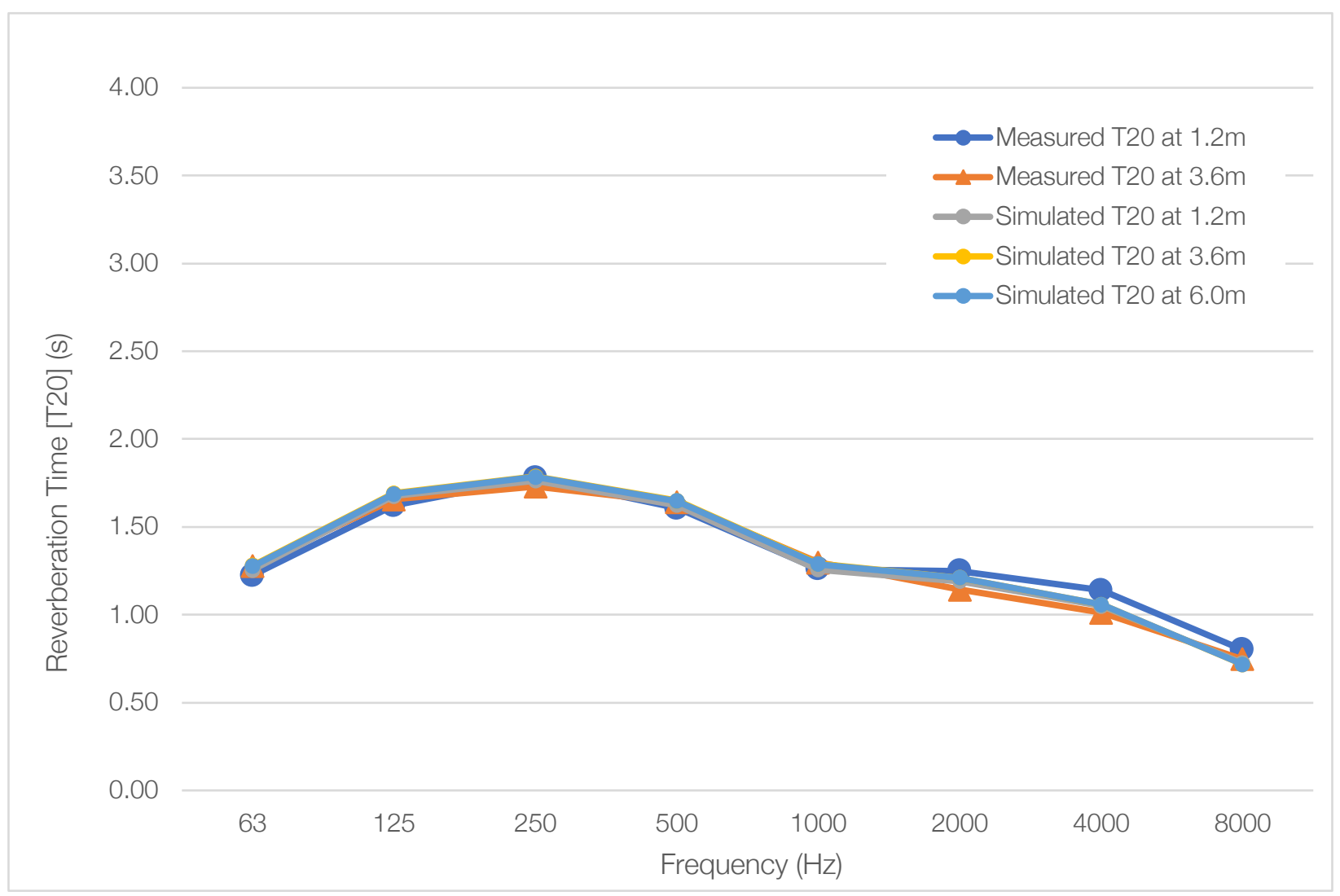

Figure 5.27: Gabrielle Roy T20 Measured vs Simulated

\begin{tabular}{|l|l|l|l|l|l|l|l|l|}
\hline & $63 \mathrm{~Hz}$ & $125 \mathrm{~Hz}$ & $250 \mathrm{~Hz}$ & \multicolumn{1}{l}{$500 \mathrm{~Hz}$} & \multicolumn{1}{l}{$1000 \mathrm{~Hz}$} & $2000 \mathrm{~Hz}$ & \multicolumn{1}{l}{$4000 \mathrm{~Hz}$} & \multicolumn{1}{l}{$8000 \mathrm{~Hz}$} \\
\hline \hline Stdev $1.2 \mathrm{~m}$ & 0.16 & 0.12 & 0.06 & 0.09 & 0.03 & 0.02 & 0.02 & 0.02 \\
\hline Stdev 3.6m & 0.17 & 0.12 & 0.06 & 0.07 & 0.02 & 0.02 & 0.02 & 0.02 \\
\hline Modelled Stdev 1.2m & 0.01 & 0.01 & 0.01 & 0.01 & 0.01 & 0.01 & 0.01 & 0.01 \\
\hline Modelled Stdev $3.6 \mathrm{~m}$ & 0.02 & 0.02 & 0.03 & 0.03 & 0.02 & 0.02 & 0.02 & 0.01 \\
\hline Modelled Stdev 6.0m & 0.02 & 0.03 & 0.03 & 0.03 & 0.02 & 0.02 & 0.02 & 0.01 \\
\hline
\end{tabular}

Table 5.20: Standard deviation of all T20 data at Gabrielle Roy

Figures 5.28, 5.29, and 5.30 are plots of the T20 data at each simulated receiver point. The graphs show that there is very little variability in the results in any frequency, which could be due to the room having a large area of absorbers and a relatively small overall size. Table 5.20 shows that the standard deviation of the data stayed consistent at all frequencies. 


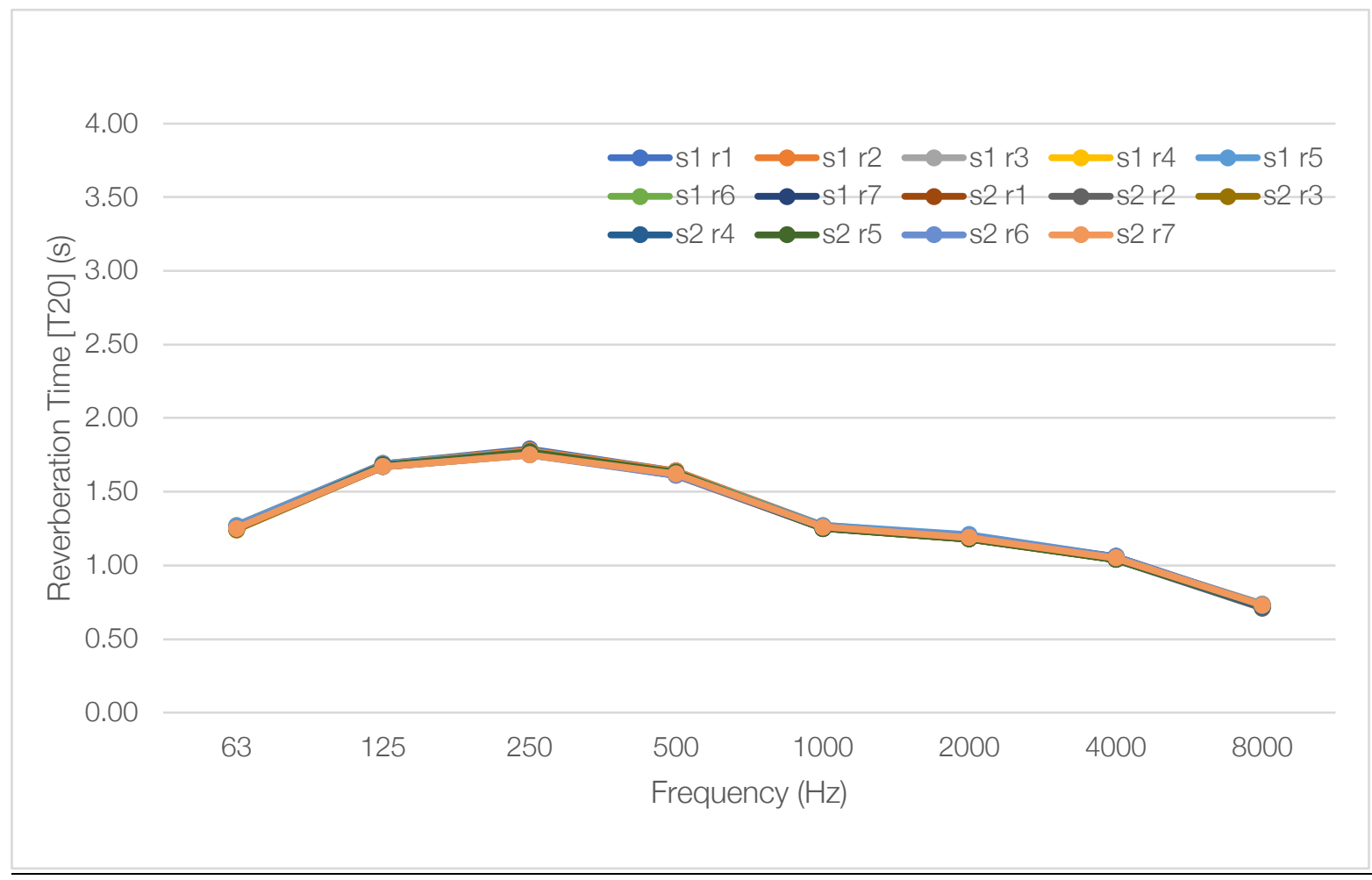

Figure 5.28: All simulated 1.2m receiver points T20 data for Gabrielle Roy

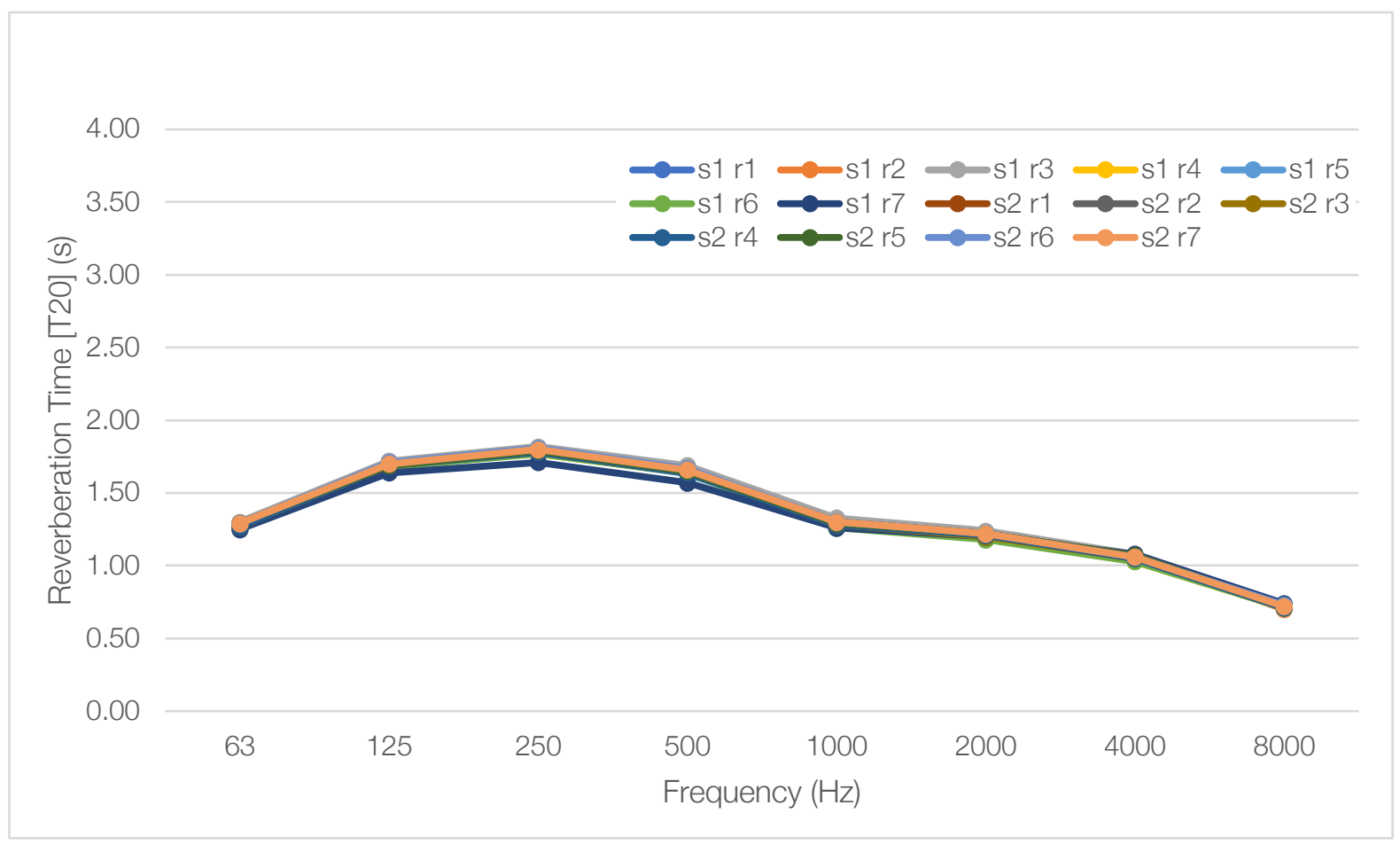

Figure 5.29: All simulated 1.2m receiver points T20 data for Gabrielle Roy 


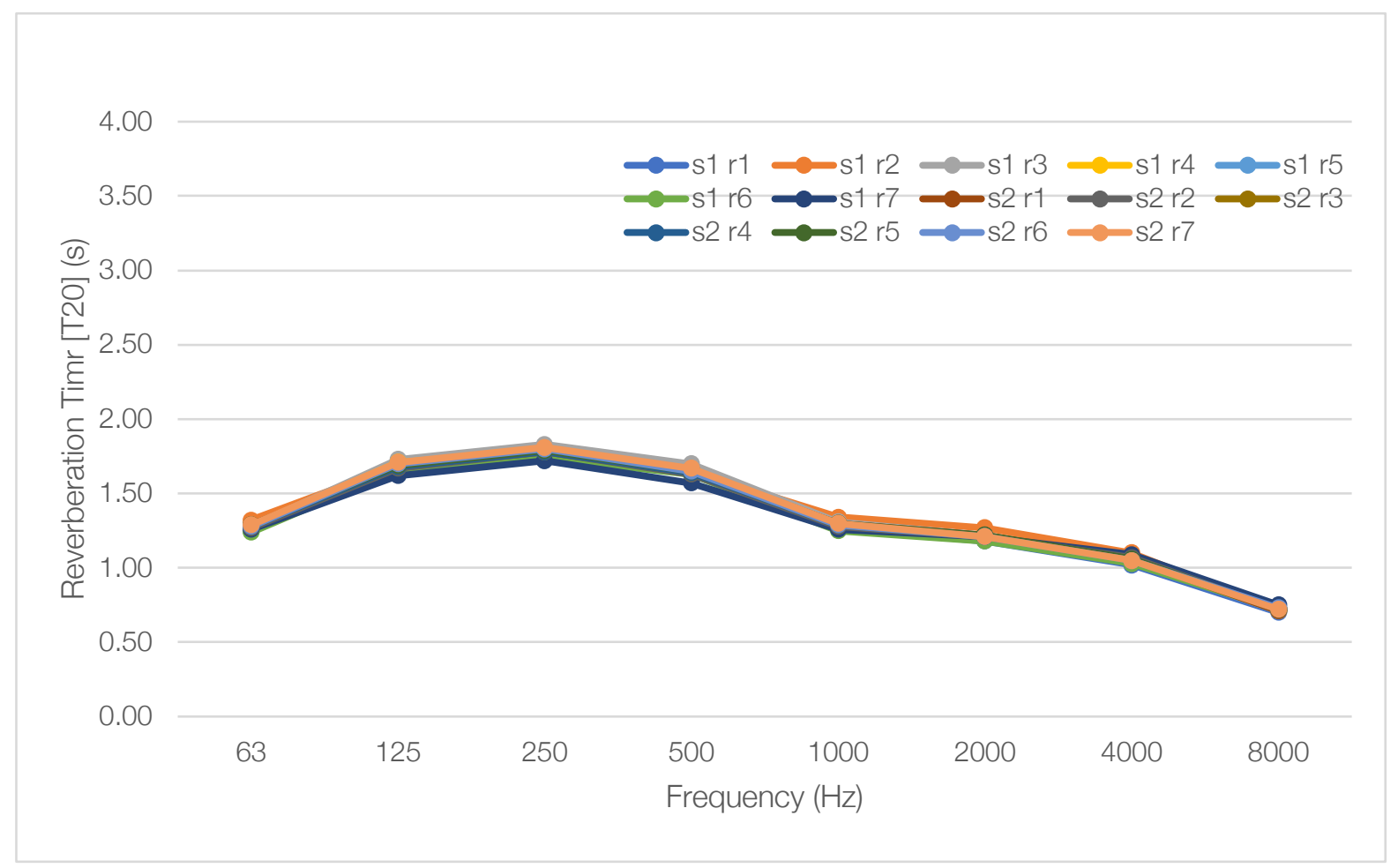

Figure 5.30: All simulated 6.0m receiver points T20 data for Gabrielle Roy

\section{Sound Pressure Level}

Figure 5.31 shows the simulated relative SPL distribution in the Gabrielle Roy gymnasium.

There is a small difference between the SPL at the three receiver heights, reaching a maximum $1 \mathrm{~dB}$ difference. Within the respective receiver heights, SPL varies around $2 \mathrm{~dB}$. Like the measured data the Gabrielle Roy SPL profile retains a relatively similar shape across all frequency bands. Unlike the measured data, the simulated 3.6m SPL does not go above the 1.2m SPL, while the $6 \mathrm{~m}$ data does at points furthest away from the source. 

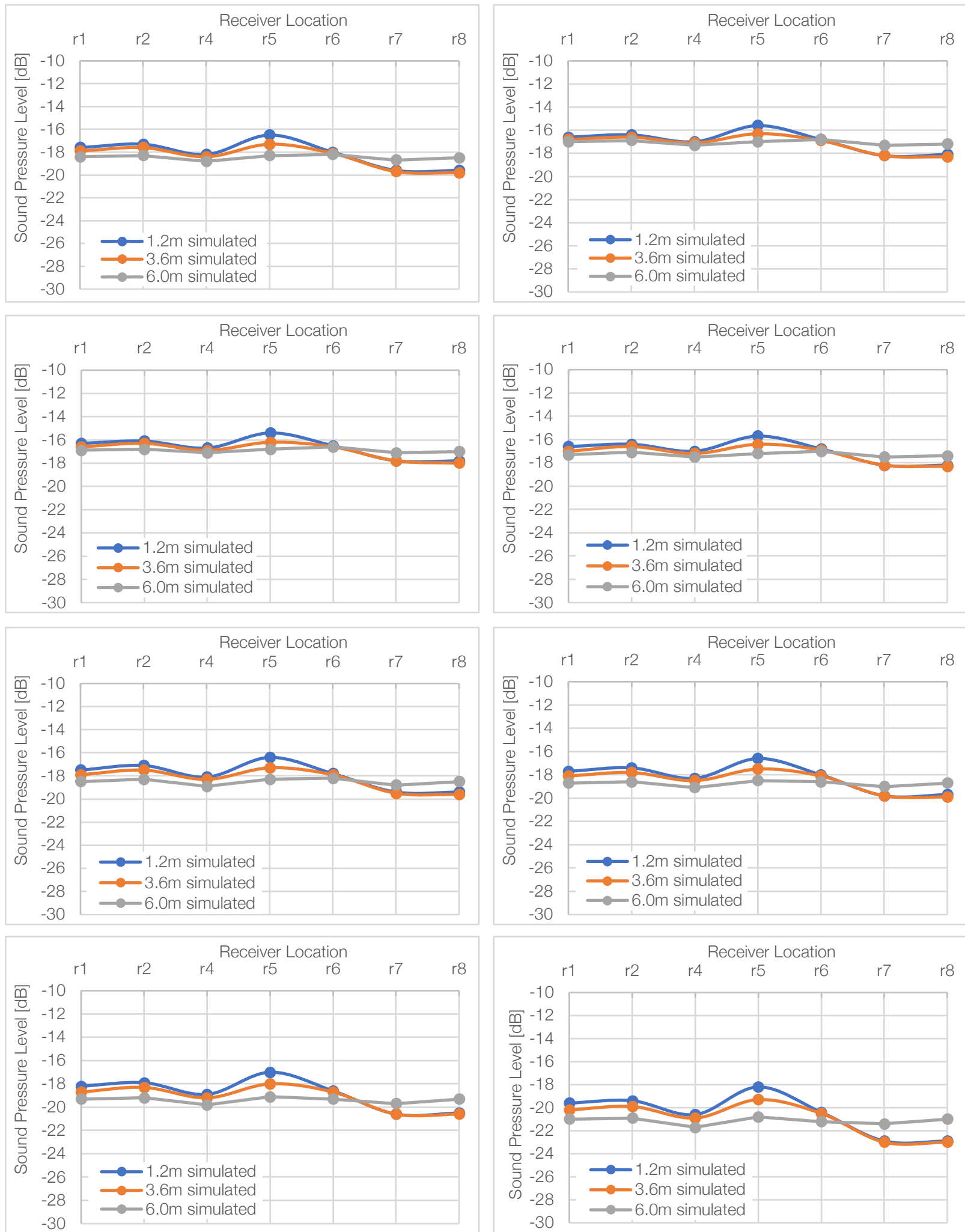

Figure 5.31: Gabrielle Roy simulated SPL distribution for all S1 receiver points at (left to right) 63Hz, $125 \mathrm{~Hz}, 250 \mathrm{~Hz}, 500 \mathrm{~Hz}, 1000 \mathrm{~Hz}, 2000 \mathrm{~Hz}, 40000 \mathrm{~Hz}$, and $8000 \mathrm{~Hz}$ 


\section{Speech Transmission Index}

The simulation's output for STI was 0.52 at $1.2 \mathrm{~m}, 0.51$ at $3.6 \mathrm{~m}$ and $6.0 \mathrm{~m}$. The model overpredicted STI by $2 \%$ at the ISO 3382 height but confirmed that the model meets CAM standards.

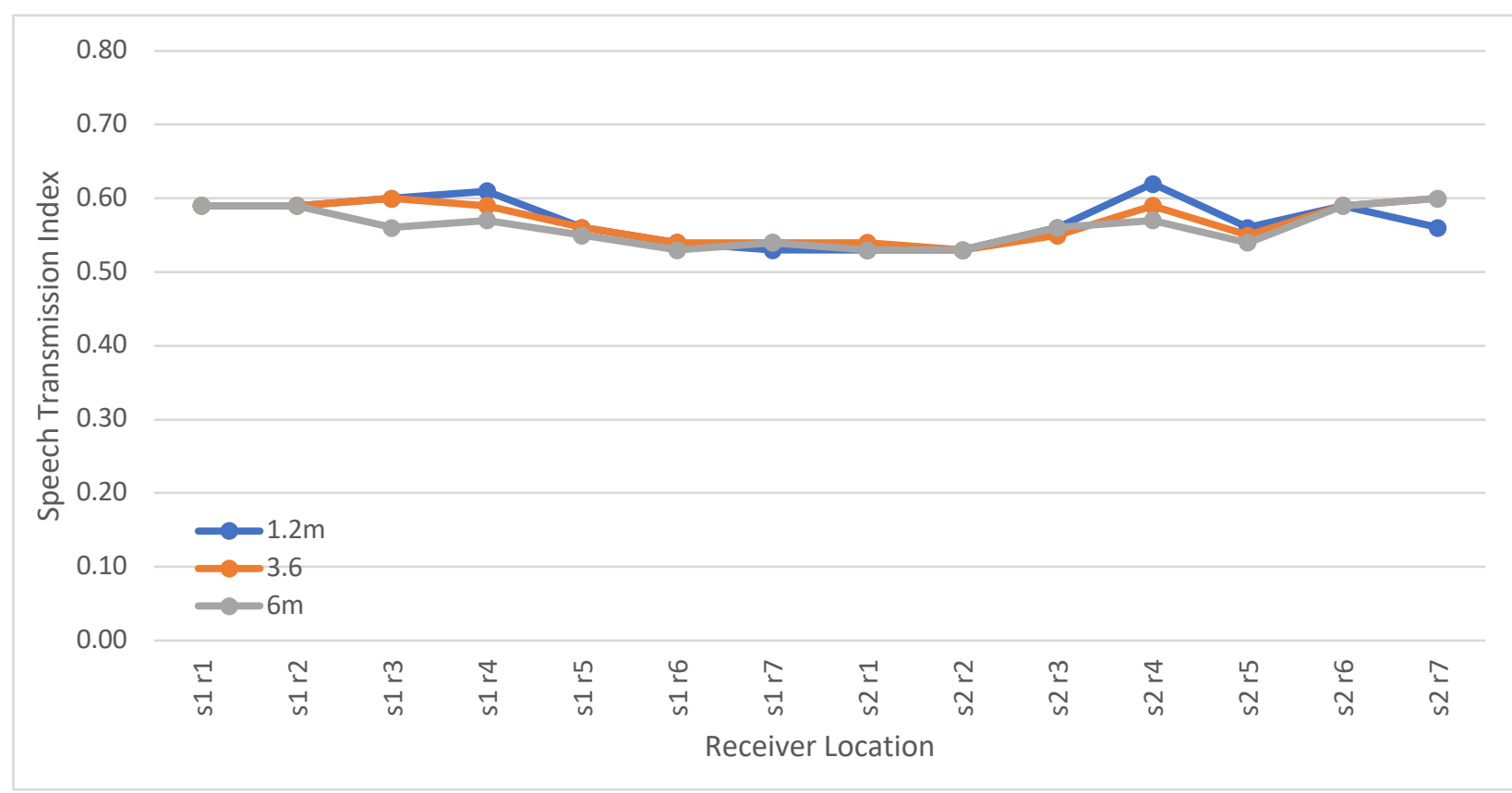

Figure 5.32: Simulated STI at 1.2m, 3.6m, and 6.0m for Gabrielle Roy 


\subsubsection{Ryerson Athletics Centre Gym II}

Table 5.21 summarizes the adjusted absorption coefficients of all the surfaces present in the digital model of the RAC Gym II. The room had pendant lighting fixtures that were not included in the 3D model.

\begin{tabular}{l|llllllll}
\hline & $63 \mathrm{~Hz}$ & $125 \mathrm{~Hz}$ & $250 \mathrm{~Hz}$ & $500 \mathrm{~Hz}$ & $1000 \mathrm{~Hz}$ & $2000 \mathrm{~Hz}$ & $4000 \mathrm{~Hz}$ & $8000 \mathrm{~Hz}$ \\
\hline \hline Wood Floor & 0.15 & 0.15 & 0.11 & 0.10 & 0.07 & 0.06 & 0.70 & 0.70 \\
Smooth, Exposed & & & & & & & & \\
Concrete & 0.02 & 0.02 & 0.03 & 0.03 & 0.03 & 0.04 & 0.07 & 0.07 \\
Steel Door [33] & 0.05 & 0.05 & 0.05 & 0.05 & 0.06 & 0.04 & 0.02 & 0.02 \\
Double Pane Glazing & 0.15 & 0.10 & 0.07 & 0.05 & 0.03 & 0.02 & 0.02 & 0.02 \\
Perforated Metal Panel & 0.10 & 0.20 & 0.38 & 0.34 & 0.79 & 0.85 & 0.57 & 0.57 \\
Rubber Mat & 0.04 & 0.04 & 0.04 & 0.08 & 0.12 & 0.10 & 0.10 & 0.10 \\
\hline
\end{tabular}

Table 5.21: Calibrated Material Absorption Coefficients for RAC II

Source 1 receiver 5 was used for model calibration; the pre and post calibration RTs are shown in Table 5.22.

\begin{tabular}{|l|l|l|l|l|l|l|l|l|}
\hline & $63 \mathrm{~Hz}$ & $125 \mathrm{~Hz}$ & $250 \mathrm{~Hz}$ & $500 \mathrm{~Hz}$ & $1000 \mathrm{~Hz}$ & $2000 \mathrm{~Hz}$ & $4000 \mathrm{~Hz}$ & $8000 \mathrm{~Hz}$ \\
\hline \hline S1 R5 measured & & 2.39 & 2.18 & 2.06 & 2.01 & 1.61 & 1.27 & 0.77 \\
\hline S1 R5 simulation & & 2.37 & 2.02 & 1.65 & 1.82 & 1.82 & 1.52 & 0.97 \\
\hline S1 R5 calibrated simulation & & 2.37 & 2.09 & 1.96 & 1.90 & 1.66 & 1.39 & 0.81 \\
\hline
\end{tabular}

Table 5.22: Calibration point T20 data for RAC II

\section{$\underline{\text { Reverberation Time }}$}

\begin{tabular}{|c|c|c|c|c|c|c|c|c|}
\hline & $63 \mathrm{~Hz}$ & $125 \mathrm{~Hz}$ & $250 \mathrm{~Hz}$ & $500 \mathrm{~Hz}$ & $1000 \mathrm{~Hz}$ & $2000 \mathrm{~Hz}$ & $4000 \mathrm{~Hz}$ & $8000 \mathrm{~Hz}$ \\
\hline Measured T20 at $1.2 \mathrm{~m}$ & & 3.06 & 2.56 & 2.87 & 2.46 & 1.98 & 1.56 & 0.96 \\
\hline Modelled T20 at $1.2 \mathrm{~m}$ & & 2.85 & 2.60 & 2.68 & 2.50 & 2.26 & 1.59 & 0.90 \\
\hline \% Difference & & $-7 \%$ & $2 \%$ & $-7 \%$ & $1 \%$ & $14 \%$ & $2 \%$ & $-6 \%$ \\
\hline Measured T20 at 3.6m & & 2.93 & 2.42 & 2.74 & 2.52 & 1.99 & 1.55 & 0.95 \\
\hline Modelled T20 at $3.6 \mathrm{~m}$ & & 2.86 & 2.57 & 2.65 & 2.47 & 2.25 & 1.59 & 0.90 \\
\hline \% Difference & & $-3 \%$ & $7 \%$ & $-4 \%$ & $-2 \%$ & $13 \%$ & $3 \%$ & $-5 \%$ \\
\hline Modelled T20 at $6.0 \mathrm{~m}$ & & 2.81 & 2.50 & 2.57 & 2.42 & 2.25 & 1.62 & 0.89 \\
\hline
\end{tabular}

Table 5.23: Comparison of measure and modelled T20 data at RAC II

The T20 outputs from the simulation were all within 0.03 s of each other at all heights, as

opposed to the 0.13 s difference the measured T20 had between 125 and $500 \mathrm{~Hz}$. The simulated data does not reflect the change in RT at an increased height; it predicts a more uniform sound field than was measured. 


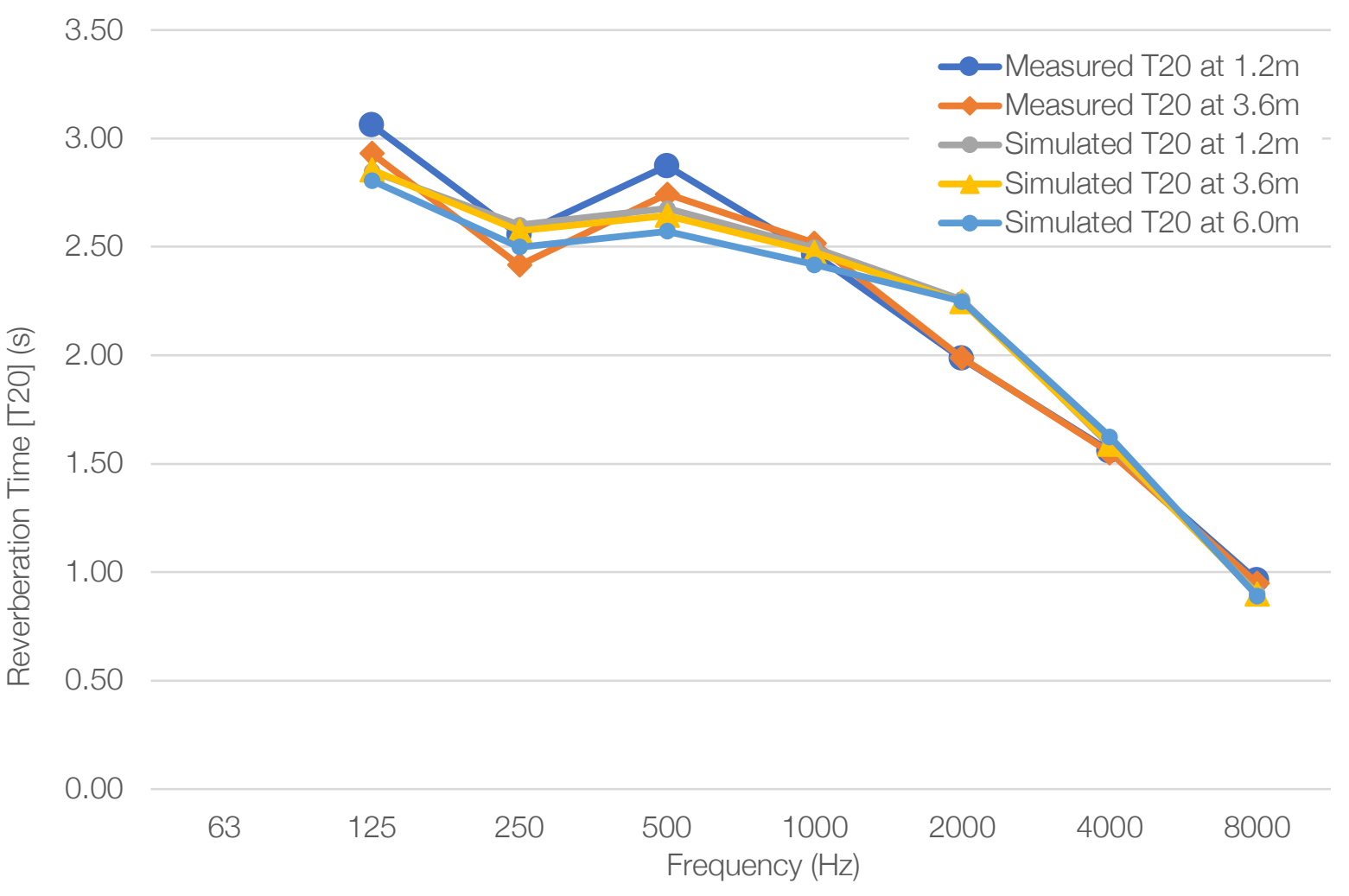

Figure 5.33: RAC II T20 Measured vs Simulated

\begin{tabular}{|l|r|r|r|r|r|r|r|r|}
\hline & $63 \mathrm{~Hz}$ & $125 \mathrm{~Hz}$ & $250 \mathrm{~Hz}$ & $500 \mathrm{~Hz}$ & $1000 \mathrm{~Hz}$ & $2000 \mathrm{~Hz}$ & $4000 \mathrm{~Hz}$ & $8000 \mathrm{~Hz}$ \\
\hline \hline Stdev $1.2 \mathrm{~m}$ & 0.16 & 0.12 & 0.06 & 0.09 & 0.03 & 0.02 & 0.02 & 0.02 \\
\hline Stdev 3.6m & 0.17 & 0.12 & 0.06 & 0.07 & 0.02 & 0.02 & 0.02 & 0.02 \\
\hline Modelled Stdev $1.2 \mathrm{~m}$ & 0.01 & 0.01 & 0.01 & 0.01 & 0.01 & 0.01 & 0.01 & 0.01 \\
\hline Modelled Stdev 3.6m & 0.02 & 0.02 & 0.03 & 0.03 & 0.02 & 0.02 & 0.02 & 0.01 \\
\hline Modelled Stdev 6.0m & 0.02 & 0.03 & 0.03 & 0.03 & 0.02 & 0.02 & 0.02 & 0.01 \\
\hline
\end{tabular}

Table 5.24: Standard deviation of all T20 data at RAC II

Figures 5.34, 5.35, and 5.36 are plots of the T20 data at each simulated receiver point. The graphs show that, unlike in the measured data, the greatest variability in $\mathrm{RT}$ comes at $250 \mathrm{~Hz}$ to $2000 \mathrm{~Hz}$. This could be because the digital model cannot account for all the small scattering elements found in the physical room and therefore simulates a less diffuse environment. The RAC II gym is comparable in size to the Gabrielle Roy gym with similar finishes apart from RAC not having much absorption. The simulation was not able to calculate the $\mathrm{RT}$ at $63 \mathrm{HZ}$ and 
could not simulate all points at $125 \mathrm{~Hz}$, meaning the number of reflections exceeded the computational limit of the software.

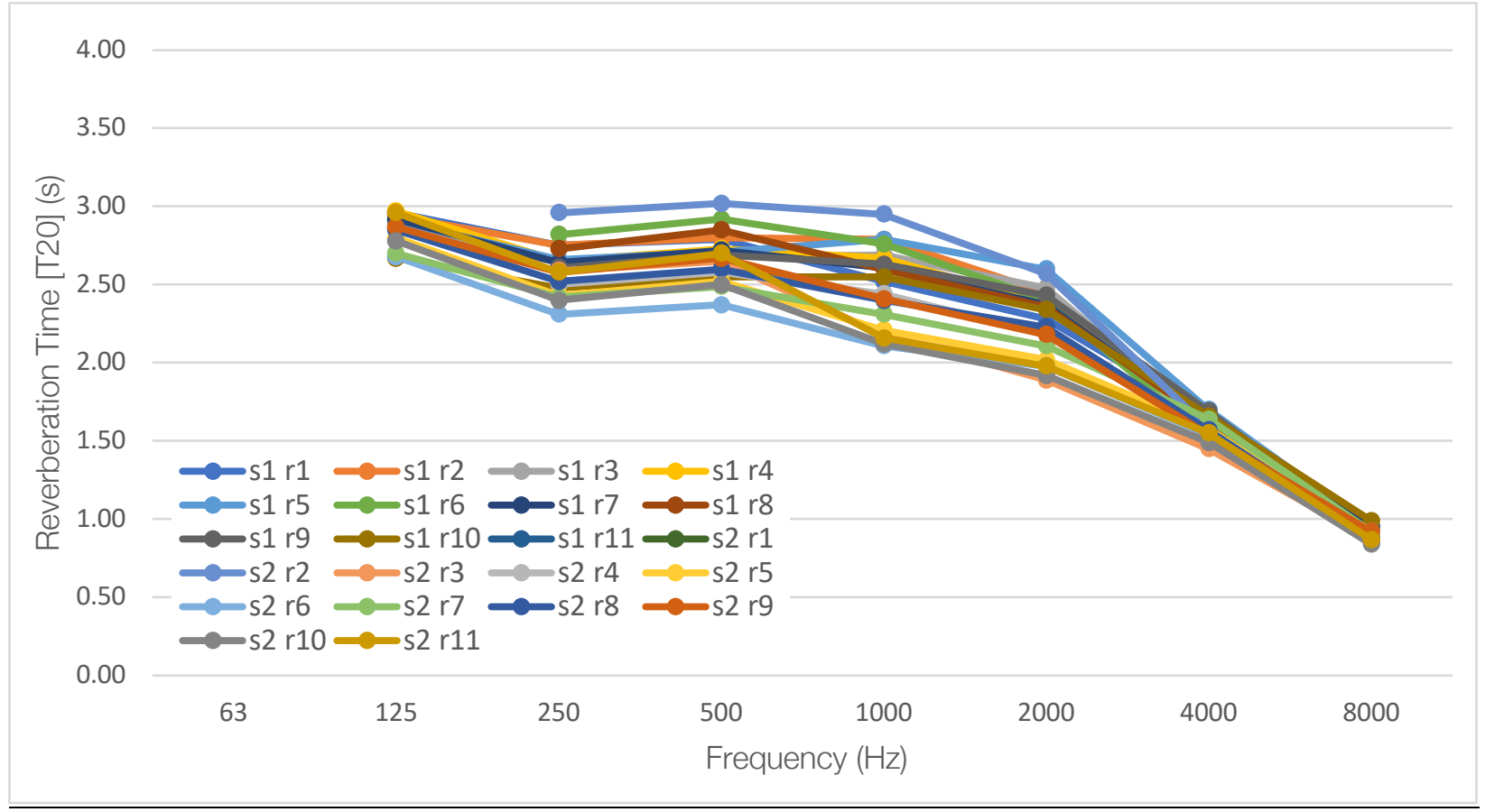

Figure 5.34: All simulated 1.2m receiver points T20 data for RAC II

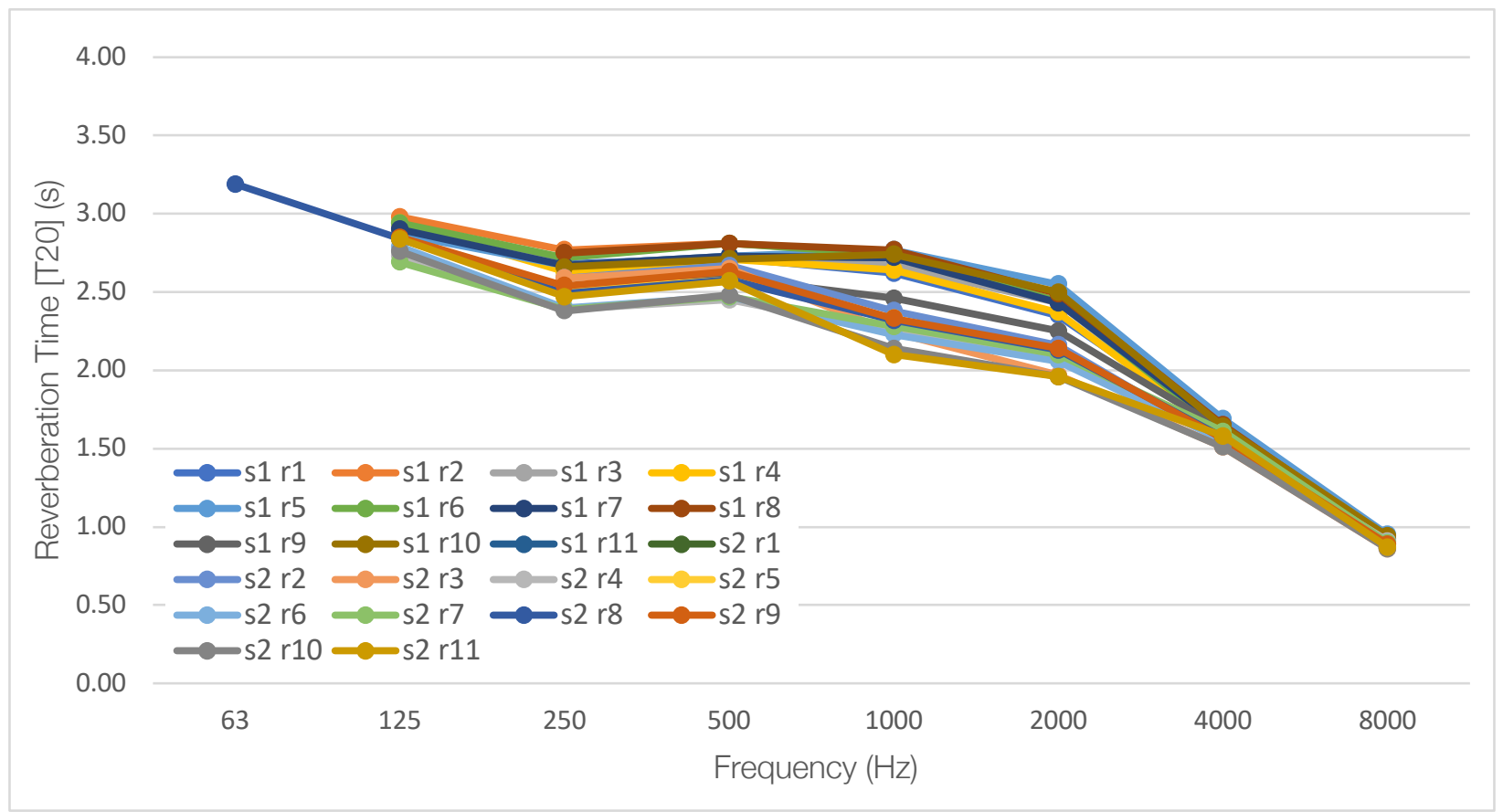

Figure 5.35: All simulated 3.6m receiver points T20 data for RAC II 


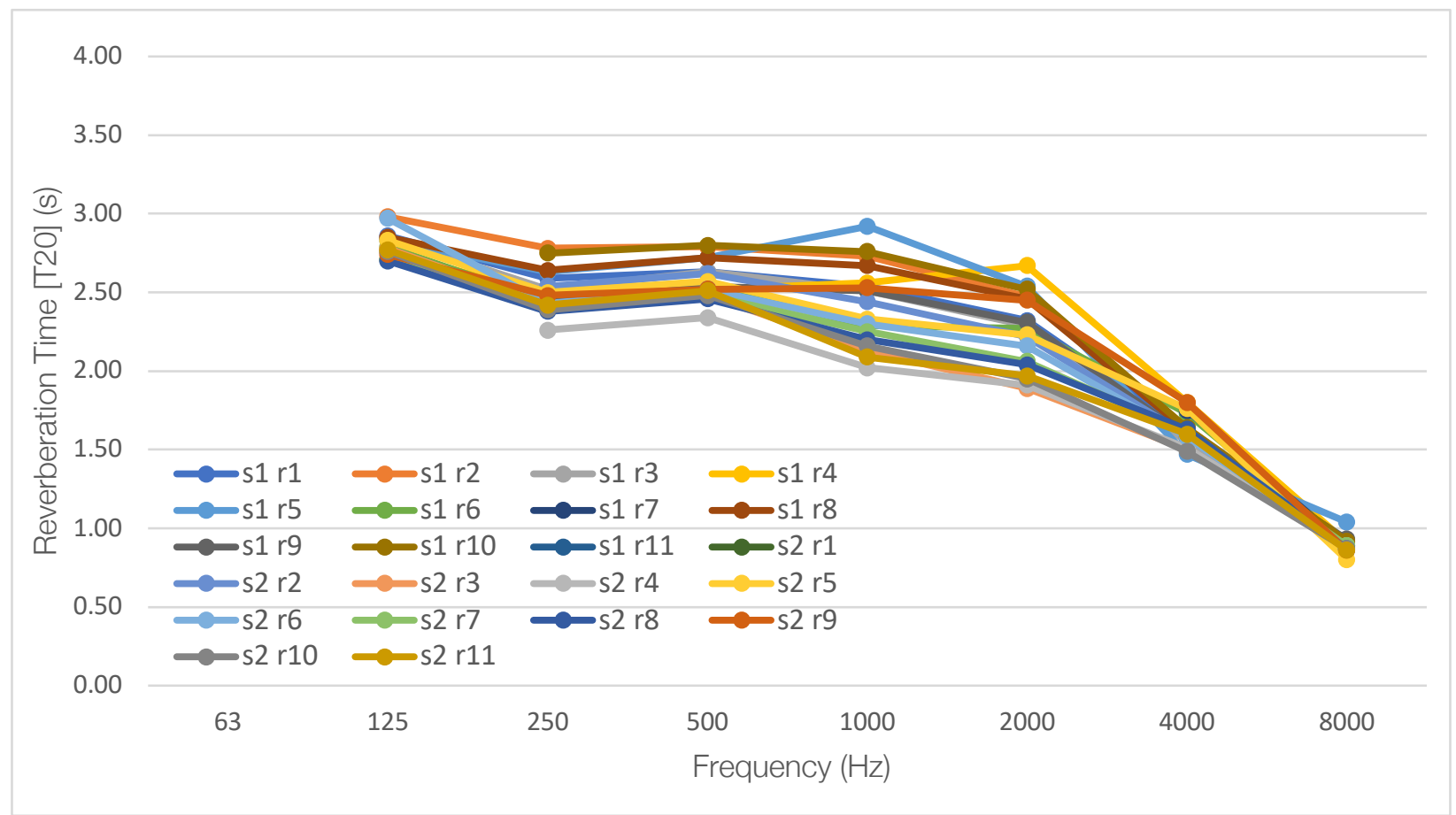

Figure 5.36: All simulated 6.0m receiver points T20 data for $R A C$ II

\section{Sound Pressure Level}

Figure 5.37 shows the simulated relative SPL distribution in the RAC gymnasium. There is a small difference between the SPL at the two receiver heights, reaching a 3dB difference at $8000 \mathrm{~Hz}$. Within the respective receiver heights, SPL varies up to $10 \mathrm{~dB}$. Unlike the measured data, the plot retains a similar shape across frequencies. The plot is more varied at higher frequencies. Unlike the measured data, the simulated $3.6 \mathrm{~m} \mathrm{SPL}$ does not go above the $1.2 \mathrm{~m}$ SPL. 

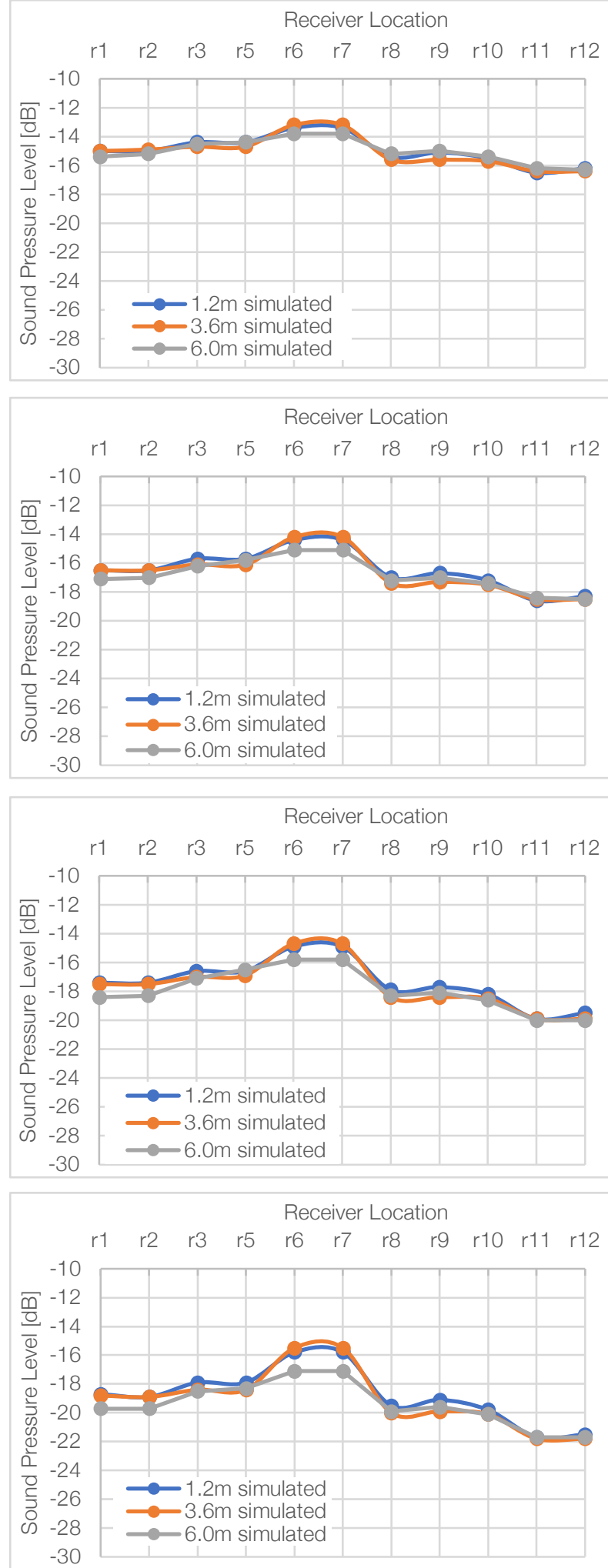
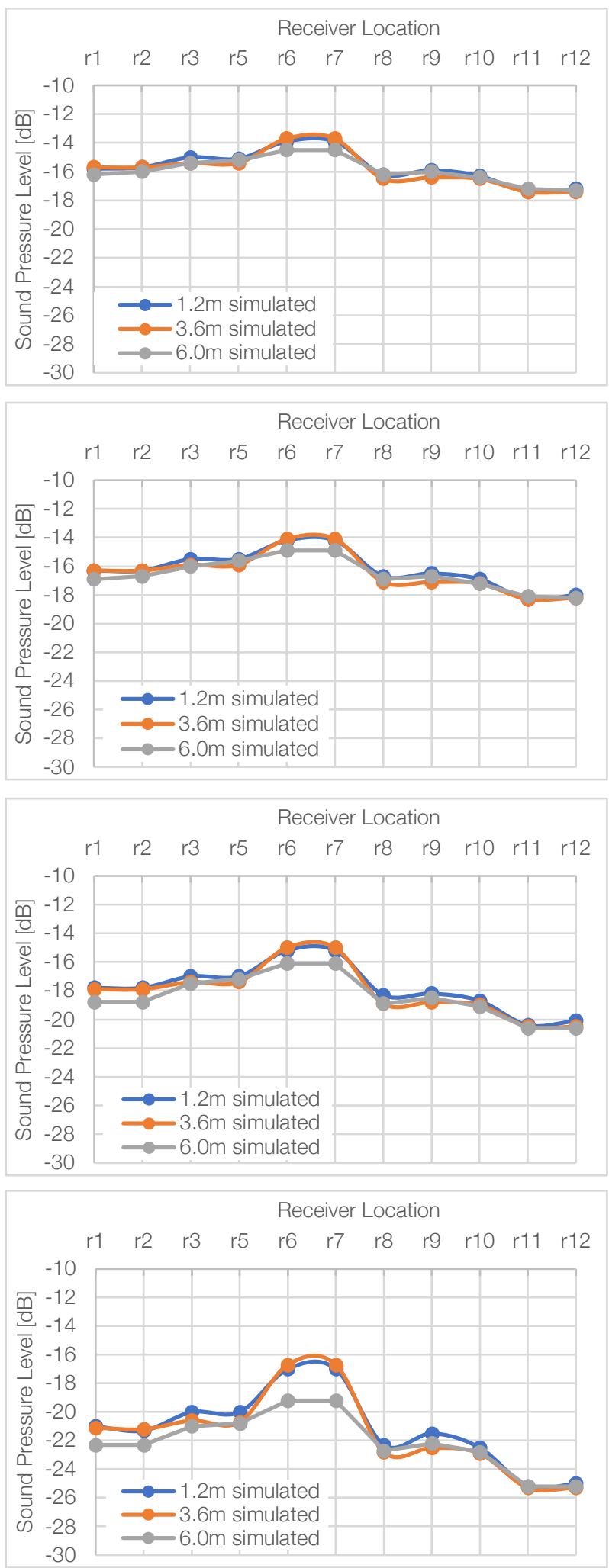

Figure 5.37: RAC II simulated SPL distribution for all S1 receiver points at (left to right) $63 \mathrm{~Hz}, 125 \mathrm{~Hz}$, $250 \mathrm{~Hz}, 500 \mathrm{~Hz}, 1000 \mathrm{~Hz}, 2000 \mathrm{~Hz}, 40000 \mathrm{~Hz}$, and $8000 \mathrm{~Hz}$ 


\section{Speech Transmission Index}

The simulation's output for STI was 0.47 at $1.2 \mathrm{~m}, 3.6 \mathrm{~m}$ and $6.0 \mathrm{~m}$, as opposed to the measured STI of 0.48 for both $1.2 \mathrm{~m}$ and $3.6 \mathrm{~m}$. The model under-predicted STI by $1 \%$ at the ISO 3382 height but confirmed that the model does not meet CAM standards.

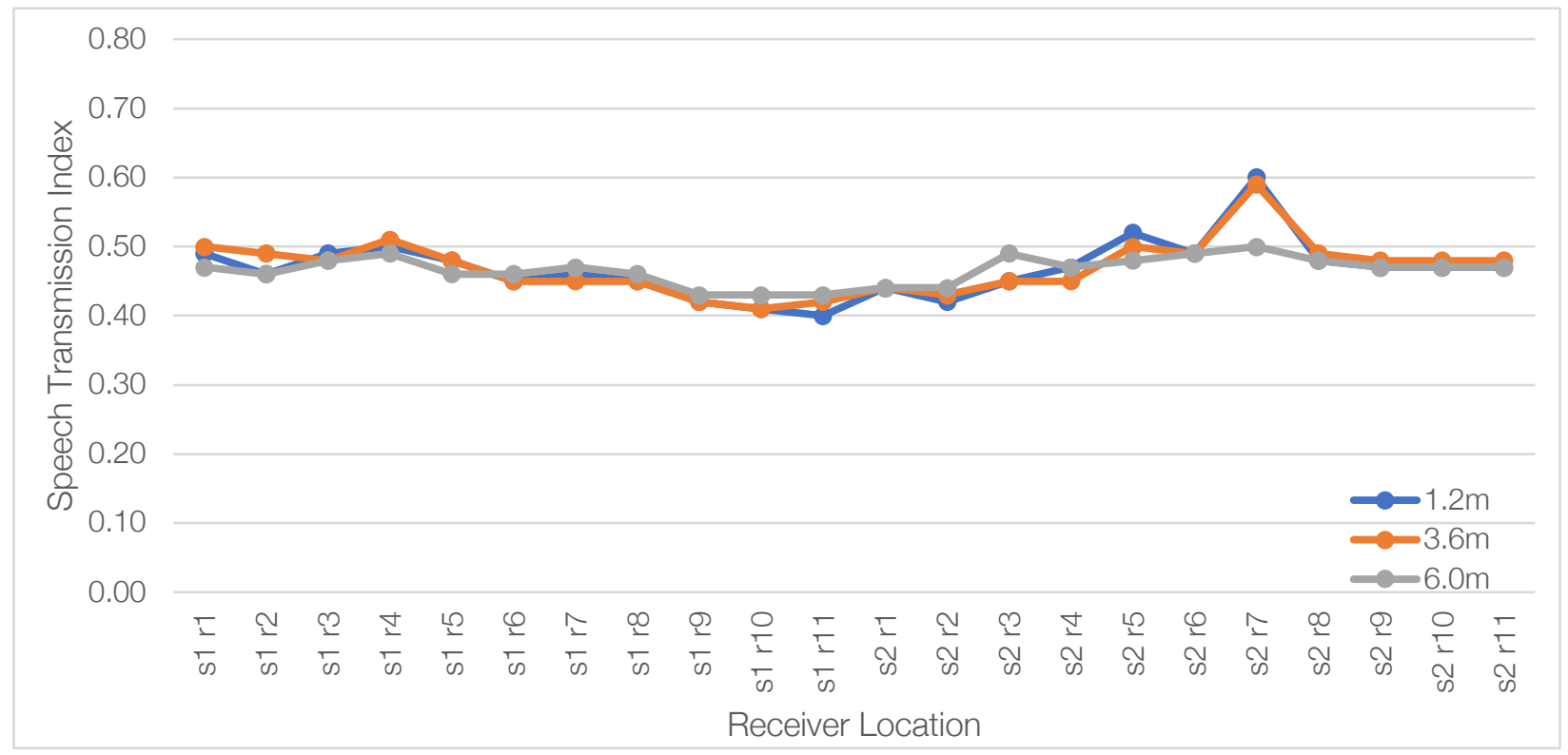

Figure 5.38: Simulated STI at 1.2m, 3.6m, and 6.0m for RAC II 


\subsubsection{Ryerson's Tecumseh Auditorium}

Table 5.25 summarizes the adjusted absorption coefficients of all the surfaces present in the digital model of Ryerson's Tecumseh Auditorium.

\begin{tabular}{l|llllllll}
\hline & $63 \mathrm{~Hz}$ & $125 \mathrm{~Hz}$ & $250 \mathrm{~Hz}$ & $500 \mathrm{~Hz}$ & $1000 \mathrm{~Hz}$ & $2000 \mathrm{~Hz}$ & $4000 \mathrm{~Hz}$ & $8000 \mathrm{~Hz}$ \\
\hline \hline Wood Floor & 0.15 & 0.15 & 0.11 & 0.10 & 0.07 & 0.06 & 0.70 & 0.70 \\
Exposed Concrete & 0.02 & 0.02 & 0.03 & 0.03 & 0.03 & 0.04 & 0.07 & 0.07 \\
Painted Concrete Block & 0.10 & 0.10 & 0.05 & 0.06 & 0.07 & 0.09 & 0.08 & 0.10 \\
Absorber Panels & 0.15 & 0.15 & 0.25 & 0.40 & 0.55 & 0.60 & 0.60 & 0.60 \\
Gypsum Board & 0.02 & 0.02 & 0.10 & 0.06 & 0.04 & 0.04 & 0.05 & 0.05 \\
HVAC [35] & 0.04 & 0.07 & 0.06 & 0.05 & 0.04 & 0.05 & 0.04 & 0.04 \\
Double Pane Glazing & 0.15 & 0.10 & 0.07 & 0.05 & 0.03 & 0.02 & 0.02 & 0.02 \\
Wooden Door & 0.14 & 0.14 & 0.10 & 0.06 & 0.08 & 0.10 & 0.10 & 0.10 \\
\hline
\end{tabular}

Table 5.25: Calibrated Material Absorption Coefficients for Tecumseh

Source 1 receiver 8 was used for model calibration; the pre and post calibration RTs are shown in Table 5.26.

\begin{tabular}{|l|l|l|l|l|l|l|l|l|}
\hline & $63 \mathrm{~Hz}$ & $125 \mathrm{~Hz}$ & $250 \mathrm{~Hz}$ & $500 \mathrm{~Hz}$ & $1000 \mathrm{~Hz}$ & $2000 \mathrm{~Hz}$ & $4000 \mathrm{~Hz}$ & $8000 \mathrm{~Hz}$ \\
\hline \hline S1 R8 measured & & 2.43 & 1.28 & 1.15 & 1.50 & 1.51 & 1.43 & 1.13 \\
\hline S1 R8 simulation & & 2.80 & 1.67 & 1.58 & 1.82 & 1.76 & 1.52 & 1.09 \\
\hline S1 R8 calibrated simulation & & 2.13 & 1.33 & 1.29 & 1.54 & 1.49 & 1.39 & 1.06 \\
\hline
\end{tabular}

Table 5.26: Calibration point T20 data for Tecumseh Auditorium

\section{Reverberation Time}

\begin{tabular}{|c|c|c|c|c|c|c|c|c|}
\hline & $63 \mathrm{~Hz}$ & $125 \mathrm{~Hz}$ & $250 \mathrm{~Hz}$ & $500 \mathrm{~Hz}$ & $1000 \mathrm{~Hz}$ & $2000 \mathrm{~Hz}$ & $4000 \mathrm{~Hz}$ & $8000 \mathrm{~Hz}$ \\
\hline Measured T20 at $1.2 \mathrm{~m}$ & 2.66 & 2.63 & 2.18 & 1.99 & 1.92 & 1.58 & 1.27 & 0.77 \\
\hline Modelled T20 at $1.2 \mathrm{~m}$ & 2.39 & 2.35 & 2.13 & 1.99 & 1.98 & 1.74 & 1.37 & 0.82 \\
\hline \% Difference & & $-10 \%$ & $-2 \%$ & $0 \%$ & $3 \%$ & $10 \%$ & $8 \%$ & $8 \%$ \\
\hline Measured T20 at 3.6m & 2.82 & 2.59 & 2.10 & 1.94 & 1.89 & 1.56 & 1.22 & 0.73 \\
\hline Modelled T20 at 3.6m & 2.37 & 2.35 & 2.11 & 1.96 & 1.93 & 1.72 & 1.38 & 0.82 \\
\hline \% Difference & & $-9 \%$ & $0 \%$ & $1 \%$ & $2 \%$ & $10 \%$ & $13 \%$ & $13 \%$ \\
\hline
\end{tabular}

Table 5.27: Comparison of measure and modelled T20 data Tecumseh Auditiorium

The T20 outputs from the simulation were all within 0.05 s of each other at both heights. The simulated data does not reflect the small change in RT at an increased height; it predicts a more uniform sound field than was measured. 


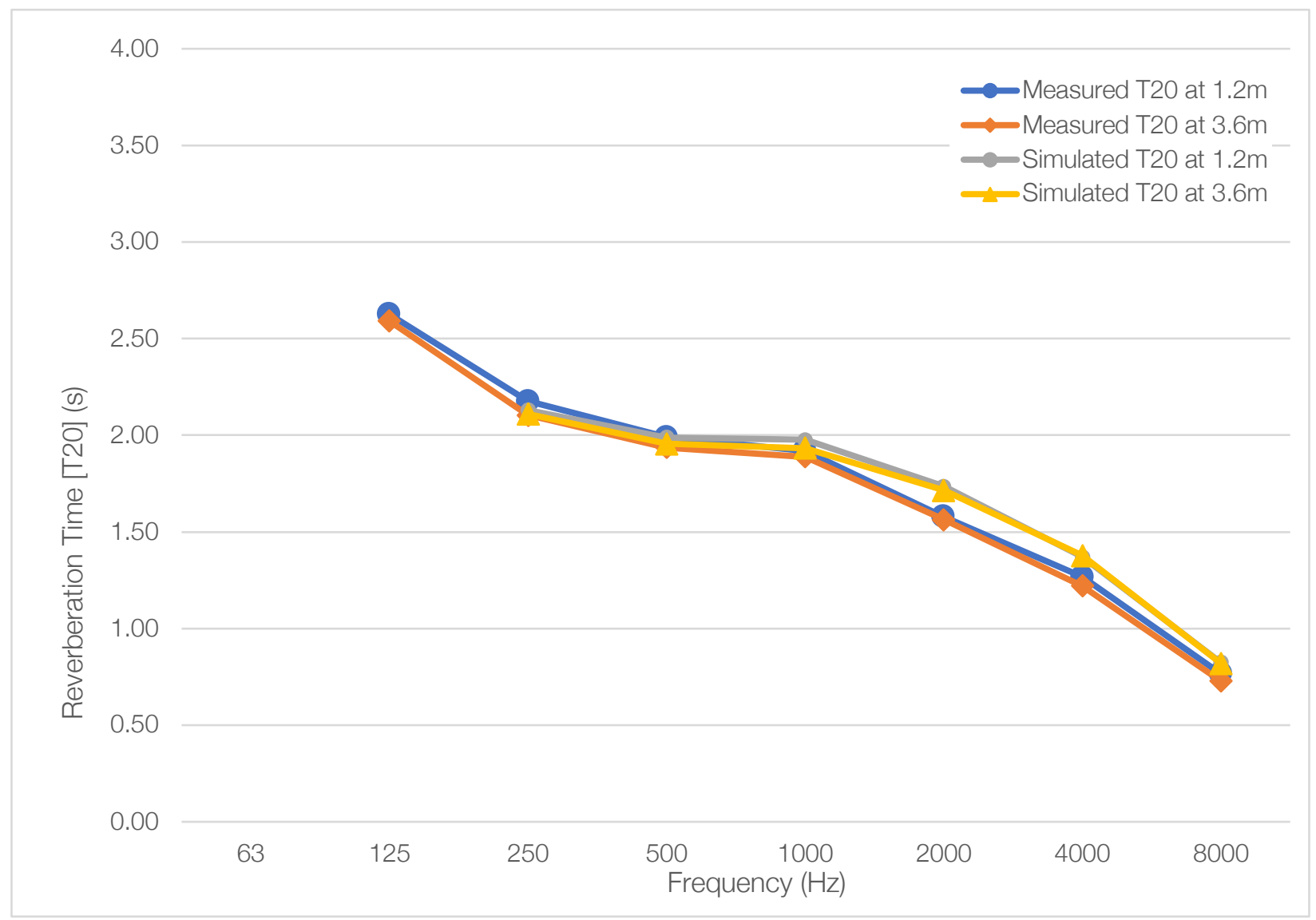

Figure 5.39: Tecumseh T20 Measured vs Simulated average

\begin{tabular}{|l|l|l|l|l|l|l|l|l|}
\hline & $63 \mathrm{~Hz}$ & $125 \mathrm{~Hz}$ & $250 \mathrm{~Hz}$ & $500 \mathrm{~Hz}$ & $1000 \mathrm{~Hz}$ & $2000 \mathrm{~Hz}$ & $4000 \mathrm{~Hz}$ & $8000 \mathrm{~Hz}$ \\
\hline \hline Stdev 1.2m & & 0.28 & 0.09 & 0.07 & 0.05 & 0.03 & 0.03 & 0.03 \\
\hline Stdev 3.6m & & 0.29 & 0.09 & 0.06 & 0.05 & 0.03 & 0.03 & 0.03 \\
\hline Modelled Stdev 1.2m & & & 0.06 & 0.06 & 0.08 & 0.06 & 0.04 & 0.02 \\
\hline Modelled Stdev 3.6m & & & 0.03 & 0.03 & 0.04 & 0.05 & 0.05 & 0.01 \\
\hline
\end{tabular}

Table 5.28: Standard deviation of all T20 data at Tecumseh Auditorium

Figures 5.40, 5.41 are plots of the T20 data at each simulated receiver point. The graphs show that there is very little variability in RT by receiver point at any frequency, which could be due to the room having a small overall size. Table 5.28 shows that the standard deviation of the data stayed consistent at all frequencies. The simulation was not able to calculate the RT at $63 \mathrm{HZ}$ and $125 \mathrm{~Hz}$ and could not simulate all points at $500 \mathrm{~Hz}$, meaning the number of reflections exceeded the computational limit of the software. 


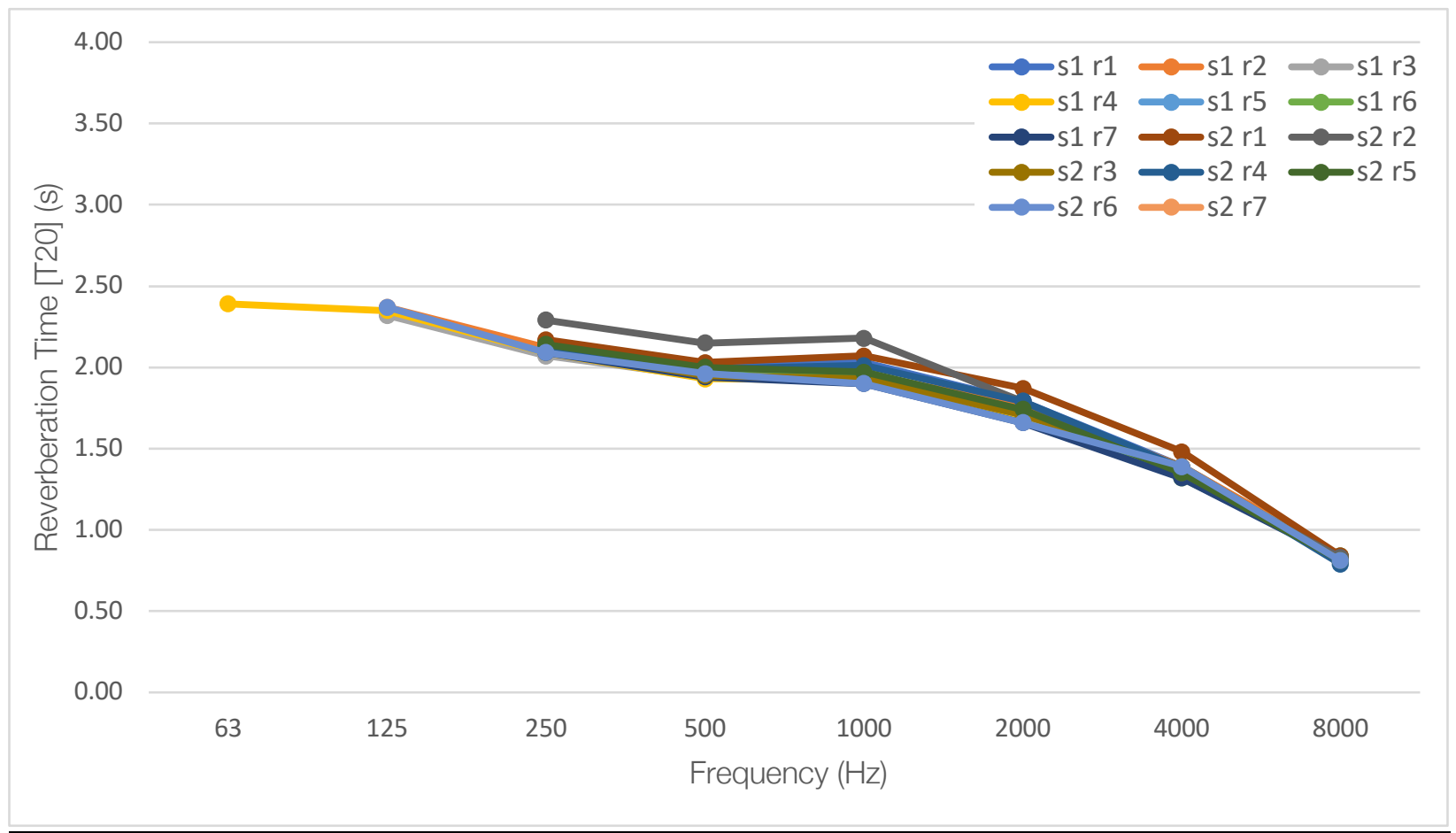

Figure 5.40: All simulated 1.2m receiver points T20 data for Tecumseh

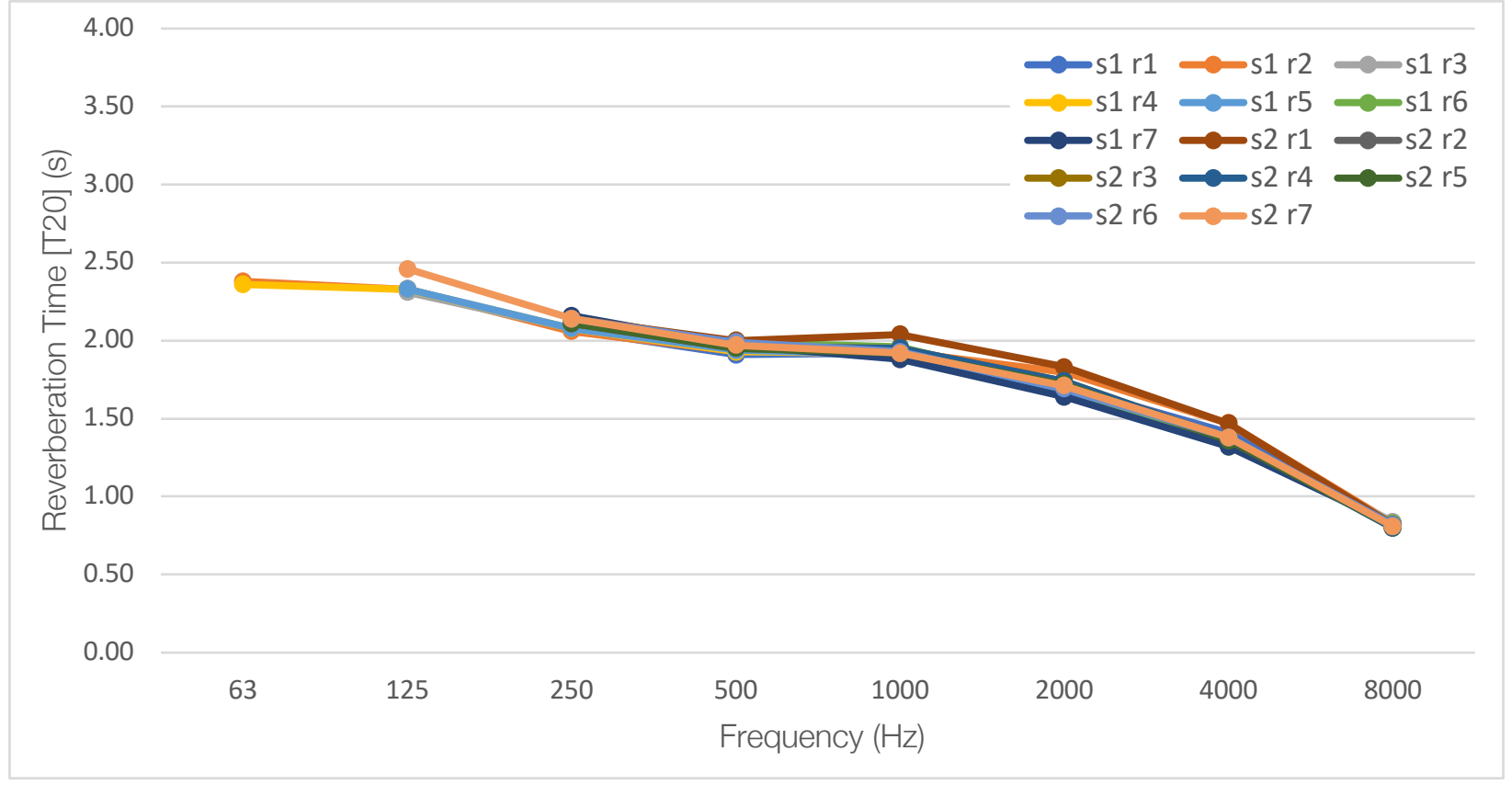

Figure 5.41: All simulated $3.6 \mathrm{~m}$ receiver points T20 data for Tecumseh 


\section{Sound Pressure Level}

Figure 5.42 show the simulated relative SPL distribution in the Tecumseh Auditorium. There is a small difference between the SPL at the two receiver heights, reaching a maximum $1 \mathrm{~dB}$ difference at any frequency. Within the respective receiver heights, SPL varies up to 4dB; there is more internal variation at higher frequencies. The Auditorium's SPL profile retains a similar shape across all frequency bands. Unlike the measured data, the simulated 3.6m SPL does not go above the $1.2 \mathrm{~m}$ SPL, while the $6 \mathrm{~m}$ data does at points furthest away from the source. 

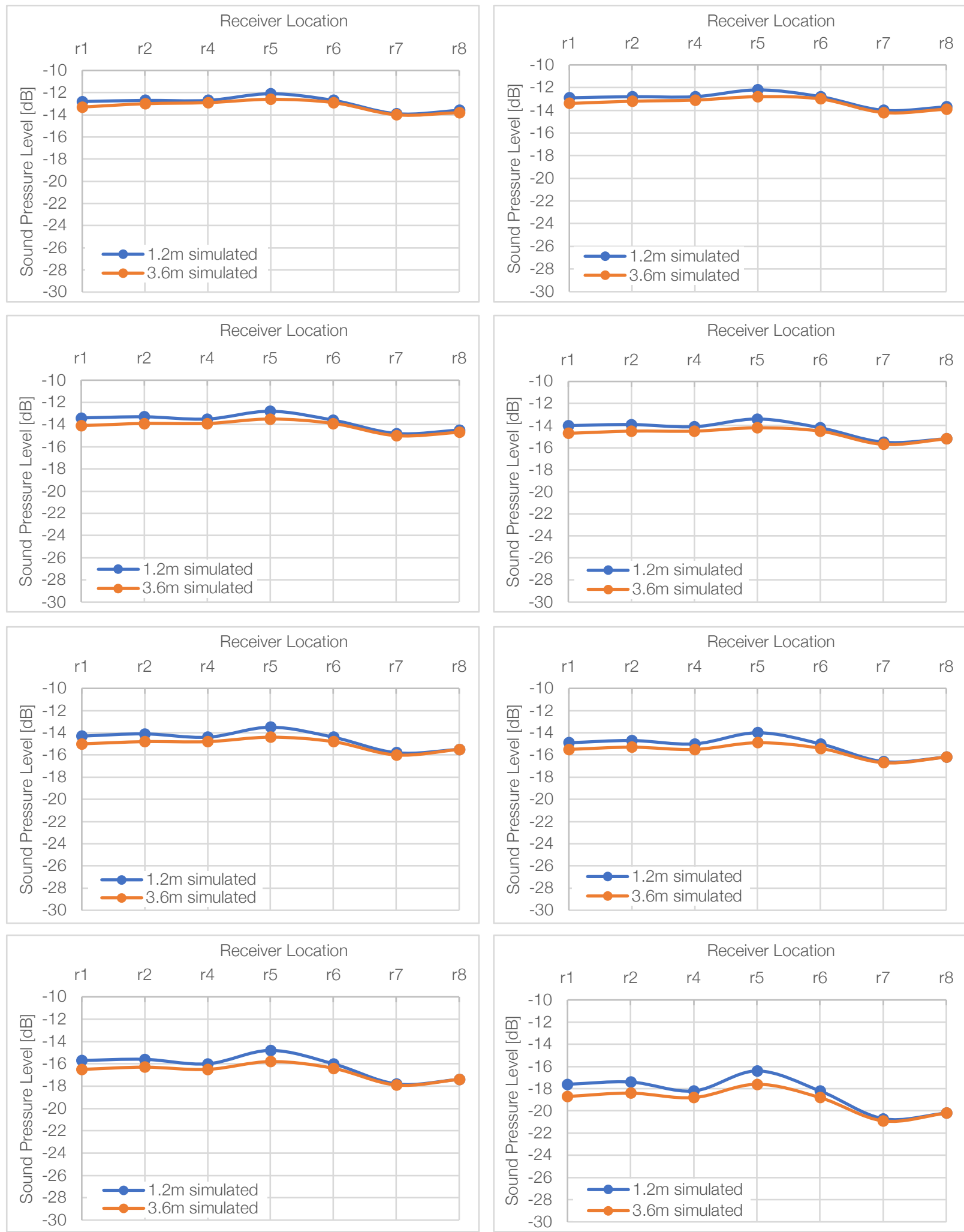

Figure 5.42: Tecumseh simulated SPL distribution for all S1 receiver points at (left to right) $63 \mathrm{~Hz}, 125 \mathrm{~Hz}$, $250 \mathrm{~Hz}, 500 \mathrm{~Hz}, 1000 \mathrm{~Hz}, 2000 \mathrm{~Hz}, 40000 \mathrm{~Hz}$, and $8000 \mathrm{~Hz}$ 


\section{Speech Transmission Index}

The simulation's output for STI was 0.50 at $1.2 \mathrm{~m}$ and 0.49 at $3.6 \mathrm{~m}$ while the measured data was 0.49 and 0.50 respectively. The model over-predicted STI by $1 \%$ at the ISO 3382 height but confirmed that the model meets CAM standards for the STI metric.

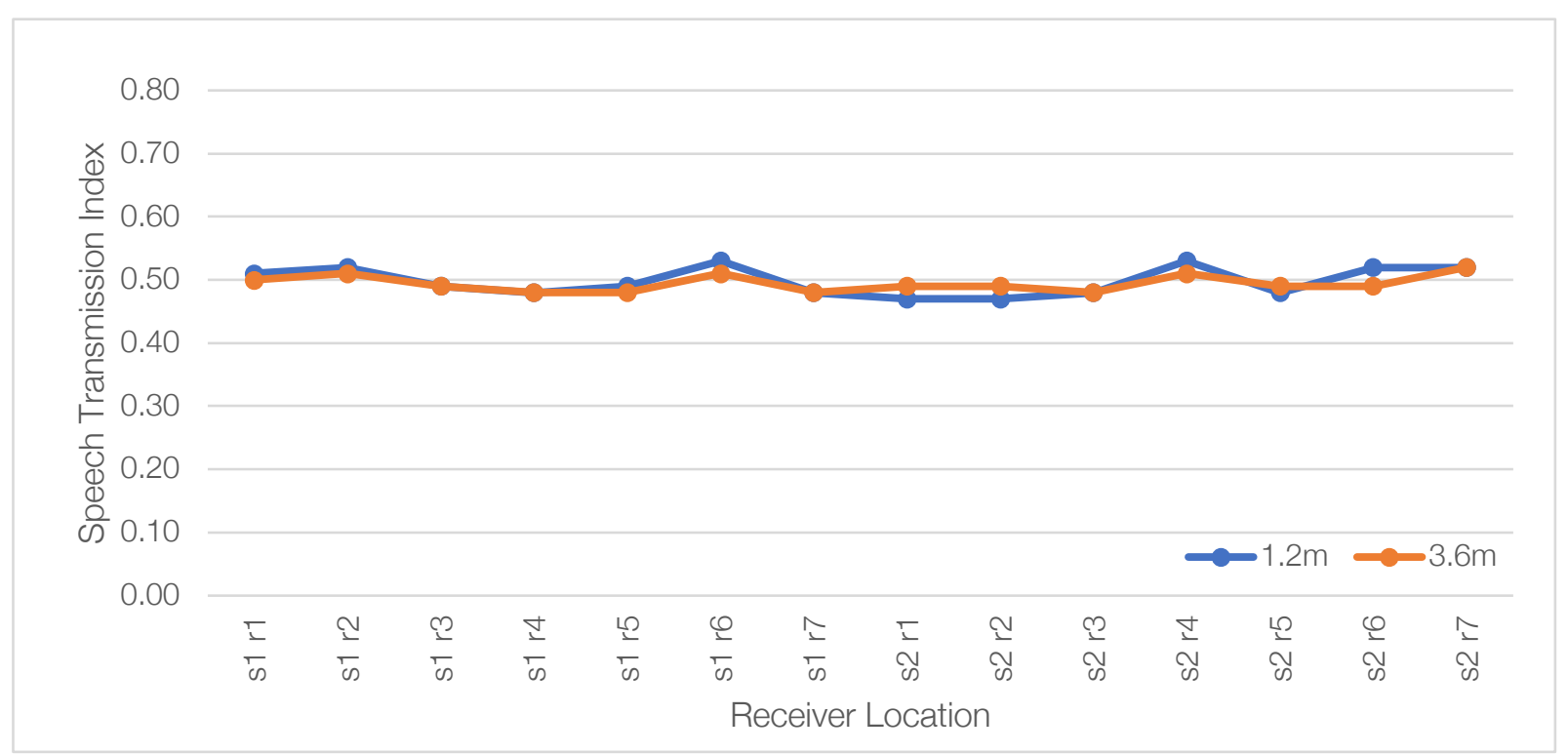

Figure 5.43: Simulated STI at $1.2 \mathrm{~m}$ and $3.6 \mathrm{~m}$ for Tecumseh 


\subsection{Simulation Results - With Perimeter Band Absorbers}

The second stage of the simulation investigation is to add perimeter absorption to the two gyms without acoustical treatments to see if the simulations predict a similar scenario as the Packer and Faszer paper, i.e. Increased variability in the sound field.

\subsubsection{Ryerson Athletic Centre Gym II}

\section{$\underline{\text { Reverberation Time }}$}

Figure 5.44 shows that the model does not predict a stratification of the sound field with the addition of absorbers. The simulated RT averages for the three heights are within $1 \%$ of each other and the standard deviation of all the receiver point data is the same as before.

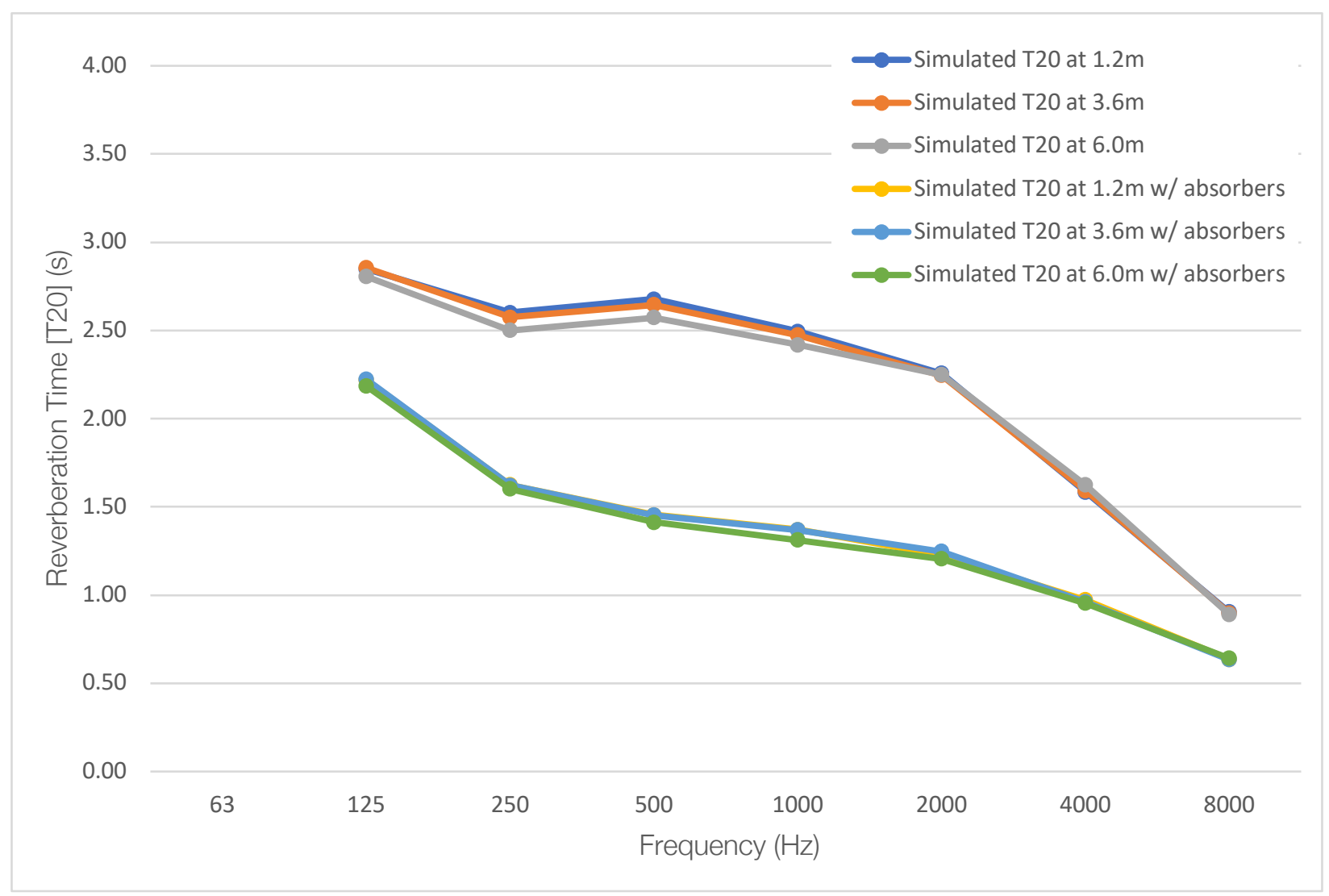

Figure 5.44: RAC II T20 simulated with and without absorption for $1.2 \mathrm{~m}, 3.6 \mathrm{~m}$, and $6.0 \mathrm{~m}$ 
Figures $5.45,5.46$, and 5.47 are plots of the T20 data at each simulated receiver point after the addition of absorbers in a perimeter band around the top half of the gym. The graphs show that the absorbers have mainly reduced the variability in $\mathrm{RT}$ at $250 \mathrm{~Hz}$ and $500 \mathrm{~Hz}$.

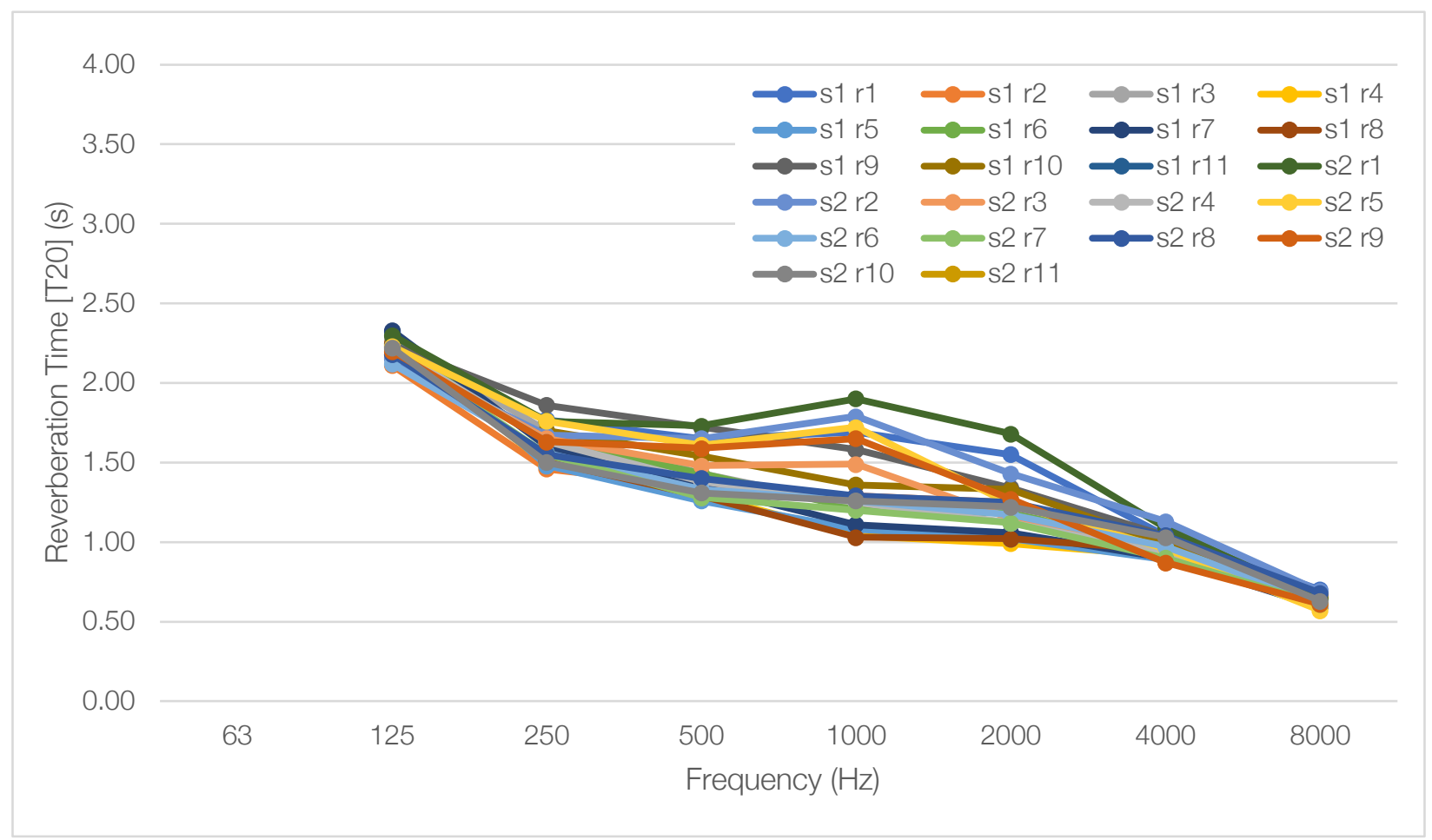

Figure 5.45: RAC II T20 all receiver points simulated with absorption for $1.2 \mathrm{~m}$ 


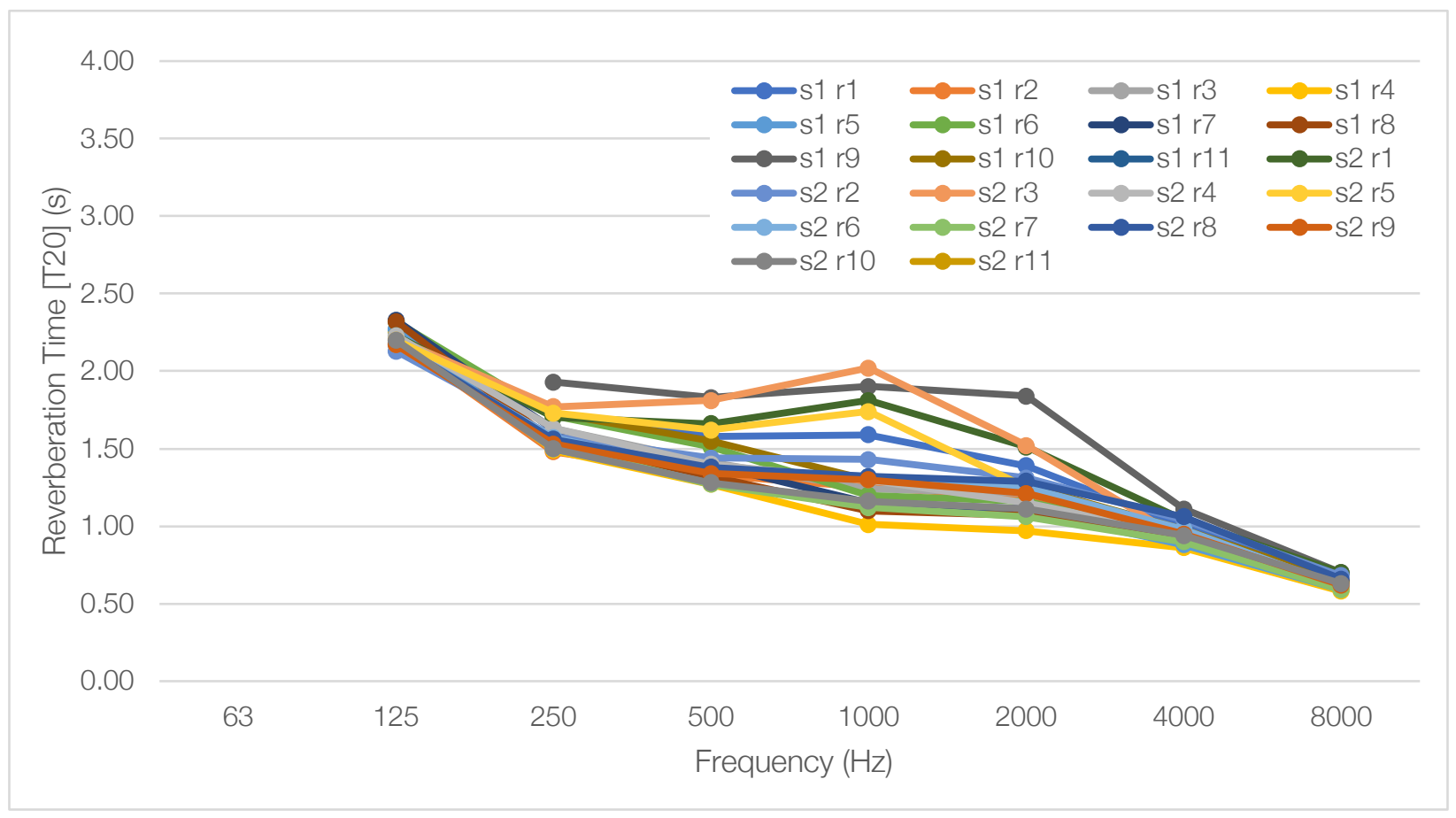

Figure 5.46: RAC II T20 all receiver points simulated with absorption for $3.6 \mathrm{~m}$

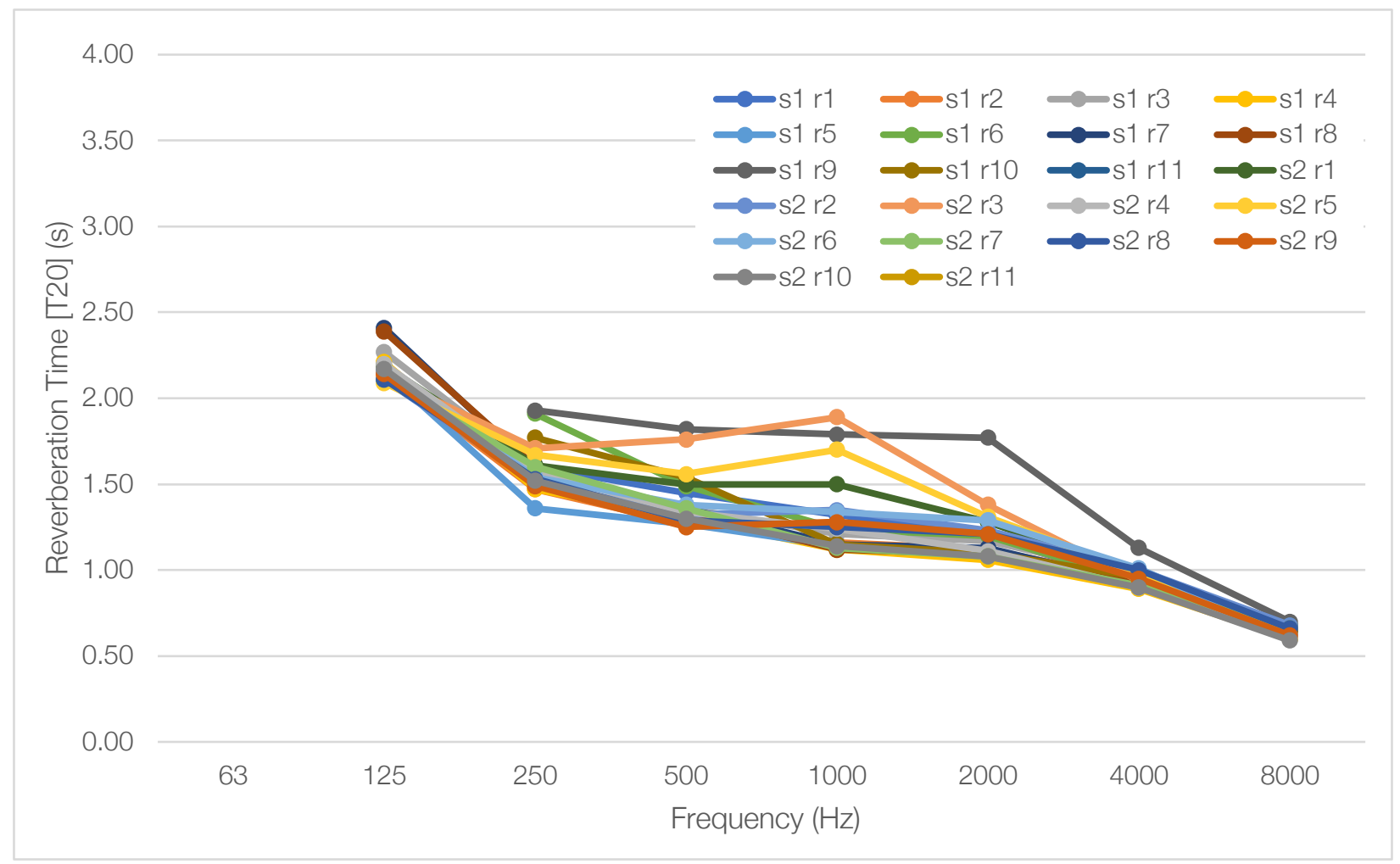

Figure 5.47: RAC II T20 all receiver points simulated with absorption for 6.0m 


\section{Sound Pressure Level}

The simulation predicts that the SPL profile of the RAC II gymnasium with absorbers is much more highly varied than if it had no absorbers. This would likely be due to absorbers reducing the overall SPL while proximity to the sound source keeps SPL high for points 5 and 6 . Since the simulations cannot predict interference patterns, the variability can be entirely attributed to general attenuation by absorption and air resistance. 


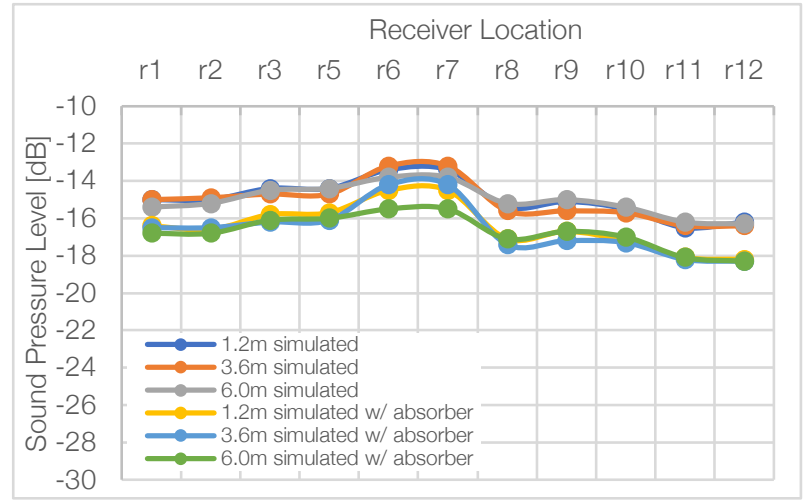

Receiver Location

$\begin{array}{lllllllllll}r 1 & \text { r2 } & \text { r3 } & \text { r5 } & \text { r6 } & \text { r7 } & \text { r8 } & \text { r9 } & \text { r10 } & \text { r11 } & \text { r12 }\end{array}$

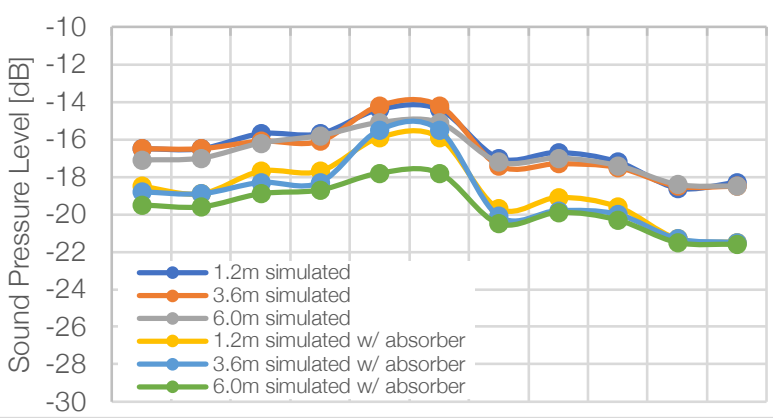

Receiver Location

$\begin{array}{lllllllllll}r 1 & \text { r2 } & \text { r3 } & \text { r5 } & \text { r6 } & \text { r7 } & \text { r8 } & \text { r9 } & \text { r10 } & \text { r11 } & \text { r12 }\end{array}$

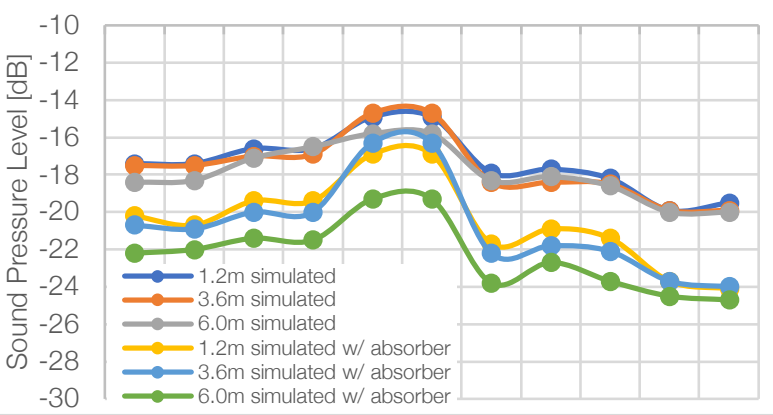

Receiver Location
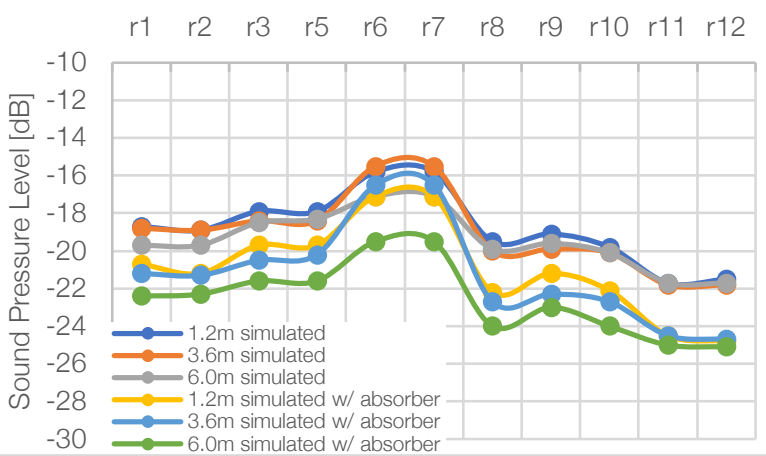

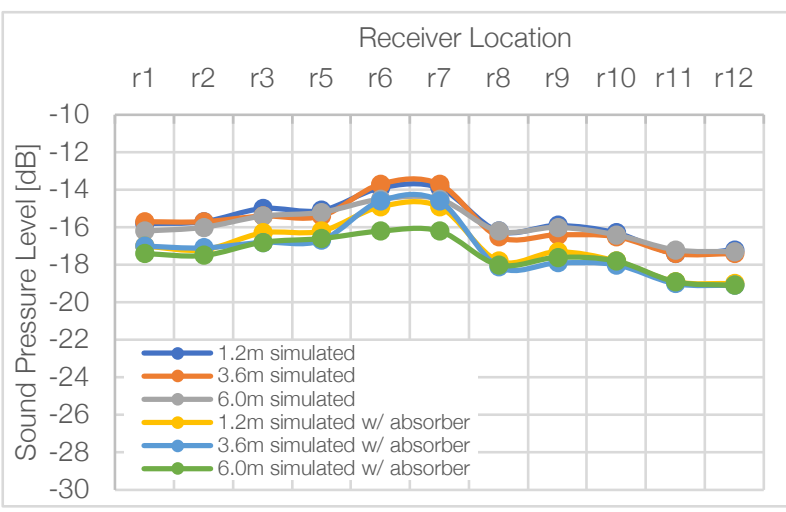

Receiver Location

$\begin{array}{lllllllllll}r 1 & \text { r2 } & \text { r3 } & \text { r5 } & \text { r6 } & \text { r7 } & \text { r8 } & \text { r9 } & \text { r10 } & \text { r11 } & \text { r12 }\end{array}$

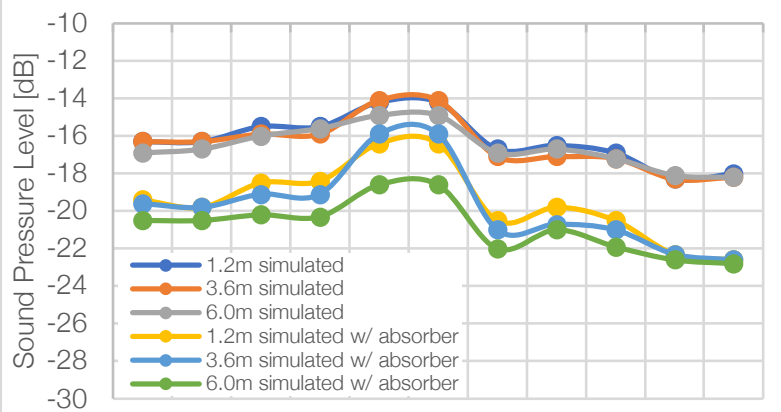

Receiver Location
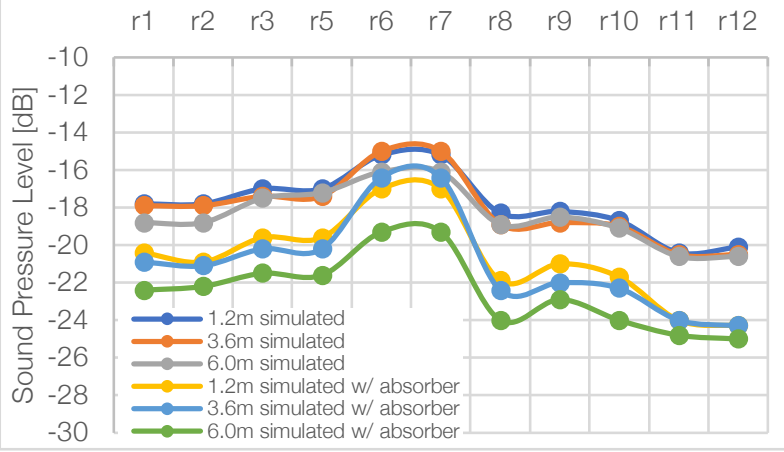

Receiver Location

$\begin{array}{lllllllllll}r 1 & \text { r2 } & \text { r3 } & \text { r5 } & \text { r6 } & \text { r7 } & \text { r8 } & \text { r9 } & \text { r10 } & \text { r11 } & \text { r12 }\end{array}$

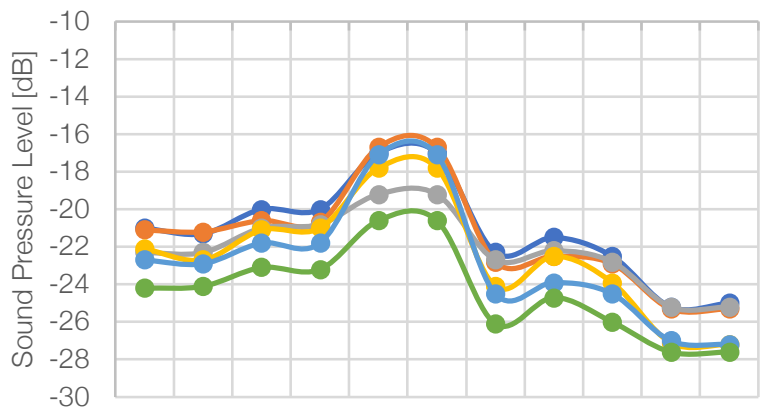

Figure 5.48: RAC II simulated SPL distribution with and without absorption at (left to right) $63 \mathrm{~Hz}, 125 \mathrm{~Hz}$, $250 \mathrm{~Hz}, 500 \mathrm{~Hz}, 1000 \mathrm{~Hz}, 2000 \mathrm{~Hz}, 40000 \mathrm{~Hz}$, and $8000 \mathrm{~Hz}$ 


\subsubsection{Tecumseh Auditorium}

\section{$\underline{\text { Reverberation Time }}$}

Figure 5.49 shows that the model does not predict a decrease in the diffuseness of the sound field with the addition of absorbers. The simulated RT averages for the three heights are within $1 \%$ of each other. The standard deviation of all the receiver point data is higher than before but not by a significant amount.

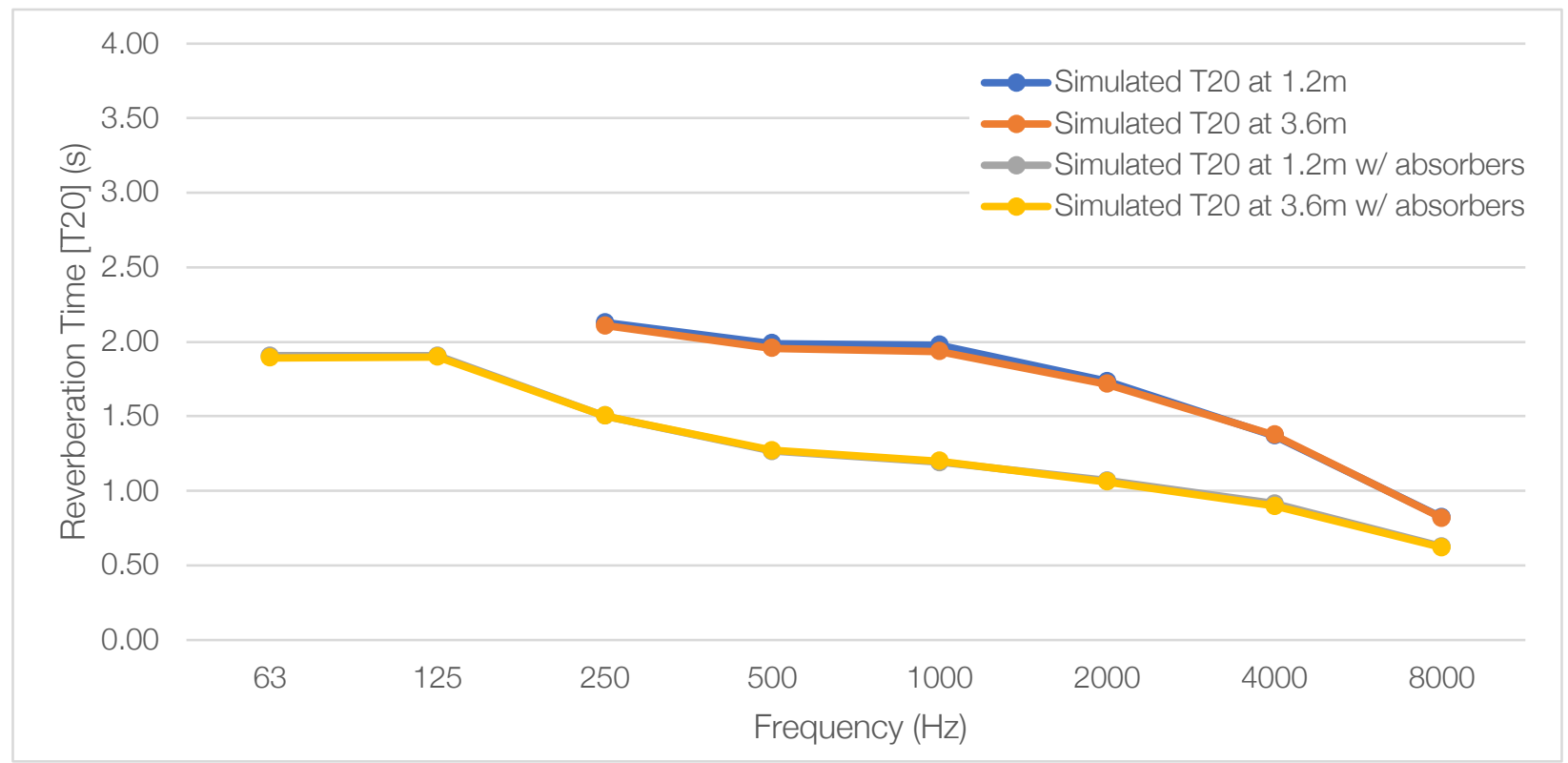

Figure 5.49: Tecumseh T20 simulated with and without absorption for $1.2 \mathrm{~m}$ and $3.6 \mathrm{~m}$

Figures 5.50 and 5.51 are plots of the T20 data at each simulated receiver point after the addition of absorbers in a perimeter band around the top half of the gym. The graphs show that the absorbers have maintained the variability in RT across all frequencies. With the addition of absorbers, the software was able to simulate a RT for $63 \mathrm{~Hz}$ and $125 \mathrm{~Hz}$. 


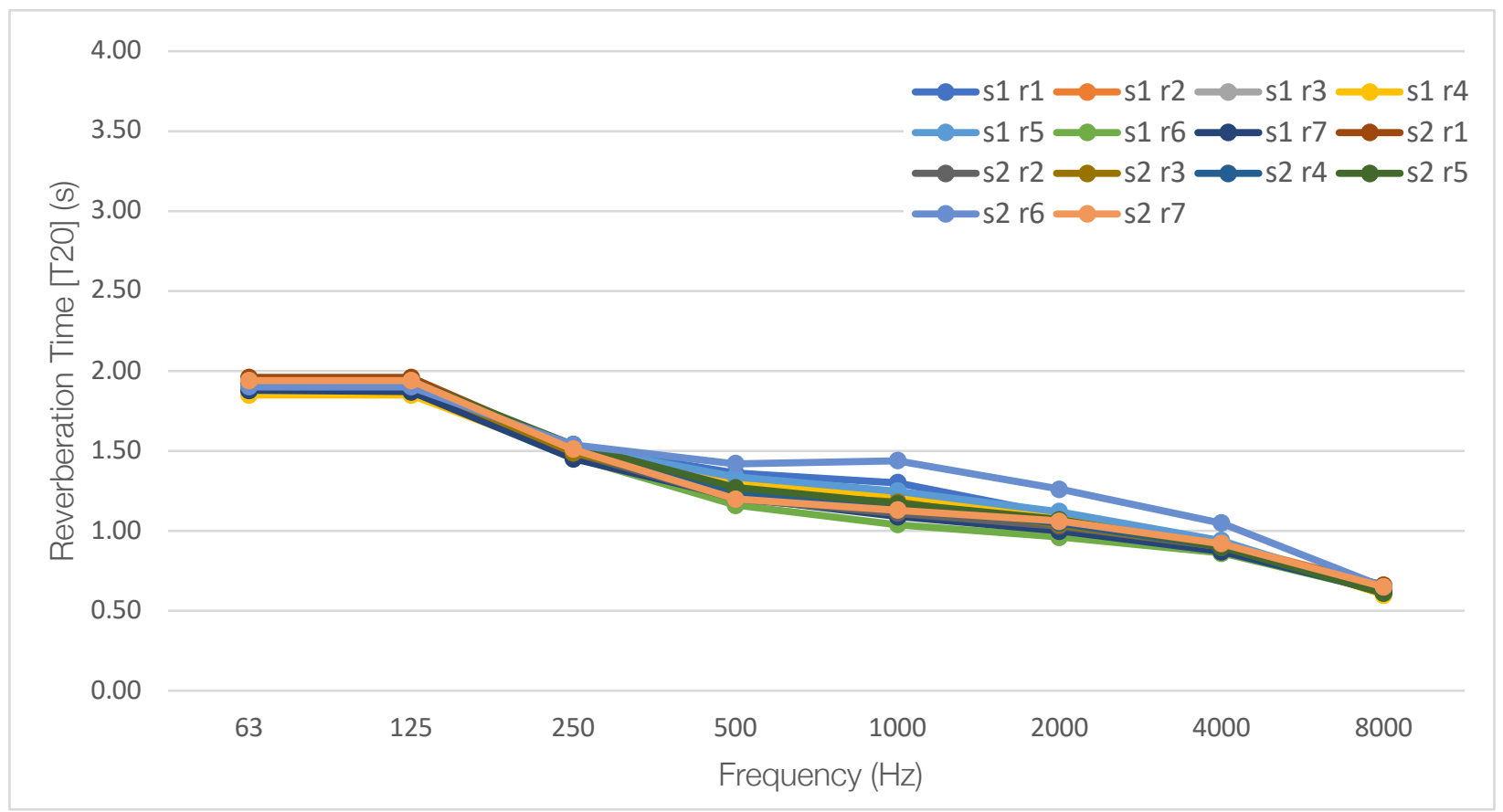

Figure 5.50: Tecumseh T20 all receiver points simulated with absorption for $1.2 \mathrm{~m}$

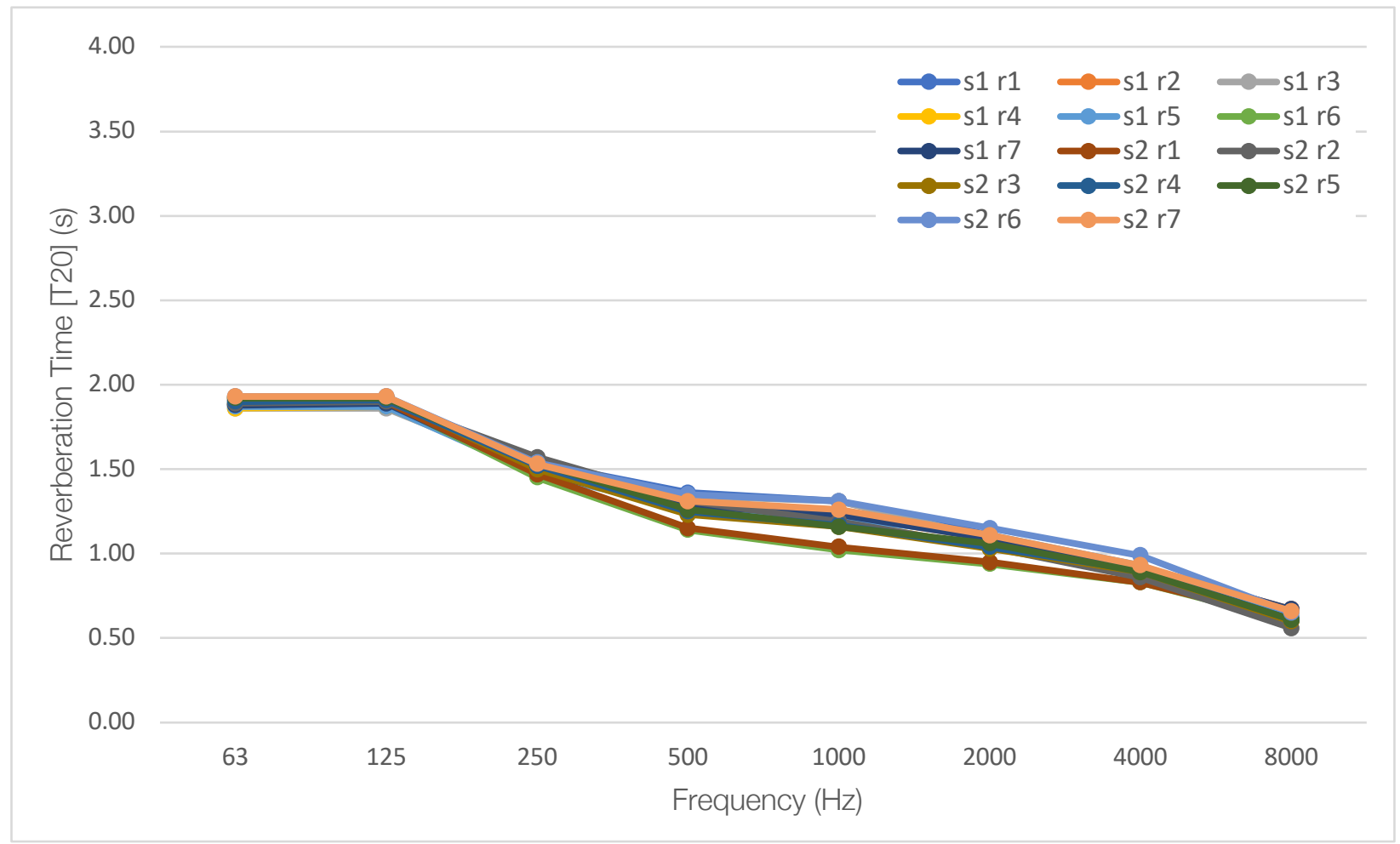

Figure 5.51: Tecumseh T20 all receiver points simulated with absorption for $3.6 \mathrm{~m}$ 


\section{Sound Pressure Level}

The simulation predicts that the effect of absorbers on the SPL profile of the Tecumseh Auditorium is a lowering of the overall SPL across the board, with a 1-2dB increase in the difference between the $1.2 \mathrm{~m}$ and $3.6 \mathrm{~m}$ SPL data. The simulation can predict a slight increase in variability that would be indicative of an increasingly stratified sound field, however not to the same degree that the field measurements indicate. This was only achievable in Tecumseh which is about half the size of RAC II. This could be due to the source-receiver distance dominating the loss of pressure in RAC, whereas the overall distance to the receiver in Tecumseh is much smaller. As a result, the drop in pressure in Tecumseh is more dominated by the proximity to absorbers. 

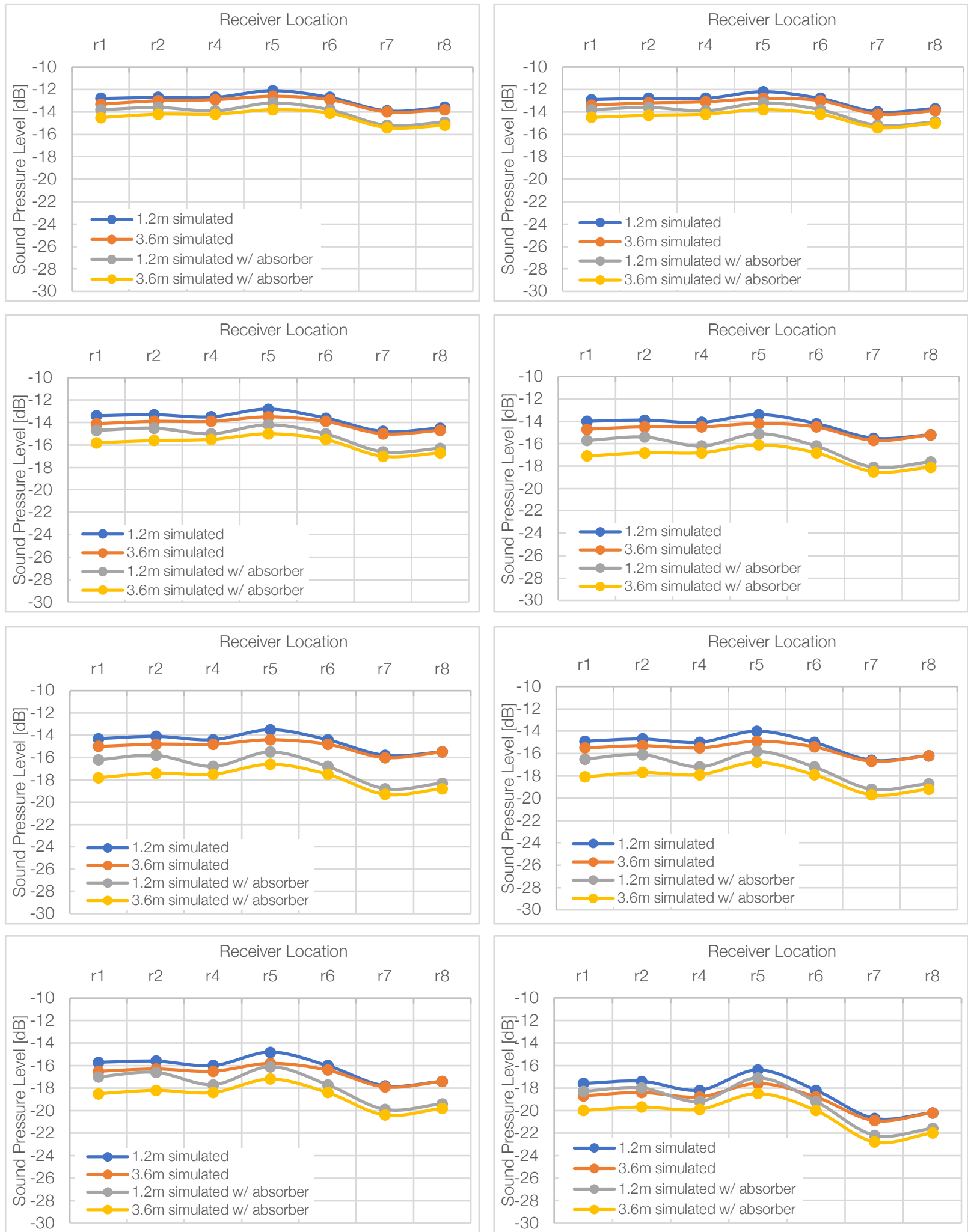

Figure 5.52: Tecumseh simulated SPL distribution with and without absorption at (left to right) 63Hz, $125 \mathrm{~Hz}, 250 \mathrm{~Hz}, 500 \mathrm{~Hz}, 1000 \mathrm{~Hz}, 2000 \mathrm{~Hz}, 40000 \mathrm{~Hz}$, and $8000 \mathrm{~Hz}$ 


\section{Analysis}

\subsection{Reverberation Time}

Royal St Georges College and Gabrielle Roy both had the most variation in measured RT times at the two different receiver heights between $1000-8000 \mathrm{~Hz}$. Both gyms have extensive absorption surfaces with their absorption profiles in the mid-to-high frequency range. As is shown by figure 6.1 , RT went down by an average of $5 \%$ and $9 \%$ respectively at the $3.6 \mathrm{~m}$ receiver height between $1000 \mathrm{~Hz}$ and $8000 \mathrm{~Hz}$. This is likely because neither gym had absorbers in the bottom half on thy gym but did have absorbers on the upper half of the walls. This indicates that the presence of absorbers caused sound propagating in the top half of the gym to dissipate slightly faster than that reflecting in the bottom half.

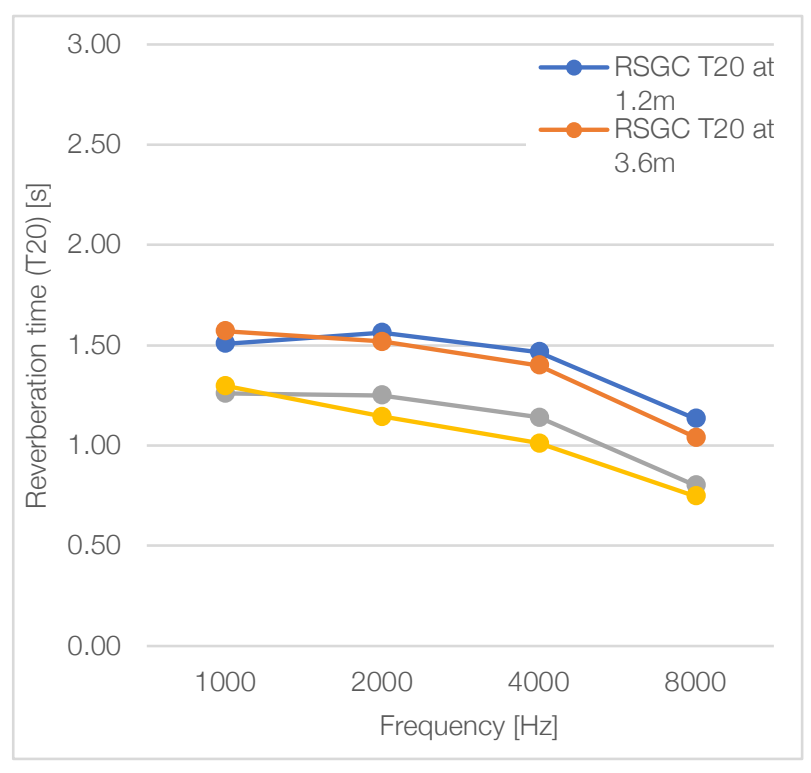

Figure 6.1: RT for RSGC and Gabrielle Roy

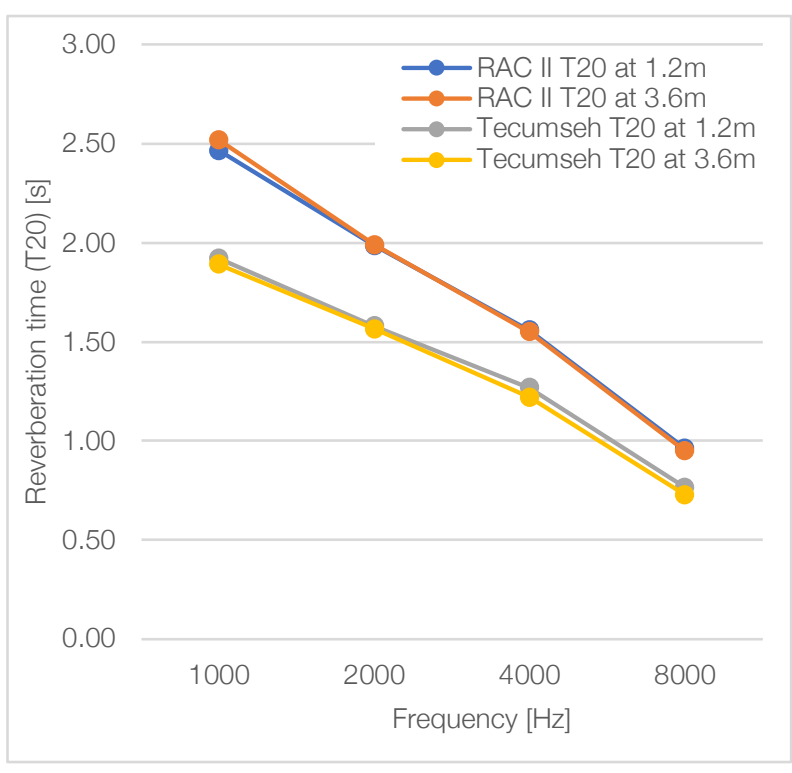

Figure 6.2: RT for RAC II and Tecumseh

Conversely, the measured data for the gyms with very little absorption showed RT averages that diverged at frequencies under $1000 \mathrm{~Hz}$, although it was to a small degree $(0.13$ seconds difference in RAC II- and 0.06 seconds difference in Tecumseh). Because of the experimental 
variability at low frequencies and the difficulty collecting reliable RTs below $125 \mathrm{~Hz}$, no conclusions can be drawn from this discrepancy. At higher frequencies, the RTs at both $1.2 \mathrm{~m}$ and $3.6 \mathrm{~m}$ were within $1 \%$ of each other. The difference in RT at different heights for the gyms with absorbers and the lack of difference in RT for those without suggests that absorbers in the upper half of the gym do cause at least some stratification of the sound field. This confirms what Dalenbäck presented in [4] and what Packer and Faszer posited [1].

Unlike the measured data, the simulations showed RTs within $1 \%$ at each height for all four gyms and the gyms where absorption was added in the software. The software consistently generated RT's by receiver point that were more varied than the measured data which indicates that it predicted a less diffuse sound field than the measured one. However, the lack of difference between the averages indicates that it cannot predict the stratification that occurs. Although the difference in the measured RT at the different heights for the gyms with absorbers is relatively small, within $5-10 \%$, it does suggest that the stratification caused by perimeter absorbers could substantially affect RTs of a gym in a way that the software can't predict. This partially explains the problems in the Packer and Faszer paper, namely that the RT was higher than predicted until surfaces were introduced that would scatter the sound field in the lower half of the gym. 


\subsection{Sound Pressure Level}

Figure 6.2 shows the SPL distribution at $500 \mathrm{~Hz}$ and $1000 \mathrm{~Hz}$ for all four gyms. These frequencies were chosen because they give a good overall representation of the trends observed in the data and are the most common frequencies where the $3.6 \mathrm{~m}$ SPL becomes higher pressure than the $1.2 \mathrm{~m} \mathrm{SPL}$. The gyms generally have higher relative $\mathrm{dB}$ readings at points close to the receivers, with inconsistent SPL distribution by receiver point from one frequency to the next. This is especially pronounced at low frequencies. This strongly suggests that there is interference between the reflected signals that causes a pattern of higher and lower pressure at different frequencies. RSGC and Gabrielle Roy, both heavily treated with absorbers, had SPL field data where the $3.6 \mathrm{~m}$ SPLs exceed the $1.2 \mathrm{~m} \mathrm{SPL}$ at lower frequencies than the untreated gyms, at $125 \mathrm{~Hz}$ and $250 \mathrm{~Hz}$ respectively. However, the inversion did not stay consistent or increase with frequency like it with the untreated rooms. A finite element analysis of the gyms at lower frequencies would help inform why this phenomenon was observed I the gyms with absorbers and not the untreated gyms.

Figure 6.3 shows the simulated SPL distribution at $500 \mathrm{~Hz}$ and $1000 \mathrm{~Hz}$. In all four gyms, the measured SPL was much more variable than that which was simulated. This enforces that the irregularities are caused by interference, as the ray-based software cannot simulate wave interference. The plot that was the most similar between the measured and simulated Gabrielle Roy gymnasium which has the advantage of being 1) relatively small and 2) heavily covered in absorbers. 

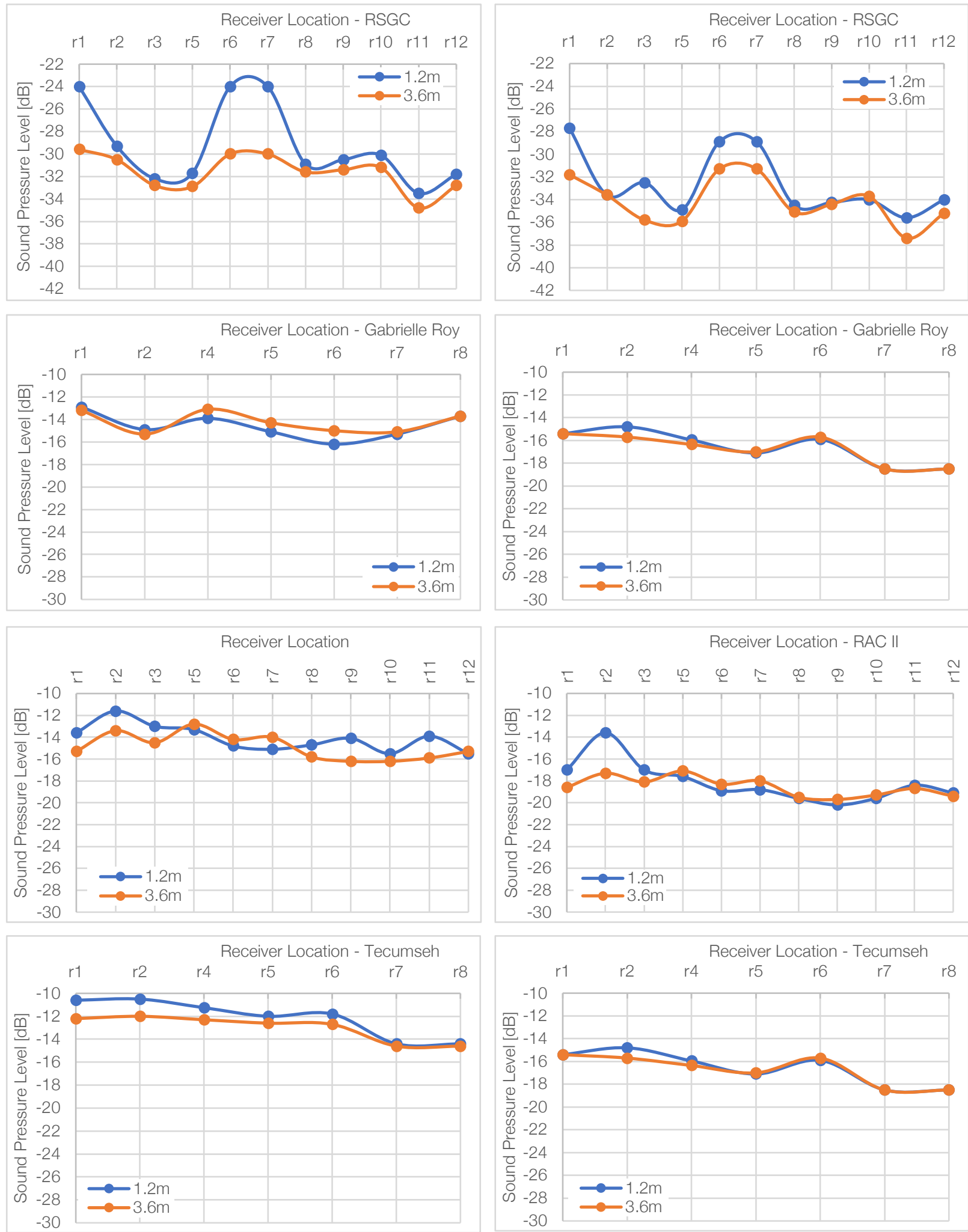

Figure 6.3: SPL distribution for $500 \mathrm{~Hz}$ (right) and 1000Hz (left) for (top to bottom) RSGC, Gabrielle Roy, RAC II and Tecumseh 

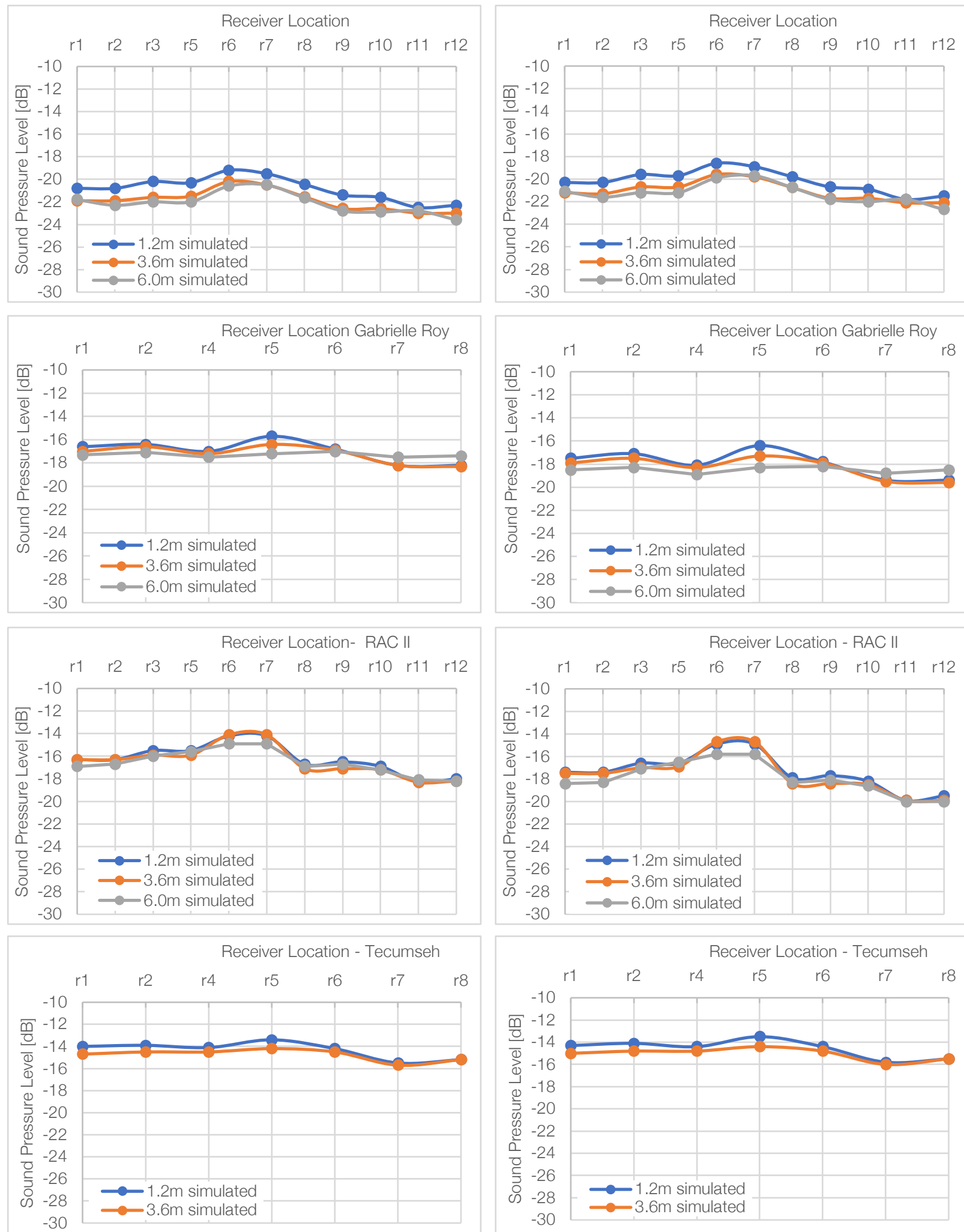

Figure 6.4: SPL distribution for $500 \mathrm{~Hz}$ (right) and 1000Hz (left) for (top to bottom) RSGC, Gabrielle Roy, RAC II and Tecumseh 


\subsection{Speech Transmission Index}

The main component of indirect full STI is the normalized modulated function, which account for all the distortion measured when comparing the signal sent to the signal received. This term is then modified by $1+$ the linear noise-to-signal ratio, which accounts for background noise. In the simulations, STI requires that background noise be included in room set-up. The background noise profile of the rooms is collected below in Table 6.1. Despite a low background noise, all four gyms had STIs between 0.48 and 0.51 , which would be consider fair for speech intelligibility. One of the problems in characterizing school gymnasia with STI is that the background noise level goes up drastically when a gym is being used for physical activity a typical value being $78 \mathrm{~dB}$ [36]. Had the gyms been measured while occupied, the difference in STI might have been greater between the treated and untreated gyms.

\begin{tabular}{|c|c|c|c|c|c|c|c|c|}
\hline & $63 \mathrm{~Hz}$ & $125 \mathrm{~Hz}$ & $250 \mathrm{~Hz}$ & $500 \mathrm{~Hz}$ & $1000 \mathrm{~Hz}$ & $2000 \mathrm{~Hz}$ & $4000 \mathrm{~Hz}$ & $8000 \mathrm{~Hz}$ \\
\hline \multicolumn{9}{|c|}{ RSGC } \\
\hline Background Noise [dB] & 29 & 31 & 34 & 37 & 35 & 33 & 29 & 24 \\
\hline \multicolumn{9}{|c|}{ Gabrielle Roy } \\
\hline Background Noise [dB] & 32 & 35 & 38 & 38 & 39 & 35 & 29 & 25 \\
\hline \multicolumn{9}{|c|}{ RAC II } \\
\hline Background Noise [dB] & 15 & 19 & 28 & 30 & 28 & 26 & 25 & 24 \\
\hline \multicolumn{9}{|c|}{ Tecumseh } \\
\hline Background Noise [dB] & 20 & 23 & 26 & 27 & 26 & 26 & 25 & 25 \\
\hline
\end{tabular}

Table 6.1: Background noise profile of all four gyms

Unlike SPL and RT, STI is measured and modeled as a single number; the product of an average over all frequency bands. This metric could be more useful if it was expanded to be specific to each octave band, as some frequencies are more critical for intelligibility than others. Another limitation of STI is that scale on which speech transmission is gauged is not very specific; anything falling in the range of $0.45-0.60$ is considered "fair". All four gyms fell within this range despite the RAC II and Tecumseh Auditorium having subjectively bad acoustics and reverberation times that far exceeded CAM and Alberta standards for gymnasia. 


\section{Conclusions}

The current investigation found that the reverberation time, sound pressure level, and speech transmission index do change with height of the receiver. Perimeter absorbers stratify the sound field in such a way that causes sound to dissipate faster in the treated portion of the gym. This partially accounts for the discrepancy between the predicted and post-absorberinstallation RTs studied in the Packer and Faszer paper. SPL distribution showed evidence of interference patterns in the gyms which, while not directly cause by the perimeter absorbers, would be reduced by the installation of absorbers or scattering in the lower half of the gym. This also explains why volume scattering fixed the discrepancy in RT in the Packer and Faszer paper. While the STI does change with height, is requires further investigation done with occupied sound levels to draw significant conclusions.

The computer simulations were found to adequately predict the average RTs; however, they did not reflect the difference caused by the presence of absorbers when compared to the field data or when absorption was added to the simulation. The simulations consistently had a higher variation in the data when compared to the field data, indicating that the software assumes a less diffuse sound field but does not reflect the stratifying effect of a perimeter band of absorbers. With SPL distribution, the software did not simulate the presence of interference since it is a ray-based software and cannot do finite element analysis. STI was reliably predicted by the simulation. 


\section{Works Cited}

[1] K. Packer and C. Faszer, "Reverberation Measurement and Prediction in Gymnasia with Non-Uniformly Distributed Absorption; The Importance of Diffusion," Canadian Acoustics, vol. 39, no. 4, pp. 47-53, 2011.

[2] W. J. Gastmeier and D. R. Aitken, "Reverberation in Gymnasia," Canadian Acoustics, vol. 4, no. 27, pp. 3-7, 1999.

[3] K. Anathaganeshan and W. Gastmeier, "Acoustical Performance Criteria, Treatments and Guidelines for Multifunctional School Gymnasia," Canadian Acoustics , vol. 4, no. 35, pp. 25-30, 2007.

[4] B. Dalenback, "Reverberation Time, Diffuse Reflection, Sabine, and Computerized Prediction, Parts I \& II (web article)," RPG Diffusor Systems, Inc, 2000.

[5] S. Bistafa and J. Bradley, "Predicting Reverberation Times in a Simulated Classroom," The Journal of the Acoustical Society of America, vol. 4, no. 108, pp. 1721-1731, 2000.

[6] Acoustical Society of America, "ANSI/ASA S12.60-2010/Part 1 American National Standard Acoustical Performance Criteria, Design Requirements, and Guidelines for Schools," Acoustical Society of America, 2010.

[7] Alberta Infrastructure and Transportation, "Standards and Guidelines for School Facilities," Goverment of Alberta, 2007.

[8] ISO 3382 - 2:2008, Acoustics - Measurement of room acoustic parameters, Switzerland: ISO, 2008.

[9] H. Kutruff, Room Acoustics, London: Spon Press, 2000.

[10] T. Cox and P. D'Antonio, Acoustic Absorbers and Diffusers: Theory, Design and Application, New York: Taylor and Francis, 2009.

[11] IEC, BS EN 60268-16:2011, BSI Standards, 2012.

[12] S. J. V. Wijngaarden and J. A. Verhave, "Speech intelligibility measurements in practice Obtaining accurate and reliable data using STIPA tools," Embedded Acoustics, Delft, 2014.

[13] M. Vorländer, "Computer Simulations in Room Acoustics: Concepts and Uncertainties," The Journal of the Acoustical Society of America, no. 133, pp. 1203-1212, 2013.

[14] B. F. Katz, "International Round Robin on Room Acoustical Impulse Response Analysis Software," Acoustics Research Letters Online, vol. 5, no. 4, pp. 158-164, 2004.

[15] Y. Lam, "A Comparison of Three Diffuse Reflection Modelling Methods Used in Room Acoustics Computer Models," The Journal of the Acoustical Society of America, vol. 100, no. 4, pp. 2181-2192, 1996.

[16] C. Christensen, "A New Scattering Method that Combines Roughness and Diffraction Effects," ODEON A/S, 2005.

[17] L. Savioja and U. P. Svensson, "Overview of Geometric Room Acoustic Modelling Techniques," The Journal of the Acoustical Society of America, vol. 2, no. 138, pp. 708730, 2015. 
[18] M. Howarth and Y. Lam, "an Assessment of the Accuracy of a Hybrid Room Acoustics Model with Surface Diffusion Facility," Applied Acoustics, no. 60, pp. 237-251, 2000.

[19] E. Deines, M. Bertram, J. Mohring, J. Jegorovs, F. Michel, H. Hagen and G. M. Nielson, "Comparative Visualization for Wave-based and Geometric Acoustics," Transactions on Visualisation and Computer Graphics, vol. 12, no. 5, pp. 1173-1180, 2006.

[20] C. Visentin, N. Prodi, V. Valeau and J. Picaut, "Experimental Analysis of the Relationship Between Reverberant Acoustic Intensity and Energy Density Inside Long Rooms," The Journal of the Acoustical Society of America, no. 138, pp. 181-192, 2015.

[21] M. Hodgson, "On Measures to Increase Sound Field Diffuseness and the Applicability of Diffuse-Field Theory," The Journal of the Acoustical Society of America, vol. 6, no. 95, pp. 3651-3653, 1994.

[22] M. Hodgson, "On the Prediction of Sound Fields in Large Empty Rooms," The Journal of the Acoustical Society of America, vol. 1, no. 84, pp. 253-261, 1988.

[23] M. Hodgson, "Evidence of Diffuse Surface Reflections in Rooms," The Journal of the Acoustical Society of America, vol. 2, no. 89, pp. 765-771, 1991.

[24] B.-I. Dalenbäck, M. Kleiner and P. Svensson, "A Macroscopic View of Diffuse Reflection," J. Audio Eng. Soc., vol. 10, no. 42, pp. 793-807, 1994.

[25] B. Shield, R. Conetta, J. Dockrell, D. Connolly, T. Cox and C. Mydlarz, "A survey of acoustic conditions and noise levels in secondary school class rooms in England," University of Salford, Manchester, 2015.

[26] ODEON A/S, "ODEON Room Acoustics Software User's Manual Version 15," ODEON A/S, Lyngby, 2019.

[27] C. Christensen, "ODEON Room Acoustics Program Version 15 Industrial, Auditorium and Combined Editions (user manual)," ODEON A/S, pp. 6-97, 2019.

[28] M. Vorländer, "Models and Algorithms for Computer Simulations in Room Acoustics," in International Seminar on Virtua Acoustics, Valncia, 2011.

[29] BNKC, "Royal St. George's College Addition \& Renovations," BNKC, 2010. [Online]. Available: http://www.bnkc.ca/portfolio/royal-st-georges-college-addition-renovations/. [Accessed 2 nov 2019].

[30] Architectural Conservancy Ontario , "ACO Toronto," ACO Toronto, 4 July 2019. [Online]. Available: https://www.acotoronto.ca/show_building.php?BuildingID=2724. [Accessed 2 Nov 2019].

[31] Ryerson University, "RAC II Gym," [Online]. Available: https://www.ryerson.ca/recreation/facilities/Rac/racll/. [Accessed 2 dec 2019].

[32] ISO 3382-1:2009, Acoustics - Measurement of room acoustic parameters, Switzerland: ISO, 2009.

[33] D. D. Reynolds, "Annex," in Engineering Principles of Acoustics - Noise Vibration Control., Boston, Allyn and Bacon, Inc., 1981, pp. 303-317.

[34] P. P. Parada, D. Sharma and P. A. Naylor, "NON-INTRUSIVE ESTIMATION OF THE LEVEL OF REVERBERATION IN SPEECH," in IEEE International Conference on Acoustic, Speech and Signal Processing (ICASSP), Florence, 2014. 
[35] F. Forouharmajd, P. Nassin, M. R. Monazzam and M. Yazdchi, "Predicted sound absorption coefficients of absorber materials lined in chamber," Int J Env Health Eng, vol. 2, no. 5, pp. 22-25, 2013.

[36] R. Conetta, B. Shield, T. Cox, C. Mydlarz, J. Dockrell and D. Connolly, "Acoustics of indoor sports halls and gymnasia," London Southbank University, London, 2015. 